Friction Phenomena in Hydrostatic Extrusion of Magnesium


0 


\section{Friction Phenomena in Hydrostatic Extrusion of Magnesium}

Ellen Moodij 
The research in this thesis is sponsored within the framework of the Innovation Directed Research Programme on Magnesium (IOP Magnesium), by the Netherlands Ministry of Economic Affairs.

De promotiecommissie is als volgt samengesteld:

Prof.dr. G.P.M.R. Dewulf

Prof.dr.ir. D.J . Schipper

Dr.ir. M.B. de Rooij

Prof.dr.ir. R. Akkerman

Prof.dr.ir. A.H. van den Boogaard

Prof.dr.ir. F.J.A.M. van Houten

Prof.dr.ir. R.P.B.J. Dollevoet

Prof.ir. L. Katgerman
Universiteit Twente Universiteit Twente Universiteit Twente Universiteit Twente Universiteit Twente Universiteit Twente Technische Universiteit Delft Technische Universiteit Delft voorzitter/ secretaris

promotor

assistent promotor

\footnotetext{
$3^{\otimes} \operatorname{MIX}$

$\sqrt{2}$ Paper from

FSC

ponsible sources

FSC $^{\circledR}$ C012854
}

Moodij, Ellen

Friction Phenomena in Hydrostatic Extrusion of Magnesium

PhD Thesis, University of Twente, Enschede, The Netherlands

December 2014

Keywords: tribology, hydrostatic extrusion, magnesium, lubrication model, contact model, wire drawing

Copyright @ 2014 by E. Moodij, Enschede, The Netherlands

Printed by Gildeprint, Enschede

Cover: Residual magnesium billet of Hydrex Materials B.V., edited

ISBN 978-90-365-3805-3 


\title{
FRICTION PHENOMENA IN HYDROSTATIC EXTRUSION OF MAGNESIUM
}

\author{
PROEFSCHRIFT
}

ter verkrijgen van

de graad van doctor aan de Universiteit Twente op gezag van de rector magnificus, prof.dr. H. Brinksma, volgens besluit van het College voor Promoties in het openbaar te verdedigen op woensdag 17 december 2014 om 14:45

\author{
door \\ Ellen Moodij
}

geboren op 23 maart 1977

te Spijkenisse, Nederland 
Dit proefschrift is goedgekeurd door:

De promotor: prof.dr.ir. D.J. Schipper

De assistent promotor: dr.ir. M.B. de Rooij 


\section{Table of Contents}













1.2 Metal forming processes: extrusion.......................................... 2





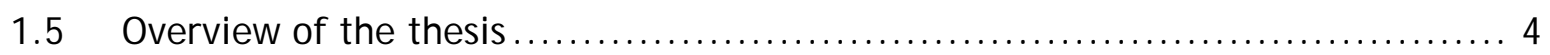

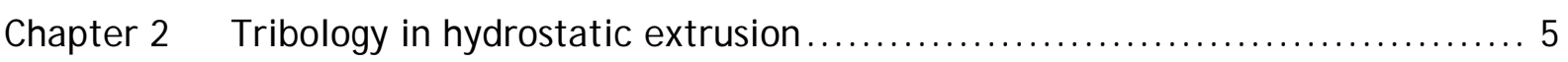



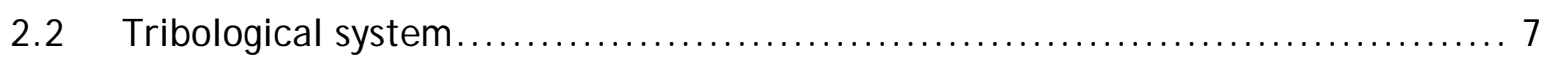



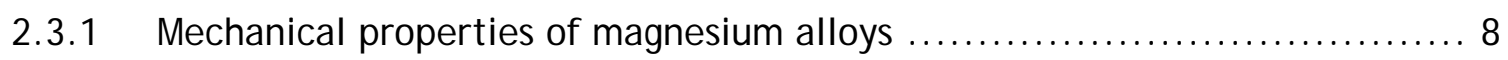

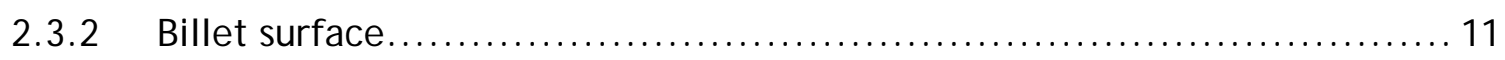

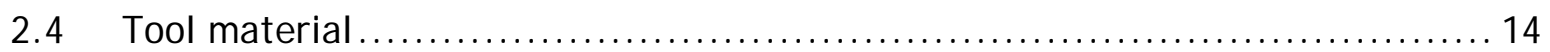

















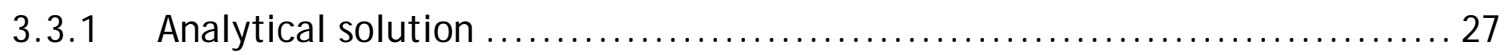





3.4.1 Analytical solution versus numerical model............................ 31

3.4.2 Parameter study of the hydrostatic extrusion process ................... 33




Chapter 4 Modelling lubrication in the work zone $\ldots \ldots \ldots \ldots \ldots \ldots \ldots \ldots \ldots \ldots \ldots \ldots \ldots \ldots \ldots \ldots \ldots \ldots \ldots$

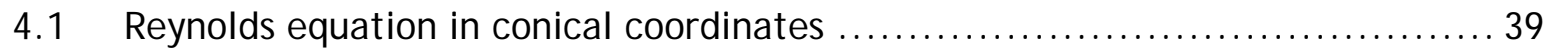

4.2 The mechanics of the hydrostatic extrusion process.......................... 43

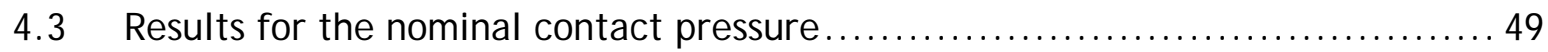

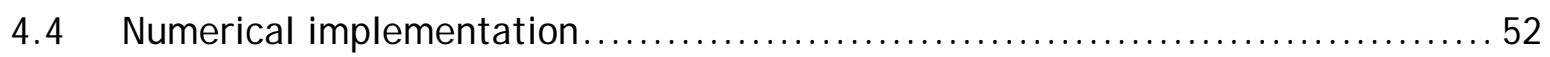

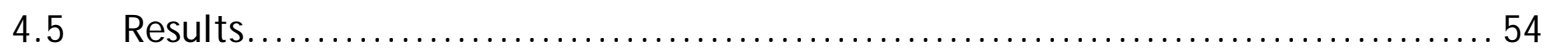

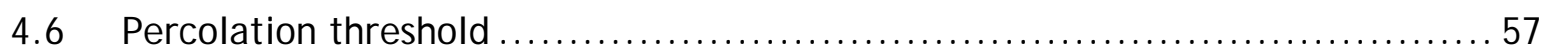

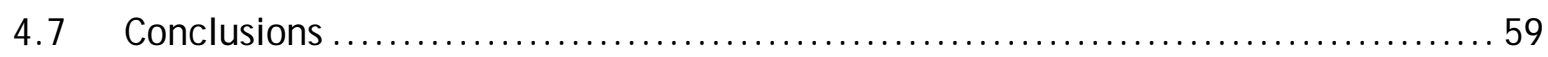

Chapter 5 Contact in hydrostatic extrusion......................................... 61

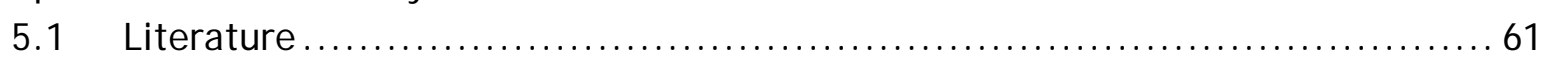

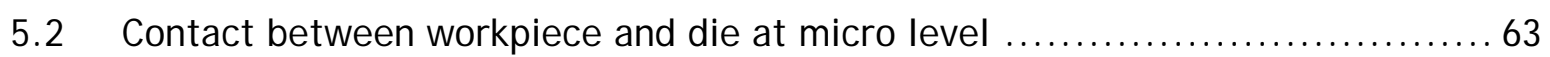



5.4 Results with the contact model of Westeneng .............................. 72







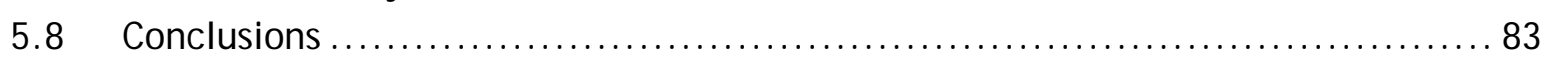

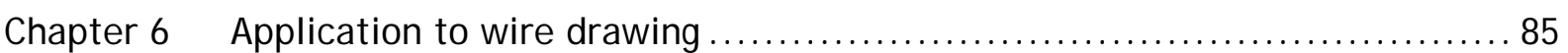





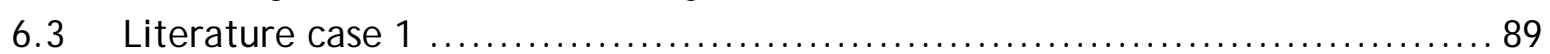





Chapter 7 Conclusions and recommendations................................. 97



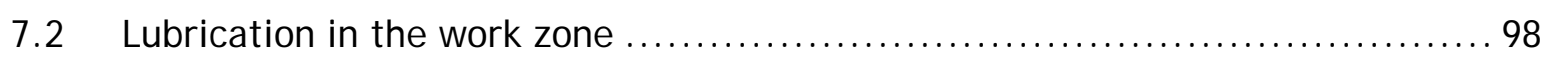

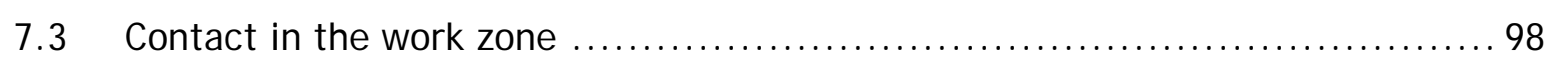





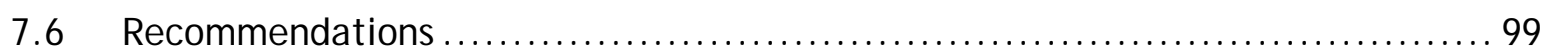

Appendix A Magnesium, tool steel and castor oil properties........................ 101

Appendix B TNO measurements lacquer layer.................................. 105

Appendix C Measurements................................................. 107



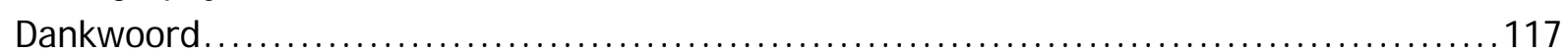




\section{Samenvatting}

Extrusie is een veel voorkomend productieproces waarbij het te vervormen materiaal door een matrijs geduwd wordt om een gewenste dwarsdoorsnede te verkrijgen. Bij conventionele extrusie oefent de pers direct een kracht uit op het te vervormen materiaal. Bij hydrostatische extrusie wordt het te vervormen materiaal omringd door een vloeistof onder druk, meestal een olie, en wordt de druk op de olie aangebracht. Deze druk is meestal in de orde van $1 \mathrm{GPa}$. Het voordeel van hydrostatisch extruderen is dat er geen direct contact is tussen het te vervormen materiaal en de wand van de pers. Hierdoor treedt er veel minder wrijving op tijdens het deformeren. Het hydrostatische extrusie proces is erg geschikt voor het maken van allerlei buizen en andere enigszins symmetrische en lange vormen. Veel verschillende materialen kunnen worden geëxtrudeerd: allerlei staalsoorten, koper, aluminium, magnesium en composiet materialen en ook super geleidende materialen. Dit onderzoek gaat over het hydrostatisch extruderen van magnesiumlegeringen. Magnesium extrusieproducten worden met name gebruikt voor toepassingen waarbij een laag gewicht erg belangrijk is, zoals voor mobiele lichtinstallaties, interieurdelen van vliegtuigen of in de automobielindustrie. Een van de problemen in de industrie is het maken van producten met een consistente, goede oppervlaktekwaliteit. In dit proefschrift worden de wrijvings- en smeringsprocessen onderzocht voor het hydrostatisch extruderen van magnesiumlegeringen. waardoor inzicht wordt verkregen over hoe de problemen met de oppervlaktekwaliteit van de extrusie producten ontstaan.

In dit onderzoek is het proces onderverdeeld in drie zones: de inlaat-, de deformatie- en de uitlaatzone. In de inlaatzone komt het materiaal in de matrijs maar er vindt nog geen plastische deformatie plaats. In de deformatiezone wordt het materiaal plastisch vervormd tot de gewenste geometrie. Tenslotte verlaat het materiaal in de uitlaatzone de matrijs en veert het materiaal enigszins elastisch terug. De oppervlaktekwaliteit van hydrostatisch geëxtrudeerde producten wordt met name bepaald in de deformatiezone. Dit in tegenstelling tot conventionele extrusie waarbij de oppervlaktekwaliteit vooral bepaald wordt in de uitlaatzone. Dit werk zal dan ook met name gaan over de wrijving en de smeringsprocessen in de deformatiezone. Om de filmdikte in de inlaatzone te berekenen is een model ontwikkeld gebaseerd op Reynoldsvergelijking en de geometrie van de 
inlaatzone. De filmdikte is berekend en vergeleken met de ruwheid van het om te vormen materiaal. Uit deze vergelijking kan worden geconcludeerd dat er in de inlaatzone grenssmering optreedt.

De dikte van de smeerfilm in de deformatiezone van het hydrostatische extrusie proces is ook gemodelleerd met de Reynoldsvergelijking. Als randvoorwaarde voor het oplossen van deze differentiaalvergelijking wordt de filmdikte, zoals berekend in het inlaatzonemodel, gebruikt. Uit de berekeningen met dit model volgt dat voor de meest gebruikte extrusie condities er ook grenssmering optreedt in de deformatiezone. Daarnaast is ook de fractie van het werkelijke contactoppervlak gemodelleerd in de deformatiezone. Een bestaand contactmodel dat geschikt is voor een willekeurige oppervlakteruwheid en daarnaast bulkvervorming bevat is uitgebreid met een afschuifterm om het geschikt te maken voor de hoge druk situatie van het hydrostatische extrusie proces. Uit berekeningen met dit nieuwe contactmodel volgt dat voor gebruikelijke hydrostatische extrusie condities de fractie van het oppervlak in contact snel naar één stijgt en constant blijft in het resterende deel van de omvormzone.

Geconcludeerd kan worden dat de smering bij hydrostatisch extrusie van magnesium zich in het grenssmeringsregime bevindt. Dit betekent dat de druk in het contact tussen het magnesium en de matrijs volledig gedragen wordt door de toppen van het oppervlak. Dit is zeer waarschijnlijk de oorzaak voor de inconsistente en soms slechte oppervlaktekwaliteit van de hydrostatisch geëxtrudeerde magnesiumproducten. Dit zou opgelost kunnen worden met verschillende maatregelen, zoals bijvoorbeeld het gebruik van een olie waarvan de viscositeit meer toeneemt met de heersende druk.

De ontwikkelde modellen zijn ook toepasbaar op andere axisymmetrische processen. Als afsluiting is dit geillustreerd met twee voorbeelden uit de literatuur over het draadtrekproces. 


\section{Summary}

Extrusion is a widely used forming process in which a material, the billet, is pushed through a die, to deform the material to a desired shape. In direct extrusion the ram applies the pressure directly onto the billet. In hydrostatic extrusion the billet is surrounded by a pressure medium, usually an oil, and the pressure is applied to this oil, typically in the order of $1 \mathrm{GPa}$. The advantage is that there is no direct contact between the billet and the surrounding container and therefore much less friction. The hydrostatic extrusion process is very suitable for making different kinds of tubes and other slightly symmetrical shapes. An important advantage is that many different materials can be extruded: steels, copper, aluminium, magnesium and composite materials as well as superconductors. The focus in this research is on the hydrostatic extrusion of magnesium. Magnesium extrusion products are used mainly for applications where low weight is important; such as truss bars, interior parts of airplanes or in the automotive industry. One of the problem areas in the industry is the ability to produce magnesium extrusion products with a consistently good surface quality. This research investigates the friction and lubrication phenomena in this process. These aspects are strongly linked to the surface quality of the extrusion products.

For this investigation the process is divided into three zones: the inlet, the work and the outlet zone. In the inlet zone the billet enters the die, but no plastic deformation takes place. In the work zone the billet is plastically deformed to its final shape. Finally, in the outlet zone the extrudate leaves the die. In this zone elastic recovery takes place and some residual stress is maintained in the process. The surface quality in hydrostatic extrusion products is mainly determined in the work zone, in contrast to direct extrusion, therefore, the focus in this research is to investigate the friction and lubrication phenomena in the work zone. To calculate the film thickness in the inlet zone a model is developed based on the Reynolds equation and the geometry of the inlet zone. The film thickness is calculated and compared to the roughness of the billet. From this comparison, it is concluded that the acting lubrication regime in the inlet zone is boundary lubrication.

The film thickness in the work zone of the hydrostatic extrusion process is modelled with the Reynolds equation in conical coordinates. The film thickness from the inlet zone 
calculation is used as the boundary condition required to solve this differential equation. The conclusion is that the prevailing lubrication regime in the work zone is also boundary lubrication for most extrusion conditions. In addition, the fraction of area in contact is modelled in the work zone. An existing contact model suitable for arbitrary surface geometry and including bulk strain is expanded with a shear effect, to make it suitable for the high pressures acting in the hydrostatic extrusion process. Applying this model to the case of hydrostatic extrusion, it was found that the fraction of real contact area increases rapidly to almost one in the work zone and stays constant in the remainder of the work zone for typical hydrostatic extrusion conditions.

The conclusion is that the prevailing lubrication regime for the hydrostatic extrusion of magnesium is the boundary lubrication regime. This means that the pressure in the contact is carried completely by the asperities of the surfaces. This is most likely the cause for the inconsistent and sometimes insufficient surface quality for the magnesium hydrostatic extrusion products. This can be changed by various measures, such as the use of a lubricant of which the viscosity is more strongly dependent on the pressure.

Finally, the developed models are also applicable to other axisymmetrical processes. This is shown by applying the models to two wire drawing cases from literature. 


\section{Nomenclature}

$\begin{array}{lll}A_{n o m} & \text { Nominal contact area } & {\left[\mathrm{m}^{2}\right]} \\ A_{r} & \text { Real contact area } & {\left[\mathrm{m}^{2}\right]} \\ d & \text { Separation } & {[\mathrm{m}]} \\ \mathrm{dx} & \text { Width of a bar } & {[\mathrm{m}]} \\ \mathrm{D} & \text { Diameter of the workpiece } & {[\mathrm{m}]} \\ \mathrm{D}_{\text {in }} & \text { Diameter of the billet } & {[\mathrm{m}]} \\ \mathrm{D}_{\text {out }} & \text { Diameter of the extrusion product } & {[\mathrm{m}]} \\ \mathrm{F}_{\mathrm{N}} & \text { Normal force } & {[\mathrm{N}]} \\ \mathrm{h} & \text { Film thickness } & {[\mathrm{m}]} \\ \mathrm{h}_{0} & \text { Central film thickness } & {[\mathrm{m}]} \\ \mathrm{h}_{\mathrm{T}} & \text { Average film thickness } & {[\mathrm{m}]} \\ \mathrm{H}_{\mathrm{L}} & \text { Lubrication parameter } & {[\mathrm{m}]} \\ \mathrm{H} & \text { Hardness of the (softest) material } & {[\mathrm{Pa}]} \\ \mathrm{k} & \text { Shear strength } & {[\mathrm{Pa}]} \\ \mathrm{I} & \text { Half asperity distance } & {[\mathrm{m}]} \\ \mathrm{L} & \text { Lubrication number } & {[-]} \\ \mathrm{L}_{d} & \text { Length of the calculation domain } & {[\mathrm{m}]} \\ \mathrm{M} & \text { Number of non-contacting bars } & {[-]} \\ \mathrm{n} & \text { Indentation parameter } & {[-]} \\ \mathrm{N} & \text { Total number of bars in contact } & {[-]} \\ \mathrm{N} * & \text { Number of indented bars (excluded the rising bars) } & {[-]} \\ \mathrm{N} * * & \text { Number of rising bars which are in contact after loading } & {[-]} \\ \mathrm{p} & \text { Pressure } & {[\mathrm{Pa}]} \\ \mathrm{P} & \text { Dimensionless load } & {[-]} \\ \mathrm{p}_{0} & \text { Nominal contact pressure } & {[\mathrm{Pa}]} \\ \mathrm{p}_{\text {nom }} & \text { Nominal contact pressure } & {[\mathrm{Pa}]} \\ \mathrm{p}_{\mathrm{r}} & \text { Constant (pr }=196.2 \text { MPa) } & {[\mathrm{Pa}]} \\ \mathrm{q} & \text { Hydrostatic pressure } & {[\mathrm{Pa}]} \\ \mathrm{Q} & \text { Activation energy of deformation } & {\left[\mathrm{J}{ }^{-1}\right]} \\ \mathrm{Q} & \text { Number of asperities per unit area } & {\left[\mathrm{m}{ }^{-2}\right]} \\ \mathrm{Q}_{b} & \text { Number of bars per calculation unit } & {[-]} \\ & & \end{array}$


R Universal gas constant

$R \quad$ Round off radius

$\left[\mathrm{J} \cdot \mathrm{K}^{-1} \mathrm{~mol}^{-1}\right]$

$R_{a} \quad$ CLA surface roughness

[m]

$R_{q} \quad$ RMS surface roughness

[m]

Axis in the conical coordinate system

[m]

$S \quad$ Shear surface

[m]

$\left[\mathrm{m}^{2}\right]$

Time

[s]

T Temperature

$U \quad$ Rise of the valleys

$\left[{ }^{\circ} \mathrm{C}\right]$ or $[\mathrm{K}]$

[m]

$\mathrm{U}_{1} \quad$ Velocity of surface 1 (Billet)

$\left[\mathrm{m} \cdot \mathrm{s}^{-1}\right]$

$\mathrm{U}_{2} \quad$ Velocity of surface 2 (Die)

$\left[\mathrm{m} \cdot \mathrm{s}^{-1}\right]$

$\left[\mathrm{m} \cdot \mathrm{s}^{-1}\right]$

$U_{s} \quad$ Sum velocity in the s-direction

$\left[\mathrm{m} \cdot \mathrm{s}^{-1}\right]$

$\left[\mathrm{m} \cdot \mathrm{s}^{-1}\right]$

$\mathrm{U}^{+} \quad$ Sum velocity

$W^{*} \quad$ Dimensionless load

$[-]$

$W_{\text {ext }} \quad$ External energy

[] ]

$W_{\text {int }} \quad$ Internal energy

[J]

$W_{\text {int }}^{a b s} \quad$ Internal absorbed energy

[J]

$W_{\text {int }}^{\text {rise }} \quad$ Internal energy needed for raising the valleys

[J]

$\mathrm{X}$

variable in the coordinate system

[m]

$z \quad$ Roelands pressure coefficient

$[-]$

a $\quad$ Fraction of real contact area

$[-]$

$y \quad$ Barus pressure coefficient

$\left[\mathrm{Pa}^{-1}\right]$

$y \quad$ Peklenik number

$\triangle \mathrm{A} \quad$ Area of an asperity and bar

$[-]$

$\varepsilon \quad$ Nominal strain

$\left[\mathrm{m}^{2}\right]$

$\varepsilon_{\mathrm{N}} \quad$ Natural strain

$[-]$

$\dot{\varepsilon} \quad$ Strain rate

$\zeta_{1} \quad$ Energy factor

$\left[\mathrm{s}^{-1}\right]$

$\zeta_{2}, \zeta_{3} \quad$ Shape factor

$[-]$

$\eta$

Asperity persistence parameter

$[-]$

$[-]$

$\eta \quad$ Dynamic viscosity

$[\mathrm{Pa} \cdot \mathrm{s}]$

$\eta_{0} \quad$ Dynamic viscosity at ambient pressure

$[\mathrm{Pa} \cdot \mathrm{s}]$

$\eta_{\infty} \quad$ Constant $\left(\eta_{\infty}=6.315 \cdot 10^{-5} \mathrm{~Pa} \cdot \mathrm{s}\right)$

$[\mathrm{Pa} \cdot \mathrm{s}]$

$\theta \quad$ Semi die angle

$\left[{ }^{\circ}\right]$

$\mu \quad$ Friction coefficient

$[-]$

$v \quad$ Kinematic viscosity

$\left[\mathrm{mm}^{2} \cdot \mathrm{s}^{-1}\right]$

$\rho \quad$ Density

$\sigma_{\mathrm{x}} \quad$ Axial stress in the work zone

$\left[\mathrm{kg} \cdot \mathrm{m}^{-3}\right]$

[Pa]

$\sigma_{y} \quad$ Yield stress

[Pa] 
$\varphi(z) \quad$ Asperity height distribution function $[-]$

$\psi \quad$ Axis in the conical coordinate system [rad] 


\section{Chapter 1}

\section{Introduction}

This introductory chapter is meant to provide a background of the research presented in this thesis. It starts with an overview of the use of magnesium in history. Than the basics of the hydrostatic extrusion process are explained. The surface quality of the extrusion products is discussed consecutively. And finally, the objective of this research is presented with an overview of this thesis.

\subsection{Magnesium alloys in engineering}

A major advantage of magnesium is its low specific mass. Unfortunately, it is relatively expensive. Therefore it is mainly used in applications where a low weight is a crucial factor, such as automotive industry and aviation applications. Magnesium is not scarce; it is the sixth most common element on earth and amounts to $2.5 \%$ of its composition [1]. Davy was the first to isolate magnesium as a metal in 1808 [2]. Prior to this discovery, it was only known in the form of salts, which seemed to heal scratches and rashes. In 1833 Faraday was the first to produce a small amount of pure magnesium by electrolysis. The commercial production of magnesium started in 1886 in Germany.

During the First and Second World War the magnesium market increased enormously, only to fall again afterwards. Magnesium alloys were used in bicycles, airplanes and cars. During the Second World War thousands of bombers were fitted with magnesium wheels, engine parts and transmissions. The most outstanding application was the Volkswagen Beetle; it contained about $17 \mathrm{~kg}$ of magnesium in its engine and transmission. After the Second World War the magnesium market collapsed mainly due to the increased attention for aluminium [1]. The magnesium market has regained its popularity in the last few decades. The worldwide production of primary ${ }^{1}$ magnesium increased from 260,000 tonnes in 1990 to 480,000 tonnes in 2000 and 800,000 tonnes in 2007. Since 2008 the international economic crisis has influenced the magnesium market and the production has dropped again. The main development in the production market in the last two decades has been the shift towards China. From only a few percent of the market China now accounts for more than $70 \%$ of the world's production [3].

\footnotetext{
${ }^{1}$ Primary magnesium is mined; secondary magnesium is produced from new and old scrap.
} 
Most of the magnesium produced is used as an alloying element in the aluminium industry. Other areas where magnesium is used are in the die-casting process, to remove sulphur in the production of iron and steel and wrought applications. Die casting products are mainly for the car industry and for consumer electronics, such as cameras, laptop casings or cellular phones [4]. The wrought market consists mainly of extrusion products, such as bicycle frames and truss bars.

\subsection{Metal forming processes: extrusion}

Magnesium can be processed in many different ways. As already mentioned the most common method of deforming magnesium is die casting. The material is melted and poured in a mould where it solidifies again in the desired shape. Another possibility is to deform the material in the solid state, either at room temperature or heated to near its melting point. Examples of the latter method are cold and hot rolling and extrusion - the focus of this research. In extrusion the billet material is pushed through a die at an elevated temperature. The most common extrusion process is direct extrusion. In direct extrusion the round billet has the same dimensions as the inner wall of the container; the billet is pushed through the die with a punch attached to the ram of the press.

In hydrostatic extrusion the billet is surrounded by a medium, usually oil. Therefore, contrary to conventional extrusion processes, the extrusion pressure is not applied directly to the billet but to this extrusion medium. This means there is no direct contact between the billet and the container or the ram. The schematic processes can be found in Figure 1.1.
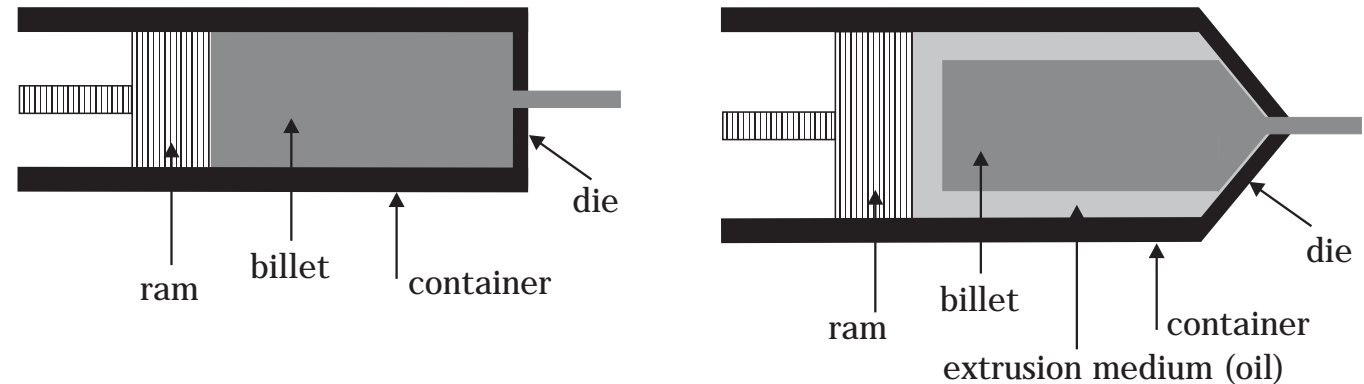

Figure 1.1 Schematic conventional extrusion (left) and hydrostatic extrusion (right).

The extrusion process can be used to make all kinds of profiles with a constant cross section: structural and architectural shapes, such as door and window frames, for example. Extruded products can be cut to the desired lengths, to form such articles as handles and the base of a gear. Direct extrusion is very suitable for making complex profiles, for instance for the construction industry. Hydrostatic extrusion is more suitable for all kinds of tubing; a certain amount of symmetry is desired. 
There are several differences between the two processes. From a tribological point of view the most outstanding difference is the reduction of friction between the billet surface and the container interface. This results in lower required extrusion pressure and the possibility to extrude at lower temperatures. The latter characteristic is very important because a lower extrusion temperature is beneficial to the material properties of the end product. A second advantage is the hydrostatic pressure itself. Some materials that are difficult to extrude tend to tear during extrusion. This is more easily prevented in hydrostatic extrusion because of the hydrostatic pressure. This makes it possible to extrude at higher speeds than in direct extrusion. Another advantage is that seamless hollow profiles can be extruded, something that is not possible with direct extrusion. This enables the extrusion products to be, for example, hydroformed, bicycle frames being a case in point. Other examples of applications where magnesium is used are automobile parts, truss bars and interior construction parts of airplanes. Examples of hydrostatically extruded magnesium profiles can be found in Figure 1.2. More information about different extrusion processes can be found in Laue [5] and Kalpakjian [6]. The hydrostatic extrusion process will be described more extensively in Chapter 2 and for further reference the reader is referred to Inoue [7].

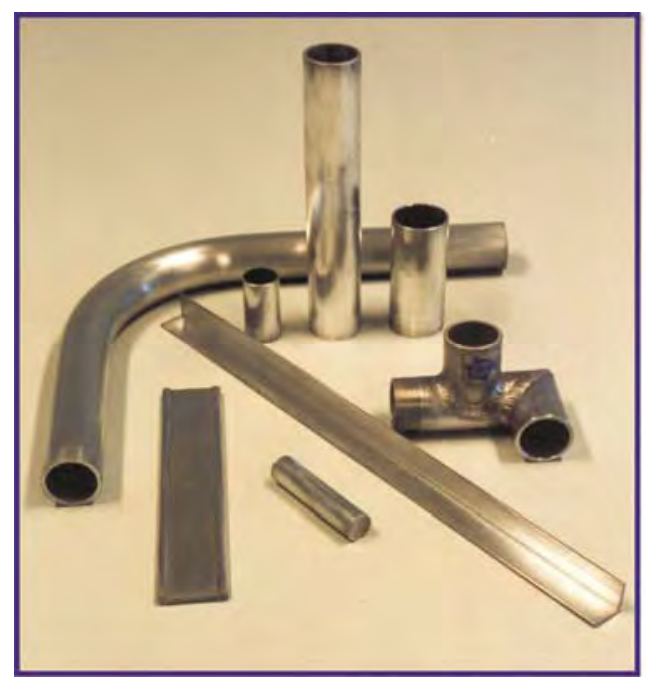

Figure 1.2 Magnesium hydrostatic extrusion products, picture courtesy of Hydrex Materials B.V.

\subsection{Surface quality of extrusion products}

Over the recent years several tests with magnesium hydrostatic pressings have been performed. The overall quality of the products was generally good; however, the surface quality of the pressing fluctuated. For some pressings the surface of the product was shiny and smooth; other products were slightly or very scratched. The motivation for this research is to understand the processes which determine the surface quality and to be able to predict the required process parameters to ensure a good surface quality. 
The surface quality in a metal forming process is determined by the processes taking place in the contact between workpiece and die. In most metal forming processes the best surface quality is obtained when the system is operating in the mixed lubrication regime. In the boundary lubrication regime all the pressure is carried by contacting asperities and scratches therefore occur easily. In the full film lubrication regime the surfaces of the workpiece and the die are fully separated, the pressure is being carried totally by the lubricant. The surface of the workpiece deforms as if a free surface, and will generally roughen [8]. This roughening occurs either because the grains do not deform in conformity with the macroscopic deformation or because the grains can turn and protrude from the surface. This first effect is seen more in HCP structured materials like magnesium because of the very limited amount of available slip planes [9]. When the product is roughened a dull and rough surface is created, referred to as orange peel. Therefore the extrusion products generally have the most consistent surface quality if the system is operating in the mixed lubrication regime.

\subsection{Objective of this research}

When magnesium is hydrostatically extruded an inconsistent surface quality is encountered. To be able to understand why this occurs, the processes taking place in the contact between billet and die during hydrostatic extrusion need to be analysed. The objective of this research is to understand the friction phenomena in the hydrostatic extrusion process. This is done by developing suitable models for the different zones of the hydrostatic extrusion process. Furthermore, calculations are performed with these models on the extrusion process to investigate the influence of the different process parameters. This study is limited to friction phenomena in the hydrostatic extrusion process, using magnesium alloys. And only phenomena within the process window are investigated.

\subsection{Overview of the thesis}

The chapter layout of this thesis is as follows. Chapter 2 describes the tribological system and the different lubrication regimes. In Chapter 3 a new lubrication model for the inlet zone of the hydrostatic extrusion process is given. Chapter 4 describes the full film lubrication model for the work zone of the hydrostatic extrusion process. A contact model for the work zone area of the hydrostatic extrusion process is developed in Chapter 5 and a parameter study is performed. Chapter 6 shows that the developed models in this thesis can also be used for other processes such as wire drawing. Finally, conclusions and recommendations are given in Chapter 7. 


\section{Chapter 2}

\section{Tribology in hydrostatic extrusion}

The surface quality of the magnesium hydrostatic extrusion product is determined in the contact between billet and die as described in Chapter 1 . In this chapter the hydrostatic extrusion process will be explained first, to determine where the surface of the extrudate exactly is generated. Then a system approach is explained to study this contact in Section 2.2. Furthermore all the components necessary to study this system will be presented in the final sections.

\subsection{Hydrostatic extrusion}

As described in the previous chapter, in hydrostatic extrusion the billet is surrounded by a pressurized medium. Although the hydrostatic extrusion process is analysed in general here, the parameters of a 4000 ton hydrostatic press are used as an example.

The billets have an original diameter of $73 \mathrm{~mm}$ or $159 \mathrm{~mm}$. The extrusions are performed with conical shaped dies. The die angle is the angle between the two opposite surfaces of the die, usually between 50 and 130 . To be able to build up the pressure to start extrusion, the front end of the billet has to have a same shape as the die. Other die shapes could also be used, e.g. spherical or with a varying die angle. However only conical dies are studied in this work.

As described earlier the extrusion speeds in hydrostatic extrusion of magnesium can be relatively high. On average, the exit speed of the extrudate is between 15 and $60 \mathrm{~m} / \mathrm{min}$, however if the process is well controlled the extrusion speed can be up to $150 \mathrm{~m} / \mathrm{min}$ depending also on the extrusion ratio. The extrusion ratio is the area of the cross section of the original billet divided by the area of a cross section of the end product. For hydrostatic extrusion process the extrusion ratio normally varies between 10 and 200, however it can be up to 1200 .

The extrusion pressure in the extrusion medium in the container is between 0.5 and 1.2 $\mathrm{GPa}$. The local pressure where the billet deforms can be higher; this will be examined more extensively in the rest of this thesis. The magnesium billets are heated to

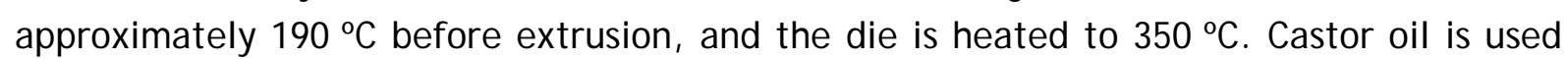


as the extrusion medium; more details about the oil can be found in Section 2.5. The most relevant process parameters can be found in Table 2.1.

\begin{tabular}{|c|c|}
\hline Billet diameter & 73 or $159 \mathrm{~mm}$ \\
\hline Die angle & $50-1300$ \\
\hline Billet temperature & $170-220 \stackrel{\circ}{C}$ \\
\hline End temperature & $350-450 \stackrel{\circ}{C}$ \\
\hline Die temperature & $350 \stackrel{\circ}{C}$ \\
\hline Extrusion medium & Castor oil \\
\hline Bearing length & $2.0-3.5 \mathrm{~mm}$ \\
\hline Extrusion pressure & $0.5-1.2 \mathrm{GPa}$ \\
\hline Extrusion speed (exit) & $\begin{array}{l}\text { average } 15-60 \mathrm{~m} / \mathrm{min}, \max 150 \mathrm{~m} / \mathrm{min} \\
(0.25-1.0 \mathrm{~m} / \mathrm{s}, 2.5 \mathrm{~m} / \mathrm{s})\end{array}$ \\
\hline Extrusion ratio & $10-200$ (normally, max 1200) \\
\hline
\end{tabular}

Table 2.1 Process parameters of the hydrostatic extrusion process.

For modelling purposes the extrusion process is divided into three zones. First, there is an inlet zone where the billet is entering the die and no plastic deformation takes place. Second, there is a work zone where the billet is reduced to its final shape. Finally, there is an outlet zone where the extrudate leaves the die and only elastic recovery takes place, see also Figure 2.1a.

The surface of the extrusion product is formed in different areas when direct and hydrostatic extrusion processes are compared. In direct extrusion the surface of the extrudate is formed in the outlet zone, i.e. the bearing area see Figure 2.1b. In the work zone the billet material shears internally, therefore the surface of the product is created in the outlet zone. In hydrostatic extrusion the work zone is the dominating area, see also Figure 2.1. The velocity difference between billet and die is accommodated by the interface between billet and die. There might be no physical contact between billet and die because of the presence of a lubricant. Since the main focus of this research is the surface quality of the hydrostatic extrusion product, the main focus is to determine the processes taking place in the contact between billet and die in the work zone.
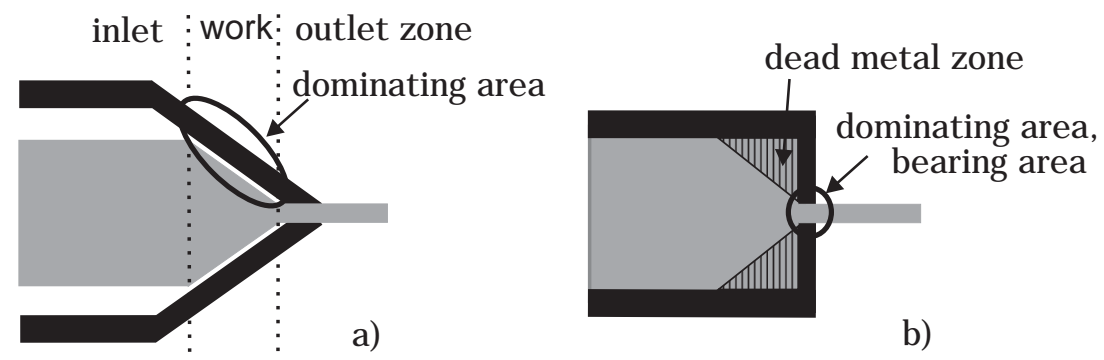

Figure 2.1 The different zones in the extrusion process with the ellipse indicating the area where the surface quality is determined for a) hydrostatic extrusion and b) conventional extrusion. 


\subsection{Tribological system}

To study any tribological phenomenon a wide range of parameters and processes need to be considered. Czichos [10] was the first to define a system approach to tribology. He considered that friction and wear are system dependent. Therefore the total tribological system has to be considered. This system generally consists of four elements as can be seen in Figure 2.2a; the two interacting surfaces (1 and 2), the lubricant (3) and the environment (4). For hydrostatic extrusion of magnesium the tribological system is as follows.

1. The magnesium billet is one of the two interacting surfaces. It has volume properties such as geometry, mechanical properties and surface properties like the micro geometry. The magnesium billet is rough and soft in comparison to the die.

2. The tool or die is the other interacting surface. The die is very smooth and hard relative to the billet. The die is considered to be rigid and smooth in this research.

3. The lubricant for the hydrostatic extrusion process. In practice, castor oil is often used. The most important property is its viscosity, which is dependent on temperature and pressure. The lubricant surrounds the billet.

4. The environment of the system consists typically of the environmental conditions in the work zone of a hydrostatic extrusion press. An example of this is the absence of oxygen in the system.

The system operates under high pressure and high velocity conditions as present in the work zone of a hydrostatic extrusion press. This total tribological system can be found in Figure 2.2b. The components of this tribological system will be studied in the remaining of this chapter. First the environment is explained in the next section. Subsequently, the magnesium billet is discussed and afterwards the tool material. Finally, some properties of the lubricant are given in Section 2.5.
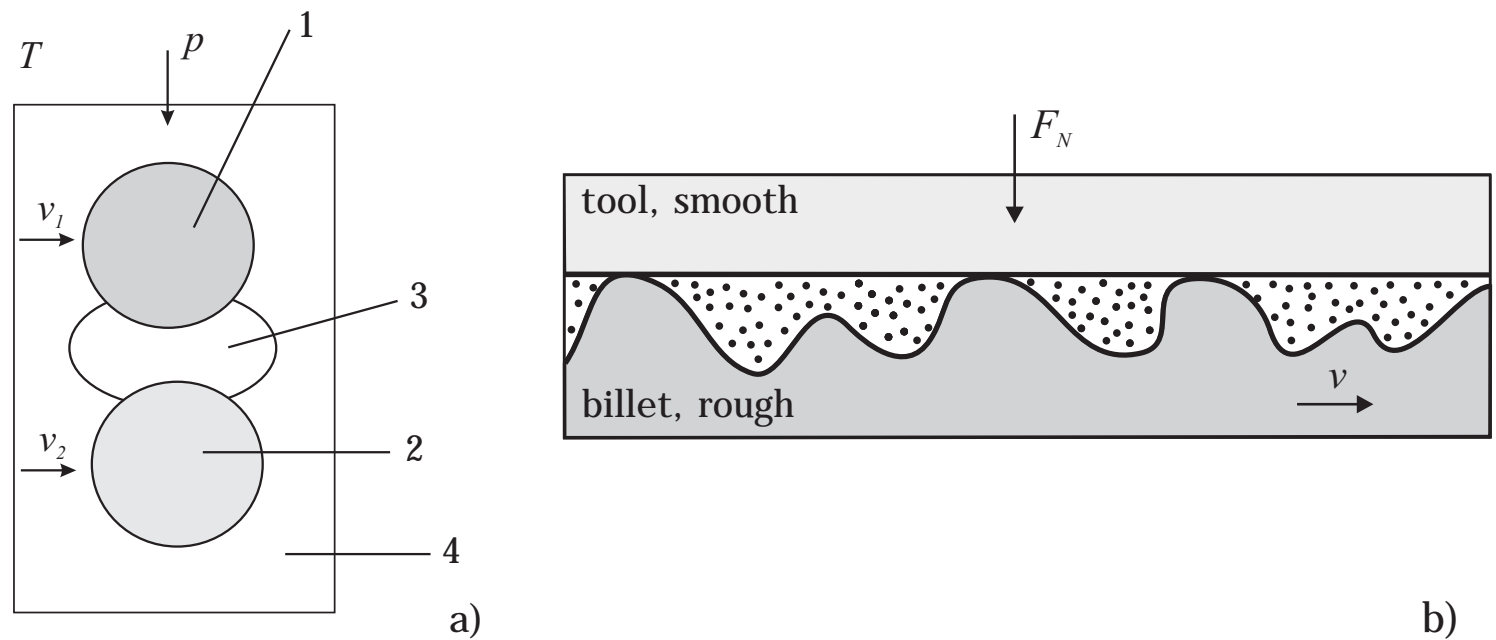

a)

b)

Figure 2.2 The tribological system: a) generic and b) hydrostatic extrusion. 


\subsection{Magnesium and magnesium alloys}

In industry almost all wrought magnesium is used in the form of alloys. Some of the most commonly used alloys will be discussed in this section. Their chemical composition and the most used manufacturing methods can be found in Table 2.2. The alloy most frequently used in wrought processes, AZ31 is used in this thesis. Section 2.3.1 deals with the mechanical properties of magnesium alloys and more specifically AZ31, also a model for the yield stress of AZ31 will be presented. Section 2.3.2 describes the surface of the magnesium billet as used in the hydrostatic extrusion process.

\begin{tabular}{|c|c|c|c|c|c|}
\hline Chemical composition & $\mathrm{Al}$ & $\mathrm{Zn}$ & $\mathrm{Mn}$ & $\mathrm{Zr}$ & common process \\
\hline AZ31 & 2.9 & 1.0 & 0.3 & & extrusion, sheet \\
\hline AZ91 & 9 & 0.7 & $\begin{array}{l}0.1- \\
0.2\end{array}$ & & $\begin{array}{l}\text { die and sand } \\
\text { casting }\end{array}$ \\
\hline AM60 & 6 & - & $>0.1$ & & die casting \\
\hline ZK60 & - & 6 & - & 0.5 & extrusion, forging \\
\hline ZM21 & & 2.0 & 1.0 & & extrusion, sheet \\
\hline
\end{tabular}

Table 2.2. Chemical composition (wt\%) of the most used magnesium alloys.

\subsubsection{Mechanical properties of magnesium alloys}

Magnesium's most outstanding property is its low specific mass. The most common material properties can be found in Table 2.3. The yield stress of magnesium alloys, which is the most important property for extrusion, is studied more extensively in this section.

Further, magnesium has an HCP crystal structure, which makes deformation at room temperature difficult since only three major slip systems are available [11]. Between 200 and $225 \stackrel{\circ}{\circ}$ (depending on alloying composition) deformation becomes easier because of the thermal activation of pyramid sliding planes in the HCP structure [12], deformation at these temperatures is considered warm deformation.

\begin{tabular}{|l|l|}
\hline Property & Value \\
\hline Density & $1.74 \cdot 10^{3} \mathrm{~kg} / \mathrm{m}^{3}$ \\
\hline Melting point & $651^{\circ} \mathrm{C}$ \\
\hline Crystal structure & $\mathrm{HCP}$ \\
\hline Young modulus & $45 \mathrm{GPa}$ \\
\hline Poisson's ratio & 0.35 \\
\hline
\end{tabular}

Table 2.3 Properties of magnesium.

The mechanical properties of the most frequently used alloys as described in the last section can be found in Table 2.4. As can be seen in Table 2.4, the yield behaviour of magnesium is different for tensile and compressive stress situations. In this work the focus is on the alloy AZ31, which is the most common alloy for extrusion applications. 


\begin{tabular}{|l|l|l|l|l|l|}
\hline & \multicolumn{2}{|l|}{ properties in tension } & \multicolumn{2}{l|}{$\begin{array}{l}\text { properties in } \\
\text { compression }\end{array}$} \\
\hline cast alloys & $\begin{array}{l}\text { Yield } \\
\text { strength } \\
(\mathrm{MPa})\end{array}$ & $\begin{array}{l}\text { Ultimate } \\
\text { strength } \\
(\mathrm{MPa})\end{array}$ & $\begin{array}{l}\text { Elongation } \\
(\%)\end{array}$ & $\begin{array}{l}\text { Yield } \\
\text { strength } \\
(\mathrm{MPa})\end{array}$ & $\begin{array}{l}\text { Ultimate } \\
\text { Strength } \\
(\mathrm{MPa})\end{array}$ \\
\hline AM60A & 130 & 240 & 13 & 130 & - \\
\hline AZ91D-F & 160 & 250 & 7 & 160 & - \\
\hline ZK60A-T5 & 215 & 305 & 16 & 160 & 285 \\
\hline wrought alloys & & \multicolumn{5}{l|}{} \\
\hline AZ31B-F & $\mathbf{2 0 0}$ & $\mathbf{2 5 5}$ & $\mathbf{1 2}$ & $\mathbf{9 7}$ & $\mathbf{2 3 0}$ \\
\hline ZK60A-T5 & 285 & 350 & 11 & 250 & 405 \\
\hline ZM21-F & 155 & 235 & 8 & - & - \\
\hline
\end{tabular}

Table 2.4 Mechanical properties of magnesium alloys, taken from [1].

The yield strength of all metals depends on temperature, strain and strain rate. In general most non-ferrous metals show an increase of the yield stress with increasing strain rate and a decrease with increasing temperature. However, for magnesium alloys the yield stress usually shows a "stress hill". With increasing strain the yield stress at first increases until a specific strain where it starts to decrease. According to Doege [13], due to the presence of precipitation, phase changes and recrystallisation the yield stress changes in a complex way with temperature, strain and strain rate. Because of the plastic deformation the material undergoes work hardening, however at higher temperatures material softening occurs due to recrystallisation. Therefore the yield stress depends on a combination of temperature and strain.

In most literature, three constitutive equations are generally used to describe the deformation behaviour of metals during hot deformation.

$$
\begin{gathered}
\dot{\varepsilon}=A^{\prime} \sigma^{n^{\prime}} \exp \left(\frac{-Q}{R T}\right) \\
\dot{\varepsilon}=A^{\prime \prime} \exp (\beta \sigma) \exp \left(\frac{-Q}{R T}\right) \\
\dot{\varepsilon}=A(\sinh (\alpha \sigma))^{n} \exp \left(\frac{-Q}{R T}\right)
\end{gathered}
$$

Where $\dot{\varepsilon}$ is the strain rate, $\sigma$ is the yield stress, Q is the activation energy of deformation, $R$ is the universal gas constant, $T$ is the absolute temperature and $A^{\prime} A^{\prime}, A^{\prime \prime}, n^{\prime}, n^{\prime}, a$ and $B$ are material constants. Equation (2.1), the power law, breaks down at high stresses which means that the $n$ ' needs to change as a function of $\dot{\varepsilon}$, according to [14]. The exponential law, Eq (2.2), may be used for hot working processes, however it has some limitations. The 
most frequently used alternative for hot forming is the hyperbolic sine law, Eq. (2.3), which is suitable for the whole range of parameters unlike the previous described equations. The constitutive relationship for AZ31B derived by $\mathrm{Li}$ [15] based on the hyperbolic sine law is used in this research.

Li performed compression tests on pre-extruded rods at different strain rates and different temperatures. The cylindrical specimens are compressed to a true strain of 1 at strain rates ranging from 0.03 to $90 \mathrm{~s}^{-1}$ at initial temperatures between 300 and $500{ }^{\circ} \mathrm{C}$. The temperature of the specimens is measured with a fast-response thermocouple to capture the temperature change during the deformation. In the process of determining the constants for the constitutive equation this temperature change is compensated. The resulting true stress strain curve at $300^{\circ} \mathrm{C}$ can be seen in Figure 2.3. The constitutive constants can be found in Appendix A. The conditions of these experiments make this work of Li very suitable as material model for calculations of hydrostatic extrusion of AZ31 magnesium.

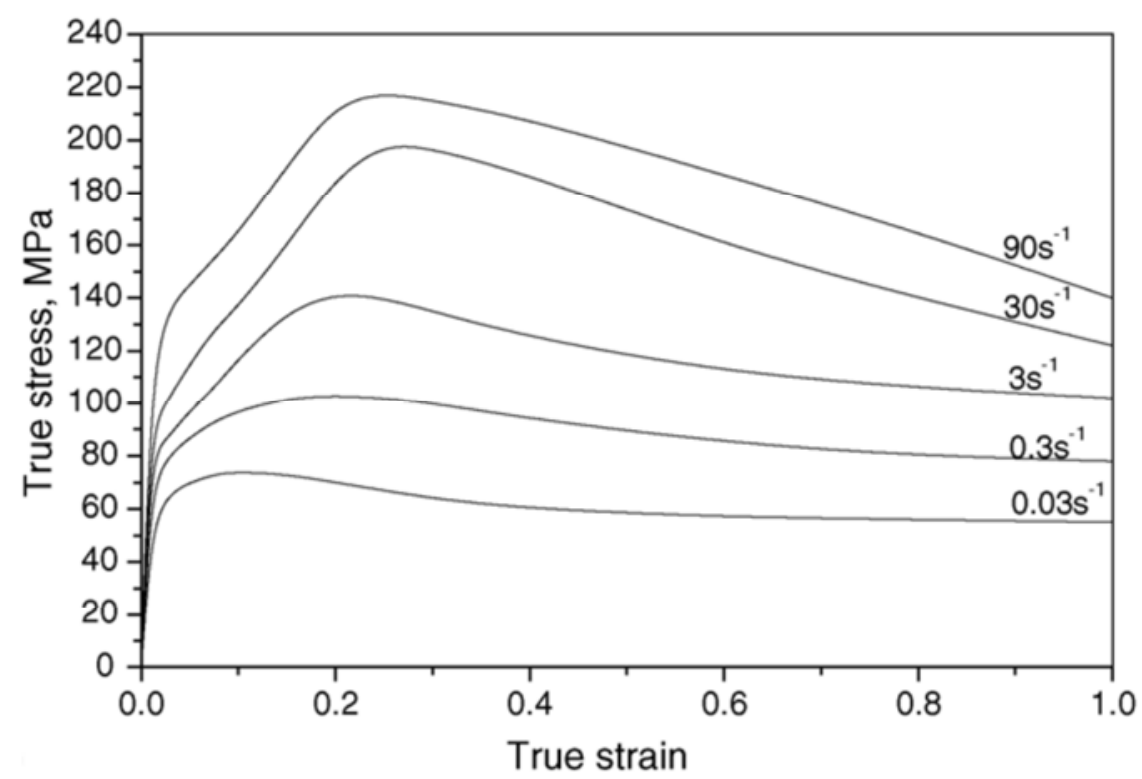

Figure 2.3 Measured true stress strain curves for AZ31 obtained from compression tests of Li, [15].

In the inlet zone of the hydrostatic extrusion process the billet material does not deform plastically. For the calculations of the film thickness in the inlet zone the yield stress of the magnesium billet is required at the transition from inlet to work zone. However since the strain and strain rate can only be calculated in the work zone of the extrusion process, an 'average' yield stress is applied for the inlet zone calculations, $\sigma_{\mathrm{y}}=100 \mathrm{MPa}$. 


\subsubsection{Billet surface}

An important tribological phenomenon is the surface roughness. The surface roughness can be presented with a roughness density function. The density function represents the probability of certain summit height occuring. Most engineering surfaces can be represented with the Gaussian probability function, see Figure 2.4 , with $\bar{z}$ the mean plane of the asperities and $\sigma=\mathrm{R}_{\mathrm{q}}$. This is explained below. Assuming fully plastic contact, then $F_{N}=A_{r} \cdot H$ if the pressure on the contacts is assumed to be equal to the hardness. A simple model to calculate the real area of contact $A_{r}$ is to calculate the area from the amplitude probability function according to

$$
A_{r}=A_{n} \int_{d}^{\infty} \varphi(z) d z
$$

This is also illustrated in Figure 2.4. The nominal contact area $A_{n}$ is contact area without the roughness taken into account.

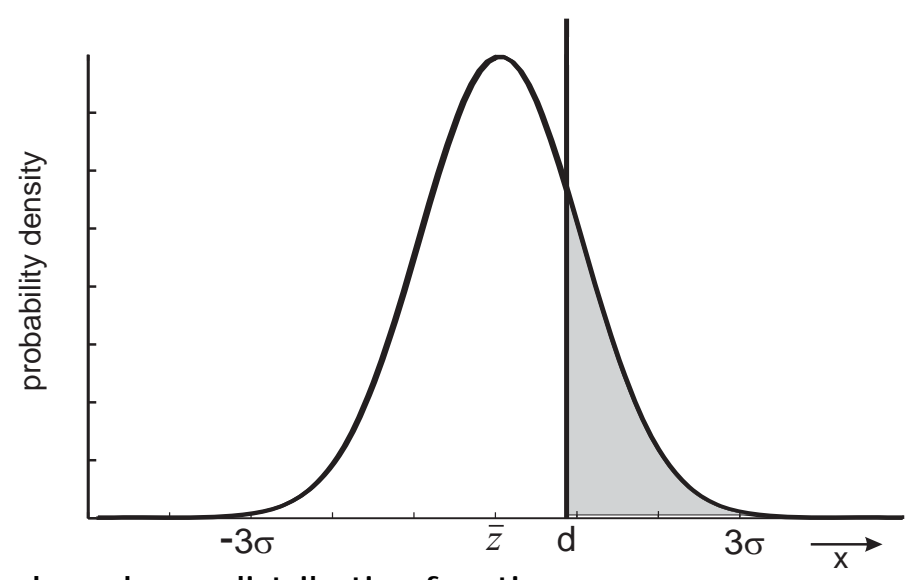

Figure 2.4 Normalised roughness distribution function.

To measure the surface roughness several standards are available. The roughness is considered to be a profile function $z(x)$ and $L$, which is the sampling length of the profile. Then the $R_{a}$, or Centre Line Average (CLA), is defined as

$$
R_{a}=\frac{1}{L} \int_{x=0}^{x=L}|z(x)-\bar{z}| d x
$$

The $\mathrm{R}_{\mathrm{q}}$, sometimes also called RMS (root mean square), is defined as

$$
R_{q}^{2}=\sigma^{2}=R M S^{2}=\frac{1}{L} \int_{x=0}^{x=L}(z(x)-\bar{z})^{2} d x
$$

The skewness of the summit height distribution is a measure for the symmetry of the distribution. For a Gaussian distribution $S_{k}=0$. If $S_{k}>0$, low surface heights occur more often than high summits and vice versa. 


$$
S_{k}=\frac{1}{\sigma^{3}} \int_{-\infty}^{\infty}(z-\bar{z})^{3} \varphi(z) d z
$$

In the hydrostatic extrusion process the billets are turned before entering the press. This results in a grooved surface with a wavelength of about $0.35 \mathrm{~mm}$ and an $\mathrm{R}_{\mathrm{q}}=6 \mu \mathrm{m}$.

The billet surface has been studied with an interference microscope. This is a noncontacting optical technique suitable for most surfaces which have some level of reflectivity. The interference microscope has a height resolution of around $1 \mathrm{~nm}$ and an inplane resolution of $1 \mu \mathrm{m}$. More information about the interference microscope can be found in [16]. A result of this measurement method can be found in Figure 2.5. The measured area is $870 \times 670 \mu \mathrm{m}$; in Figure 2.5 the amount of pixels is indicated on the axes, pixel size is $\pm 3 x \pm 3 \mu \mathrm{m}$. The height of the surface is given in metres.

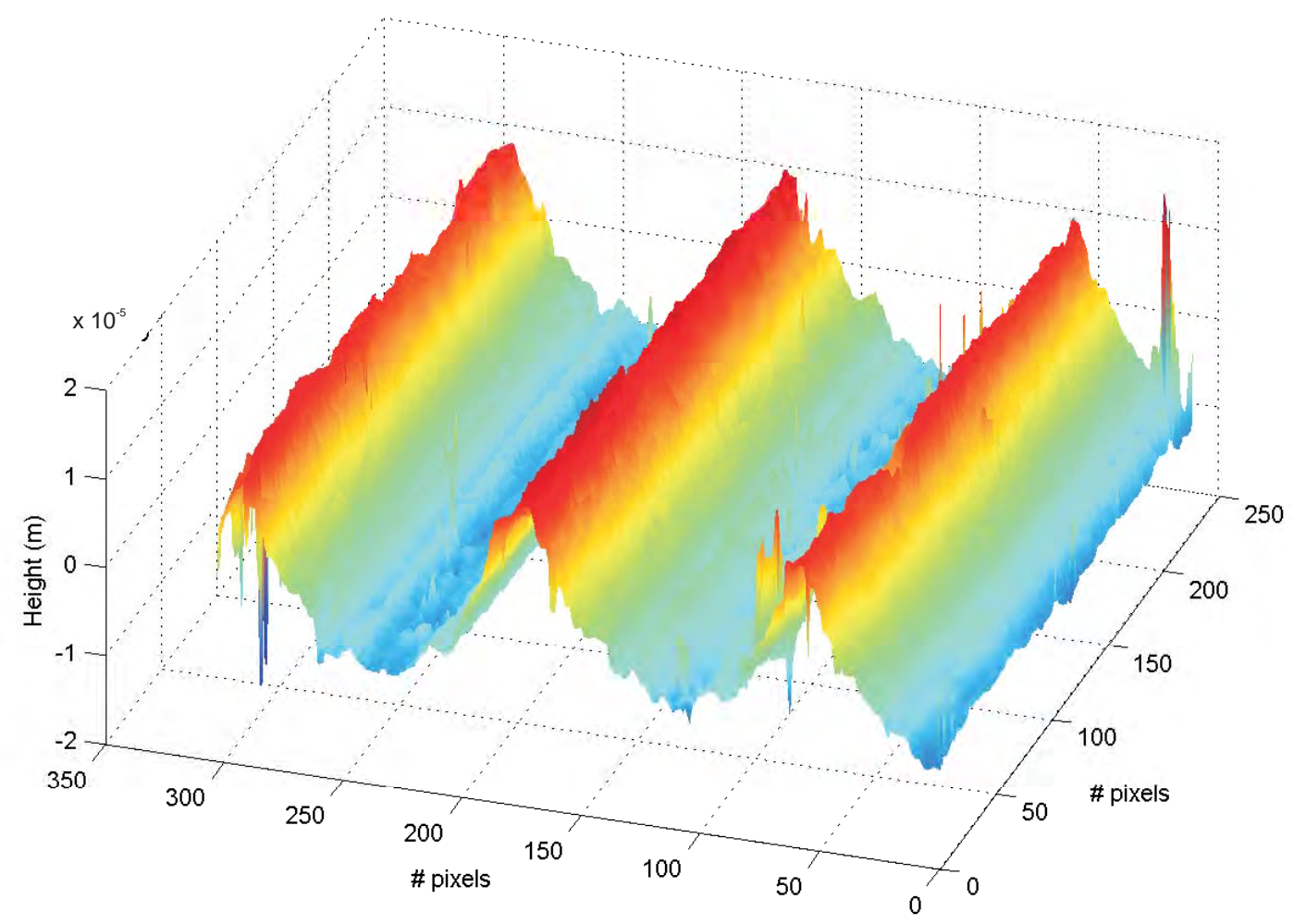

Figure 2.5 Roughness measurement of the turned billet surface.

The surface roughness density function of Figure 2.5 is depicted in Figure 2.6. The turned surface can be recognized in the positive skewness. A turned surface has wide valleys with sharp summits. Therefore low surface heights occur more often than the higher ones. 


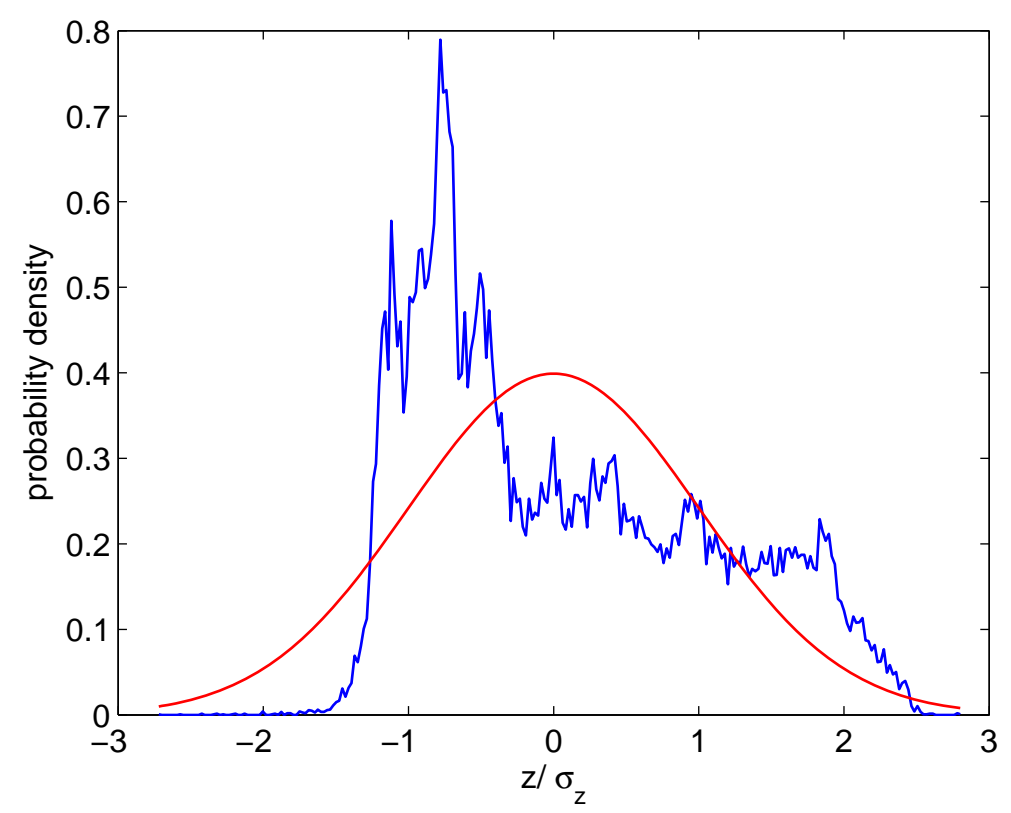

Figure 2.6 Probability density function of the surface roughness of the turned billet and the equivalent Gaussian distribution function.

The surface of the work zone of a residual billet is also studied with an interference microscope. The probability density function measured is depicted in Figure 2.7. It can be seen that the positive skewness found in Figure 2.6 has changed to a negative skewness. This is caused by the plateaus originating from the contact between billet and die during deformation.

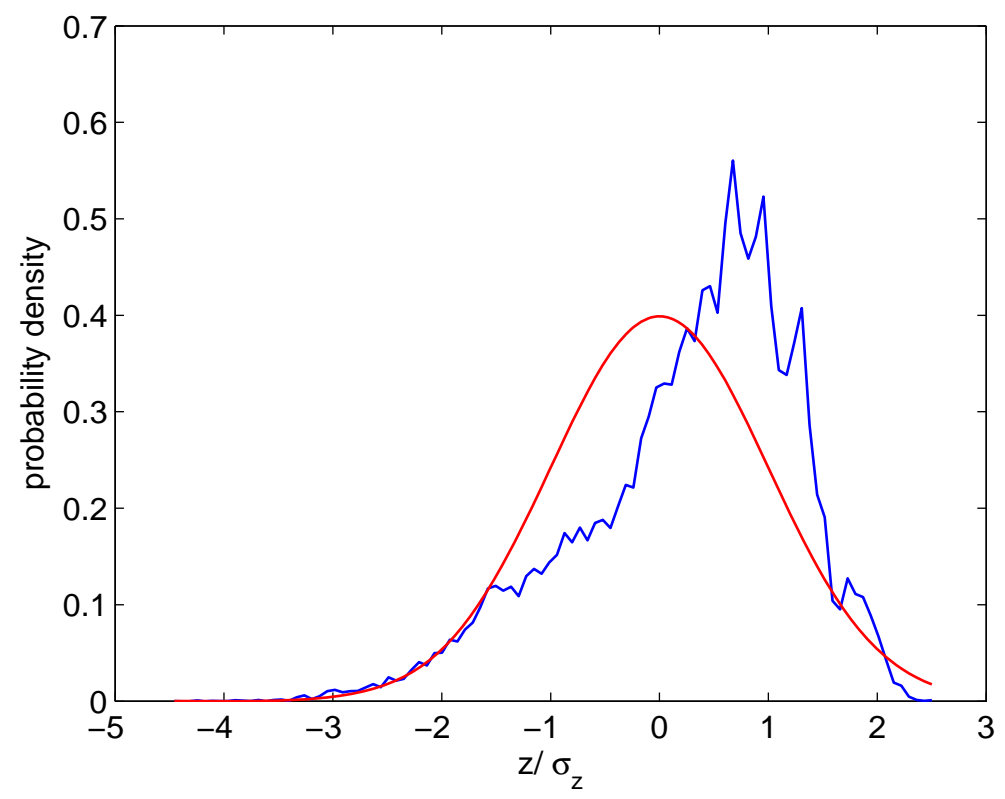

Figure 2.7 Probability density function of the surface roughness of the work zone from a residual billet and the equivalent Gaussian distribution function. 


\section{Lacquer layer}

On some of the test pressings done a lacquer layer is found on part of the work zone area of the residual billet. Tests were performed on one of these residual billets [17]. Figure 2.8 shows a cross section of the surface of the residual billet. It clearly shows a separation line between the layer, roughly $100 \mu \mathrm{m}$ thick, and the billet. This indicates that the layer is not attached properly and therefore it is most likely that the billet material flows underneath the layer.

Furthermore, analysis with a SEM (scanning electron microscope) has been performed. Measurements of the original alloy in cross section show an AZ31 alloy, as was expected. Measurements of the bare surface show an oxidized surface and a relatively high carbon level. In the layer a much higher level of carbon is found, indicating that the layer contains an organic substance. It is therefore most likely that the layer is caused by (burned) castor oil residues. If such a layer is formed, it sticks to the die and the billet material starts to flow underneath this interfacial layer. The original tribological system changes from die against billet to an interfacial layer system. When the layer remains intact this does not dramatically change the situation and can still lead to a good surface quality. However, when the layer starts to decompose the surface quality of the product deteriorates because of the abrasive effect of the loose particles of the layer. A more extensive description of these measurements can be found in Appendix $B$.

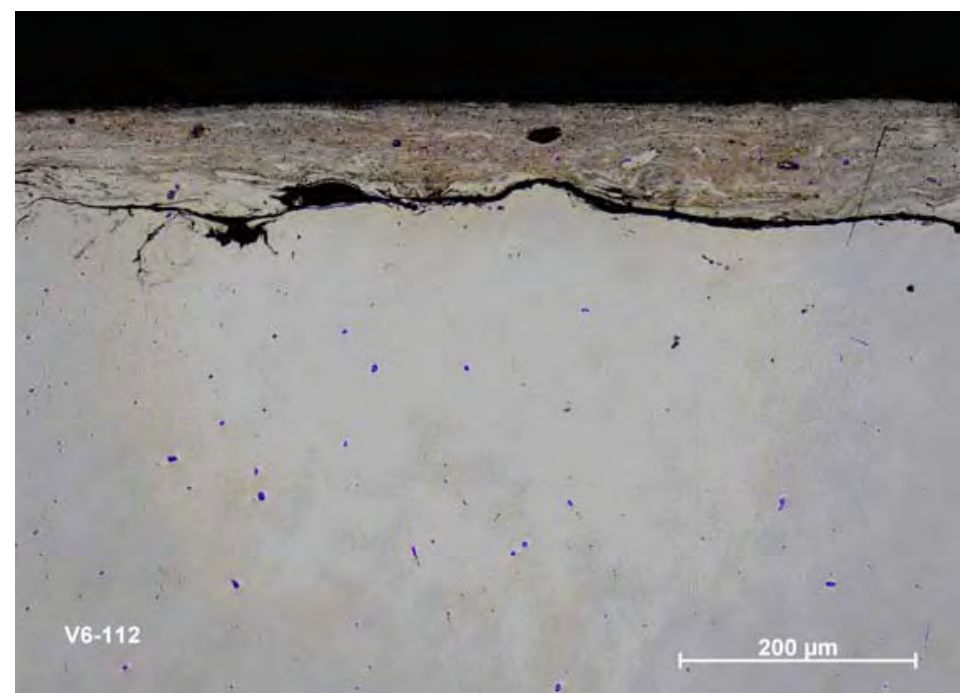

Figure 2.8 Cross sectional view of billet and lacquer layer, picture courtesy of [17].

\subsection{Tool material}

In hydrostatic extrusion the die consists of two parts: the die cone and the die insert. The die cone forms the major part of the work zone, which is most commonly made of steel 1.2343 or 1.2367 . The chemical compositions of these steels can be found in Appendix A. The last few percent of the die in the work zone and the transition from work zone to 
outlet zone is the die insert, which is made of Rex 76. The schematic die is depicted in Figure 2.9.

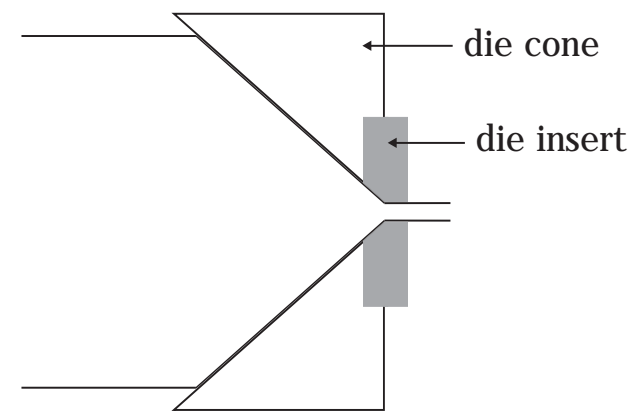

Figure 2.9 The die of a hydrostatic extrusion press.

Rex 76 is a super high-speed steel made by the Crucible Particle Metallurgy (CPM) process, see also Appendix A. This process is very suitable for hard alloys like the ones used for extrusion dies. The chemical composition of Rex 76 can be found in Appendix A and some mechanical properties of the material in Table 2.5, [18]. The die insert is hardened and polished to a very smooth surface finish.

\begin{tabular}{|l|l|}
\hline Property & Value \\
\hline Modulus of Elasticity & $214 \mathrm{GPa}$ \\
\hline Rockwell C Hardness & $67-70$ \\
\hline
\end{tabular}

Table 2.5 Mechanical properties of Rex 76.

\subsection{Pressure medium - castor oil}

In the hydrostatic extrusion process castor oil is normally used as the pressurized medium. Castor oil is a vegetable oil, which makes it a natural product with properties that fluctuate to a certain extent. Its most outstanding feature is that it polymerizes rapidly when the temperatures rises, resulting in an oil with better lubricating properties. Furthermore, castor oil thermally degrades above $370^{\circ} \mathrm{C}$ in atmospheric conditions [19]. The viscosity of castor oil will be discussed more extensively in the next paragraph.

There are different parameters for modelling the viscosity of a fluid. The most common parameters are the dynamic viscosity and the kinematic viscosity. In the current context, the dynamic viscosity is the most suitable. Where viscosity is mentioned in the rest of this work, this refers to dynamic viscosity. The viscosity is highly dependent on the acting pressure and temperature in the oil. Most existing viscosity models incorporate either the pressure effect or the temperature effect; therefore a combination of models is required.

The temperature effect can be modelled with

$$
\log \log (v+0.7)=A-B \log T
$$


where $v$ is the kinematic viscosity $\left(\mathrm{mm}^{2} / \mathrm{s}\right)$ and $T$ is the temperature in $\mathrm{K}$. $\mathrm{A}$ and $\mathrm{B}$ are dimensionless constants which can be calculated if the kinematic viscosity is known for at least two temperatures. In [20] the kinematic viscosity values for castor oil at $40{ }^{\circ} \mathrm{C}$ and $100{ }^{\circ} \mathrm{C}$ can be found. Using Eq. (2.8) at the measured values gives $A=9.10$ and $B=3.49$. The kinematic viscosity is linked to the required dynamic viscosity via the density $\rho$,

$$
v=\frac{\eta}{\rho}
$$

The values for both the kinematic and dynamic viscosity of castor oil at different temperatures and the density of castor oil can be found in Appendix A.

The pressure dependency of the viscosity is most commonly modelled with the equation introduced by Barus in 1893 [21],

$$
\eta(p)=\eta_{0} e^{\gamma p}
$$

where $\eta(\mathrm{Pa} \cdot \mathrm{s})$ is the dynamic viscosity, $\eta_{0}(\mathrm{~Pa} \cdot \mathrm{s})$ the viscosity at ambient pressure, $\mathrm{p}(\mathrm{Pa})$ the pressure and $y\left(\mathrm{~Pa}^{-1}\right)$ the viscosity-pressure coefficient. The temperature effect can be incorporated by means of the temperature dependency of $\eta_{0}$. The advantage of Barus equation is its simplicity. However at high pressures the Barus equation is known to overestimate the viscosity. A more suitable alternative for elevated pressures is Roelands relation [22].

$$
\eta(p)=\eta_{0} \exp \left[\left\{\left(1+\frac{p}{p_{r}}\right)^{z}-1\right\} \cdot \ln \left(\frac{\eta_{0}}{\eta_{\infty}}\right)\right]
$$

Where $\eta, \eta_{0}$ and $p$ are the same as in the Barus equation, $p_{r}$ is a constant of $196.2 \mathrm{MPa}$, $z(-)$ is the pressure viscosity coefficient and $\eta_{\infty}$ is a constant of $6.315 \cdot 10^{-5} \mathrm{~Pa} \cdot \mathrm{s}$. The pressure viscosity coefficient $z$ for castor oil is found to be 0.43 , [20]. This is relatively low; usually the pressure coefficient is between 0.5 and 0.9 for lubricants. This means that the viscosity increase as a result of the high pressure is lower than for other oils.

However, for higher temperatures and pressures the applicability of the above- mentioned relations is questionable. Data is available only for lower pressures and temperatures. Nakamura [23] performed measurements on the viscosity of castor oil up to $200^{\circ} \mathrm{C}$ and 2.5 GPa with a falling sphere method in a diamond-anvil pressure cell. The results can be found in Figure 2.10. Above $10^{3} \mathrm{~Pa} \cdot \mathrm{s}$ the sphere stops falling and therefore the viscosity cannot be measured with this setup. In Figure 2.10 Nakamura refers to measurements done by Nishihara up to $0.5 \mathrm{GPa}$ and $100^{\circ} \mathrm{C}$. Details can be found in [24]. 


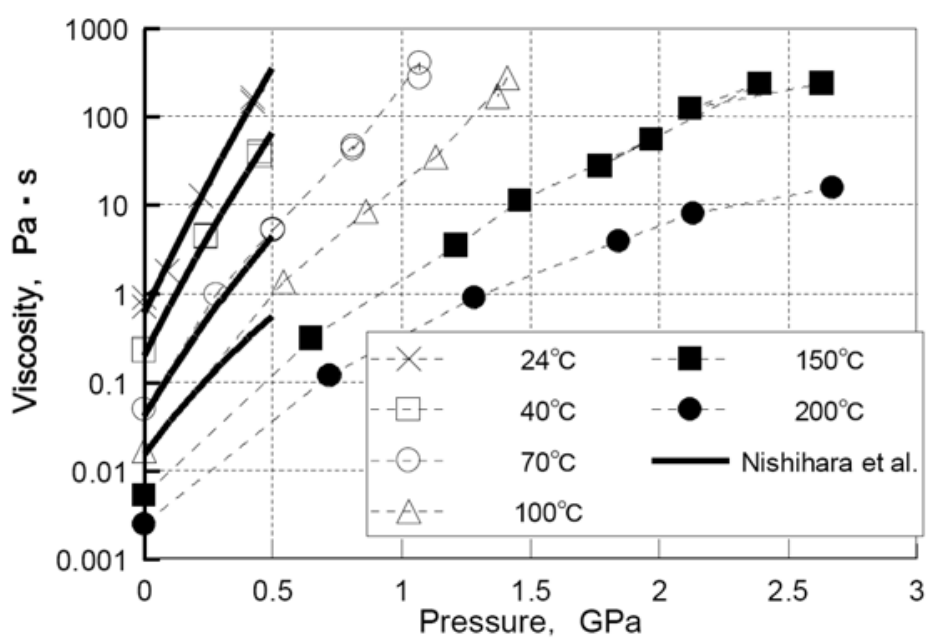

Figure 2.10 Measurements of the viscosity of castor oil performed by Nakamura, taken from [23].

Nakamura fitted his data in the Barus viscosity equation by adjusting $y$ according to

$$
\gamma(T, P)=-1.055 P+0.0002 T^{2}-0.093 T+15.17
$$

where $\mathrm{T}$ is the temperature in ${ }^{\circ} \mathrm{C}$ and $\mathrm{P}$ is the pressure in $\mathrm{GPa}$. This model is in reasonable agreement with the measured data [25]. The model of Nakamura is compared to the Roelands equation in Figure 2.11, and the applicable measurements from Figure 2.10 are added. For both displayed temperatures it can be seen that the measurements are closest to the Roelands equation. The measurement at $\mathrm{T}=100^{\circ} \mathrm{C}$ and $\mathrm{P}=1.35 \mathrm{GPa}$ is the exception. However, this point in Nakamura's figure is also relatively high and the pressure range between 0.5 and $1.5 \mathrm{GPa}$ is much more relevant for the hydrostatic extrusion process. Furthermore, the temperature of the contact is more in the range of $\mathrm{T}=200{ }^{\circ} \mathrm{C}$ than $\mathrm{T}=100^{\circ} \mathrm{C}$. The conclusion is therefore that the Roelands relation performs most accurately for the desired temperature and pressure range. Therefore the Roelands equation, Eq. (2.11), will be used in most of the calculations in this work.

However, when solving equations analytically, the Roelands equation is not very convenient, the Barus equation being more suitable. As mentioned before, the Barus equation predicts too high a viscosity at high pressure. An alternative is to manually adapt the pressure-viscosity coefficient $y$ to fit the Roelands relation in the pressure regime present in hydrostatic extrusion. For $\mathrm{T}=100{ }^{\circ} \mathrm{C}$ and the pressure between $0.5 \mathrm{GPa}$ and 1.0 GPa, $y$ is adapted to $7.0 \mathrm{GPa}^{-1}$, see also Figure 2.12. This adapted coefficient will be used in the analytical solutions in this work. Nakamura's model is less suitable to use in the analytical solution because $y$ is dependent on the pressure as well as on the temperature. 


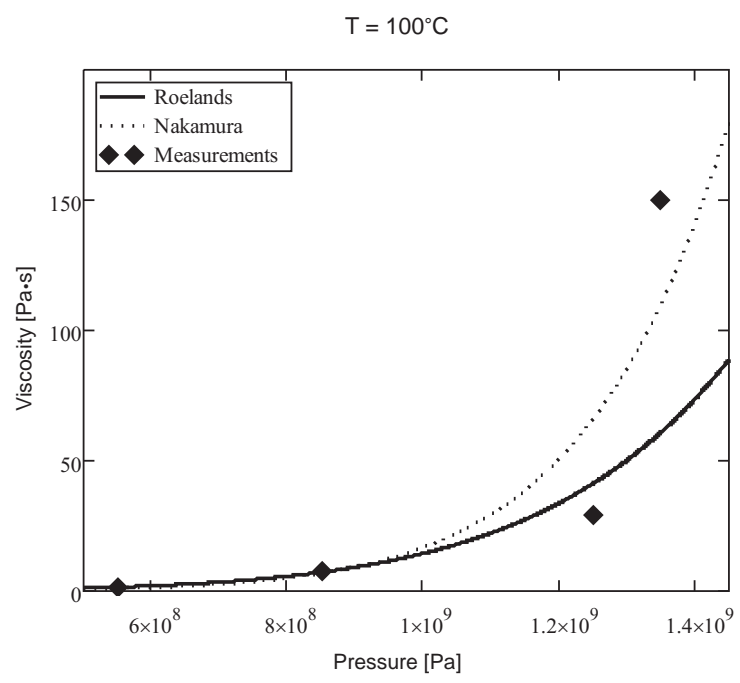

a)

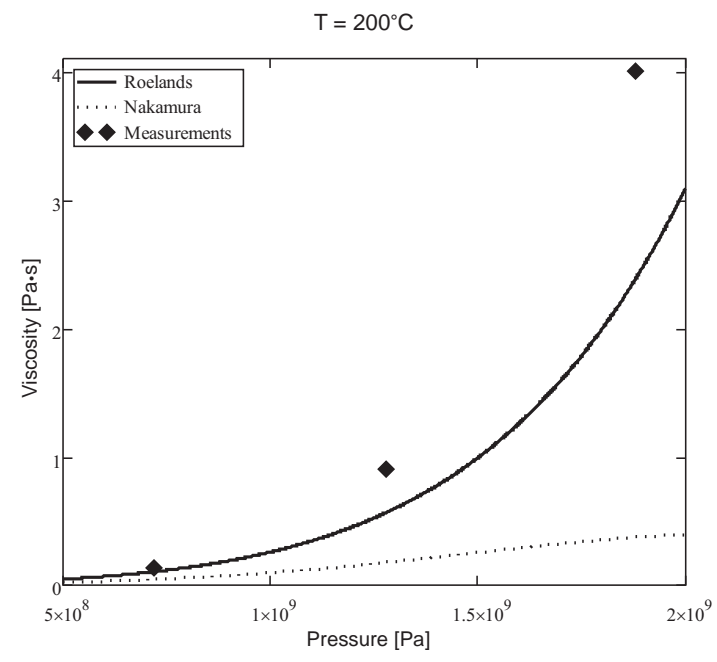

b)

Figure 2.11 Comparison viscosity models of Nakamura and Roelands at a) $100^{\circ} \mathrm{C}$ and b) $200{ }^{\circ} \mathrm{C}$.

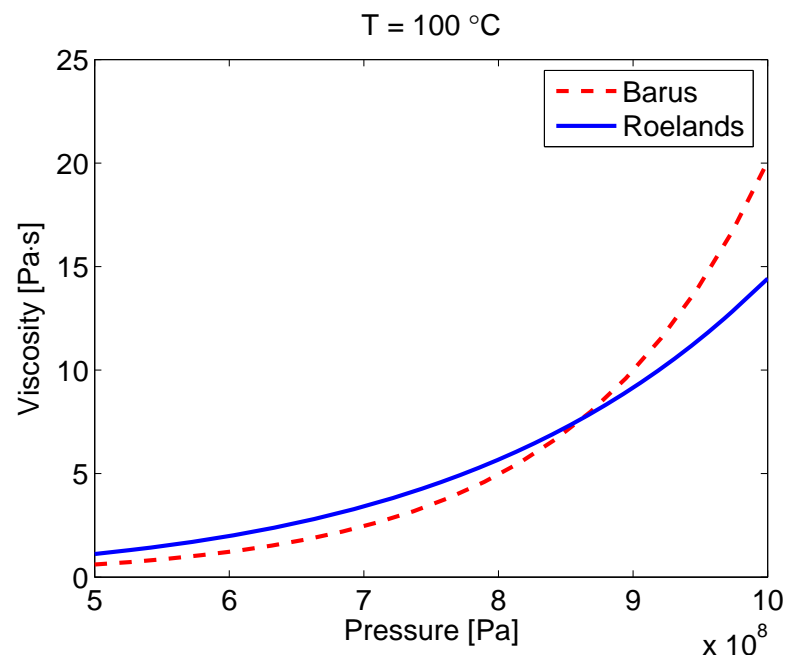

Figure 2.12 Comparison viscosity models of Roelands and Barus with the manually adapted pressure-viscosity coefficient at $100^{\circ} \mathrm{C}$.

\subsection{Summary}

The tribological system is described in this chapter. The four elements of the tribological system are presented. The environment of the system follows from the hydrostatic extrusion process. The process is described and divided into different zones. The work zone is the determining zone for the surface quality of the extrusion product. Furthermore, some properties of the magnesium alloy used, are given as one of the two interacting surfaces. Several constitutive equations are presented, one of which one was chosen based on literature. Roughness measurements of a magnesium billet are presented before extrusion and in the work zone of a residual billet. The opposing surface is the tool 
material. Some properties of the steel used for the die and die insert are presented. Finally the lubricant and pressure medium castor oil is described. Several viscosity models depending on temperature and/or pressure are presented. The Roelands equation is chosen as the best fitting viscosity model for this system. However, if an analytical solution is required the Barus equation is be used.

The most important parameters of this tribological system are presented in Table 2.6. This data set is used for all calculations performed in this work unless stated otherwise.

\begin{tabular}{|l|l|l|}
\hline Symbol & Value & Description \\
\hline$q$ & $0.6 \mathrm{GPa}$ & extrusion pressure \\
\hline$r_{1}$ & $73 \mathrm{~mm}$ & billet diameter \\
\hline$r_{2}$ & $18.5 \mathrm{~mm}$ & end diameter \\
\hline & 16 & extrusion ratio \\
\hline$U_{1}$ & $8.8 \mathrm{~mm} / \mathrm{s}$ & entry velocity of the billet \\
\hline$\theta$ & $45^{\circ}$ & semi die angle \\
\hline$R$ & $0.1 \mathrm{~m}$ & round-off radius of the billet \\
\hline$\sigma_{\mathrm{y}}$ & $100 \mathrm{MPa}$ & yield stress magnesium under compression $(\mathrm{AZ31})$ \\
\hline $\mathrm{T}$ & $200^{\circ} \mathrm{C}$ & oil temperature \\
\hline$\eta_{0}$ & $2.88 \mathrm{mPa} \cdot \mathrm{s}$ & viscosity of the lubricant at 1 bar at $200^{\circ} \mathrm{C}$ \\
\hline$y$ & $7 \cdot 10^{-9} \mathrm{~Pa}-1$ & viscosity pressure coefficient \\
\hline$z$ & 0.43 & Roelands pressure viscosity coefficient \\
\hline $\mathrm{R}_{\mathrm{q}}$ & $6 \mu \mathrm{m}$ & $\mathrm{R}_{\mathrm{q}}$ of the magnesium billet \\
\hline
\end{tabular}

Table 2.6 Dataset for magnesium extrusion using castor oil. 


\section{Chapter 3}

\section{Modelling lubrication in the inlet zone}

The surface quality of the hydrostatic extrusion product is determined by the contact between billet and die [7]. In the hydrostatic extrusion process oil is present in this contact. To what extent there are hydrodynamic effects present has to be determined. In any lubricated contact three different lubrication regimes are possible: Full Film Lubrication, Mixed Lubrication and Boundary Lubrication. These regimes and the relation between them will be discussed further on.

As explained previously, the inlet zone in the hydrostatic extrusion process is the zone where no plastic deformation takes place. The pressure in the extrusion medium rises in the inlet zone until the material starts to flow. The point where the critical pressure is reached is the transition from the inlet zone to the work zone. In the major part of the inlet zone, the geometry determines that full film lubrication is the acting lubrication regime. However, at the transition point to the work zone, the acting lubrication regime is unknown. This chapter is devoted to calculating the film thickness at the transition from the inlet to the work zone. The film thickness at this transition point will be called the central film thickness. The full film lubrication calculations will be based on the Reynolds equation [26]. In this chapter the yield stress of the magnesium will be taken constant so that the effect of each parameter can be seen clearly. In Section 3.2 of this chapter, the lubrication regimes will be discussed as well as the Reynolds equation. An existing model of Wilson and Walowit [27] describing lubrication phenomena of hydrostatic extrusion and lubricated wire drawing will be discussed in Section 3.3. In Section 3.4 this model will be extended and the results of calculations can be found in Section 3.5. Finally, conclusions will be drawn in Section 3.6.

\subsection{Theory}

\subsubsection{Stribeck curve}

As mentioned before, there are three possible lubrication regimes: Full Film Lubrication, Mixed Lubrication and Boundary Lubrication.

- In Full Film Lubrication (FFL) the two surfaces are fully separated by a fluid film. The load is therefore entirely carried by this film. The coefficient of friction in this 
regime is caused by shear in the lubricant film and is rather low, in the order of 0.01 . If the pressure is so low that the elastic deformation of the surfaces can be neglected, e.g. in journal bearings, this lubrication regime is also referred to as the Hydrodynamic Lubrication regime $(\mathrm{HL})$. When the pressure is higher, whereby one or both the surfaces deform elastically, this lubrication regime is referred to as Elasto-Hydrodynamic Lubrication (EHL) regime. This occurs in, for example, ball bearings and gears. In the more extreme case one of the bodies deforms plastically and Plasto-Hydrodynamic Lubrication (PHL) occurs. This can be the case in metal forming processes like rolling and hydrostatic extrusion. Hydrodynamic lubrication has to be distinguished from the hydrostatic pressure present in the hydrostatic press. The hydrodynamic pressure is a local effect as the result of the lubricant being dragged in a wedge while the hydrostatic pressure is present around the whole billet because of the loading of the ram. In general, fluid flow can be modelled with the fluid dynamics theory, i.e. the Navier-Stokes equations. In the thin film situation the more simplified Reynolds equation is often sufficient. In this regime, the coefficient of friction generally increases with velocity.

- In the Boundary Lubrication regime $(\mathrm{BL})$ the load is carried entirely by the contacting asperities of the two surfaces. The velocity difference between the two surfaces leads to shear in the boundary layers at the surfaces. The coefficient of friction is therefore relatively high. Typical values of the coefficient of friction are between 0.1 and 0.3 . Here, the coefficient of friction is more or less independent of the velocity.

- Mixed Lubrication regime (ML) is a combination of FFL and BL. The load is carried partly by the contacting asperities and the remaining part by the lubricant film. Therefore the coefficient of friction also has an intermediate value, i.e. $0.01<$ $\mu<0.1$. For obvious reasons this is the most complex regime to model; however, this regime is the important regime in many metal forming processes, [28]. Here, the coefficient of friction decreases with velocity.

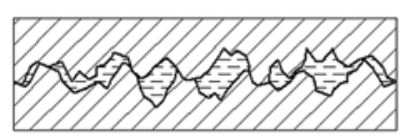

a)

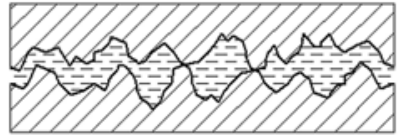

b)

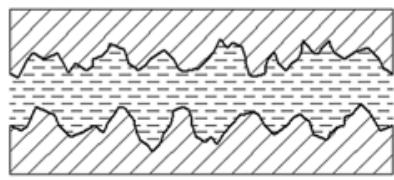

c)

Figure 3.1 Lubrication regimes; a) boundary lubrication, b) mixed lubrication and c) full film lubrication.

Stribeck [29] was the first to note a friction dependency of the shaft velocity in a journal bearing in the beginning of last century. He established a diagram with friction force against shaft velocity curves to show the different lubrication regimes generally known as the Stribeck curves. In a Stribeck curve all three lubrication regimes are encountered when the velocity is increased or similarly when the pressure is decreased: first $B L$, then $M L$ and finally FFL. 
Later, several people extended this diagram with a lubrication number instead of the velocity and sometimes a logarithmic horizontal axis. A lubrication number typically includes in the nominator a velocity component (angular velocity $\omega$ in $[\mathrm{rad} / \mathrm{s}]$, or revolutions per minute $[\mathrm{rpm}]$ or the velocity $[\mathrm{m} / \mathrm{s}]$ ) and the viscosity $\eta[\mathrm{Pa} \cdot \mathrm{s}]$ of the lubricant. The denominator of a lubrication number usually contains a pressure or load parameter and sometimes a roughness parameter is included. The generalised Stribeck curve as introduced by Schipper [30] is presented here; he uses the dimensionless lubrication number $L$ and lubrication parameter $H_{L}$. $H_{L}$ is defined as

$$
H_{L}=\frac{\eta \cdot U^{+}}{p_{0}}
$$

where $\eta$ is the dynamic viscosity of the lubricant, $\mathrm{U}^{+}$is the sum velocity of the two surfaces and $p_{0}$ is the nominal contact pressure. $H_{L}$ is very close to the well-known Hersey number, [31], which is defined as $\eta \cdot U_{\text {rev }} / p$, where $U_{\text {rev }}$ is the rotational velocity. $L$ is defined as

$$
L=\frac{H_{L}}{R_{a}}
$$

where $R_{a}$ is the arithmetic mean of the combined surface roughness. The presence of $a$ roughness value such as $R_{a}$ does not mean that the curve is independent of roughness. Generally, as the roughness decreases the curve in the mixed lubrication regime becomes steeper, the transitions from $B L$ to $M L$ and $M L$ to $F F L$ are more abrupt and the $M L$ regime occurs in a smaller velocity range. For the inlet zone calculations performed in this chapter the central film thickness divided by the billet roughness is used.

$$
\frac{h_{0}}{R_{q}}
$$

In the hydrostatic extrusion process this is a representative parameter for the acting lubrication regime, as will be discussed shortly.

When modelling the hydrostatic extrusion process the film thickness $(\mathrm{h})$ of the lubricant is an important parameter. Naturally, the film thickness is very low in BL and increases towards FFL. The general tendency of the film thickness is also depicted in Figure 3.2. The rest of this chapter is devoted to calculating the film thickness at the transition point from inlet to work zone, see Figure 3.3 for the definition of the different zones. Because of the link between the film thickness and the lubrication regime the calculated film thickness can be used as an indicator of which lubrication regime is operational. Generally speaking, if the film thickness $h$ divided by the roughness $R_{q}$ is greater than 3 , the system is considered to be in FFL, if $h / R_{q}<0.1, B L$ is expected and if $0.1<h / R_{q}<3$, ML is acting. 


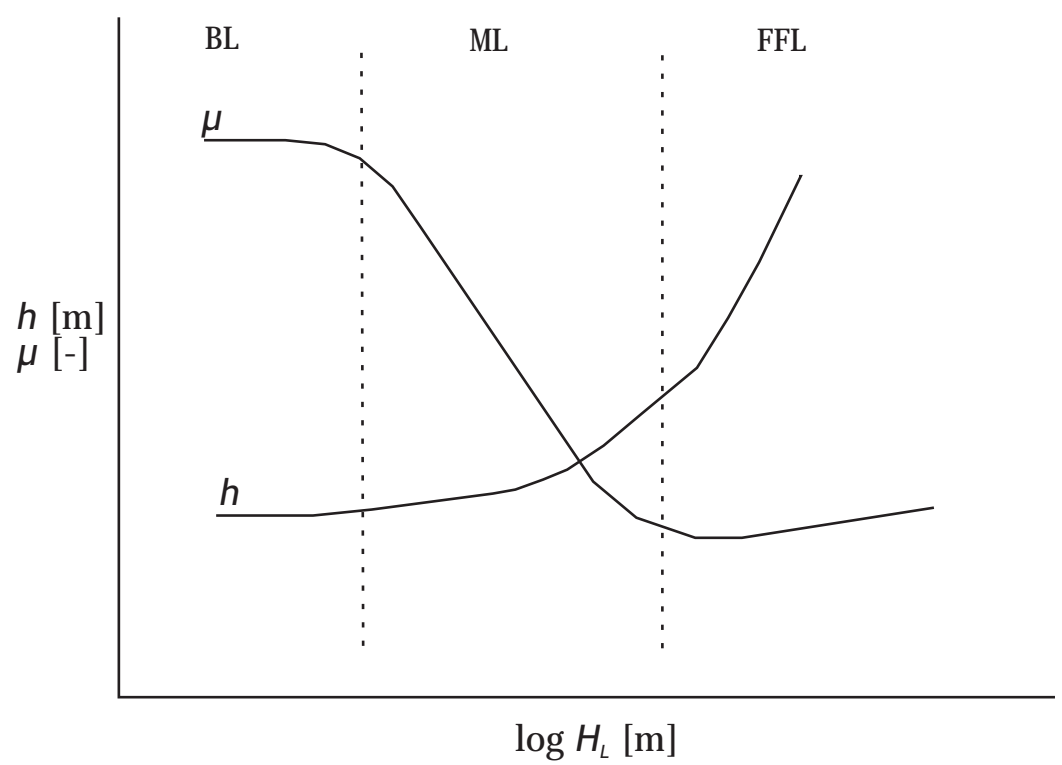

Figure 3.2 Qualitative generalised Stribeck curve and corresponding lubricant film thickness, $h$.

The value of 3 can be explained by the definition of $R_{q}$. As already explained in Section 2.3.2, this is the standard deviation of the distribution function of the surface heights. If the film thickness is larger than three times this standard deviation almost no surface peaks are in contact with the opposing surface, therefore FFL is acting. The transition from BL to ML typically occurs at $h / R_{q}=0.1$, as shown in [32].

\subsubsection{Reynolds equation}

In FFL pressure and film thickness can be calculated with the fluid dynamics theory, i.e. the Navier-Stokes equations. For thin fluid layers like in lubricating films with mass conservation this can be done more easily with a simplified version: the well-known Reynolds equation [26]. In one-dimensional form the Reynolds equation reads:

$$
\frac{\partial}{\partial x}\left(\frac{\rho h^{3}}{12 \eta} \frac{\partial p}{\partial x}\right)=\underbrace{\frac{U_{1}+U_{2}}{2} \frac{\partial \rho h}{\partial x}}_{\text {wedge }}+\underbrace{\frac{\rho h}{2} \frac{\partial}{\partial x}\left(U_{1}+U_{2}\right)}_{\text {stretch }}+\underbrace{\frac{\partial \rho h}{\partial t}}_{\text {squeeze }}
$$

where $\rho$ is the density of the lubricant, $h$ is the film thickness, $p$ is the pressure, $U_{1}$ and $U_{2}$ are the velocities of the surfaces, $x$ is the Cartesian space coordinate and $t$ is the time. The three terms on the right hand side of the equation denote the three possible effects that can take place to influence the pressure. The first term is the wedge effect. The lubricant is drawn into a converging wedge, resulting in a pressure increase. The second term is the stretch effect. Here the variation in velocity of the surface due to the elongation of the billet causes a pressure effect. The last term models the squeeze effect. This models the effect of the time-dependent film thickness change on pressure. 


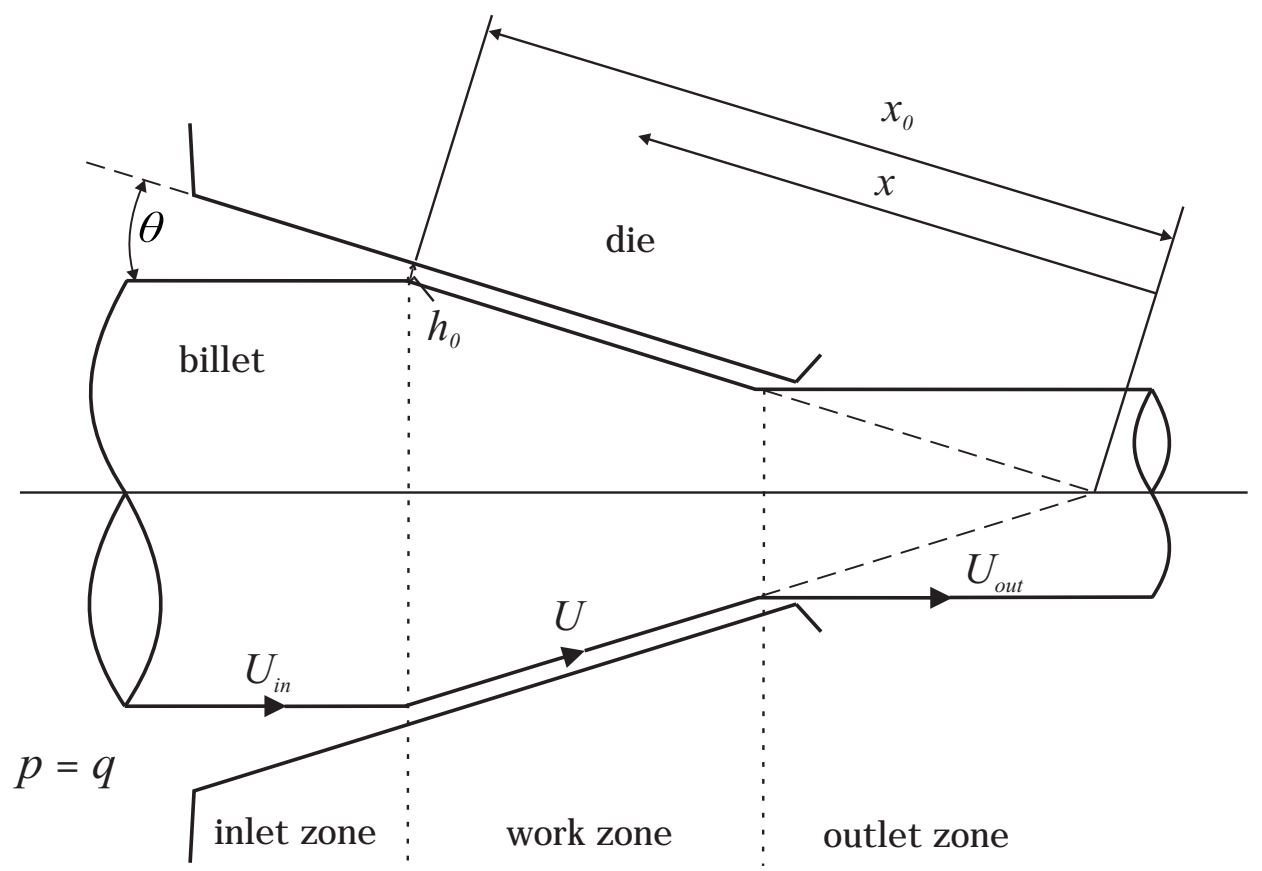

Figure 3.3 Schematic hydrostatic extrusion process.

\subsection{Wilson and Walowit's model}

As explained in the introduction of this chapter, in a large part of the inlet zone of the hydrostatic extrusion process the geometry determines that FFL takes place. The flow of the lubricant in the inlet zone can be modelled with the Reynolds equation, see Eq. (3.4). With this equation the film thickness of the lubricant at the transition from inlet to work zone, $h_{0}$, can be calculated. In Figure 3.3 the schematic hydrostatic extrusion process can be seen with its most important variables. Wilson and Walowit [27] modelled the hydrostatic extrusion process and thus also the inlet zone. Their model will be explained in this section and is referred to as the WW model in the rest of this thesis.

According to Wilson and Walowit the inlet zone is governed by the wedge effect. After a short initial start-up phase of the hydrostatic extrusion of each billet, it is a stationary process. Therefore the squeeze term in Eq. (3.4) can be neglected. The stretch term models the variation in surface velocity, but in the inlet zone the velocity is constant, as depicted in Figure 3.3. So the stretch term can also be neglected. This leads to this simplified Reynolds equation valid for the inlet zone.

$$
\frac{\partial}{\partial x}\left(\frac{h^{3}}{\eta} \frac{\partial p}{\partial x}\right)=-6\left(U_{1}+U_{2}\right) \frac{\partial h}{\partial x}
$$

In the WW model the viscosity of the lubricant is modelled with the Barus equation, Eq. (2.10), which can be substituted in the above equation. Boundary conditions are required in order to solve this differential equation. At the beginning of the inlet zone the lubricant layer is thick and the pressure is equal to the hydrostatic pressure, i.e. $p=q$ for $x \rightarrow \infty$. 
The transition from inlet zone to work zone is defined as the point where the billet material starts to deform plastically, therefore the pressure has to be equal to the hydrostatic pressure plus the yield stress of the billet material, i.e. $p=q+\sigma_{y}$ for $x=x_{0}$. Now the film thickness at $x=x_{0}$ can be calculated as.

$$
h_{0}=\frac{3 U_{1} \gamma \eta_{0} \mathrm{e}^{\gamma q}}{\left(1-e^{-\gamma \cdot \sigma_{y}}\right) \tan \theta}
$$

Wilson and Walowit showed furthermore that the film thickness decreases in the work zone of the extrusion process due to the stretch effect, [27]. Therefore $h_{0}$ is also a good indication of the acting lubrication regime in the work zone.

Applying this model to the hydrostatic extrusion of magnesium leads to a central film thickness in the order of $10^{-10}$ to $10^{-9} \mathrm{~m}$. For the standard data set as defined in Appendix $A$ can be calculated $h_{0}=7.1 \cdot 10^{-11} \mathrm{~m}$, with $R_{q}=6 \mu \mathrm{m}$ giving $h_{0} / R_{q}=1.2 \cdot 10^{-5}$. These calculations clearly indicate that FFL is not present at the transition point from inlet to work zone.

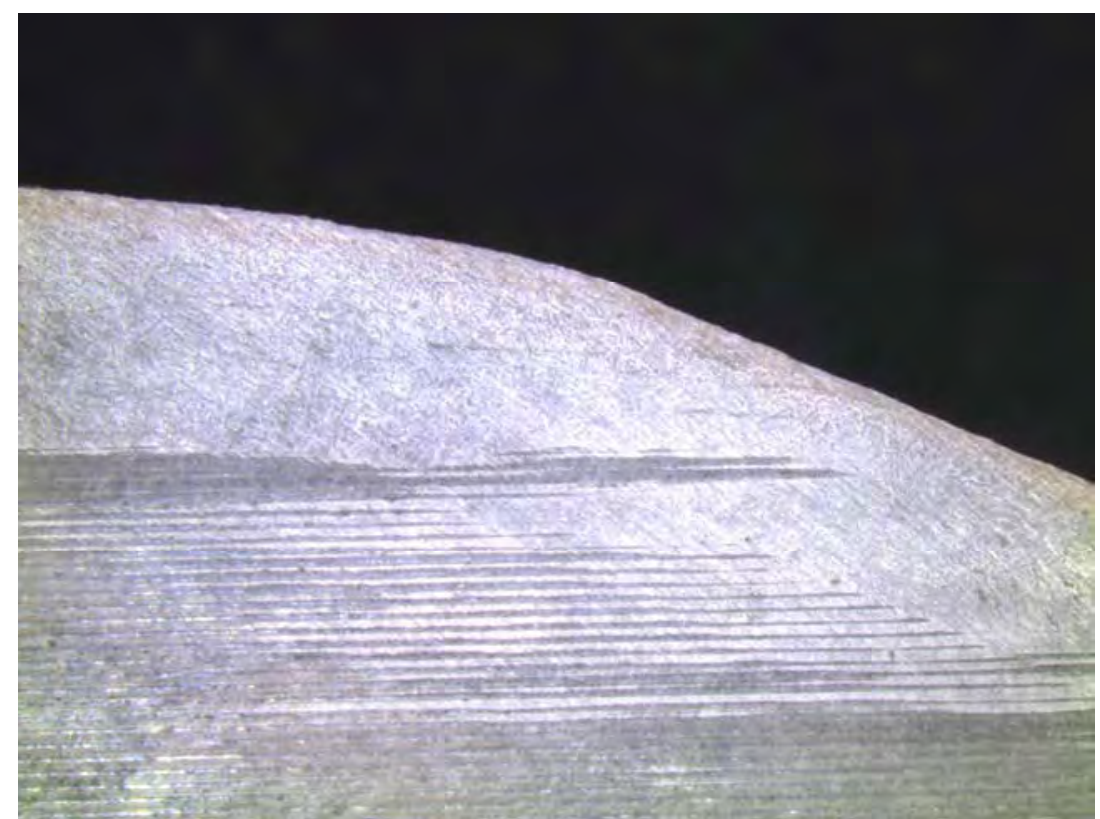

Figure 3.4 The transition from inlet to work zone photographed of a cross section of a residual billet.

\subsection{Lubrication effects in the inlet zone}

Residual billets from the hydrostatic extrusion process show that the transition from inlet to work zone does not occur abruptly, as assumed in the WW model but is formed as a rounded edge, as can be seen in Figure 3.4. As already explained in [33] this round edge can greatly influence the wedge effect in the Reynolds equation. Therefore the WW model 
is extended with this rounded edge and a new Hydrostatic Extrusion Lubrication Model (HELM) is developed.

The rounded edge is modelled with a parabolic function

$$
h(x)=\frac{\left(x-x_{0}\right)^{2}}{2 R}+h_{0} \quad \text { for } x>x_{0}
$$

where $x$ and $x_{0}$ are defined as in Figure 3.3 and $R$ is the radius of the round edge. This parabola has been chosen because if $x$ is close to $x_{0}$, the function is a very similar to a circle and it can be substituted into the Reynolds equation and solved analytically. For $x>x_{0}$ the difference between the actual geometry and this parabola is quite large. However, this is not a problem because the pressure build up takes place very close to $x_{0}$, as will be proven shortly. The boundary conditions result from the pressure constraints and are the same as used in the WW model. Integrating Eq. (3.5) once leads to

$$
\frac{\partial p}{\partial x}=6 U_{1} \eta(p) \frac{h-h_{0}}{h^{3}}
$$

with boundary conditions

$$
\begin{aligned}
p=q \text { for } x \rightarrow \infty \\
p=q+\sigma_{y} \text { for } x=x_{0}
\end{aligned}
$$

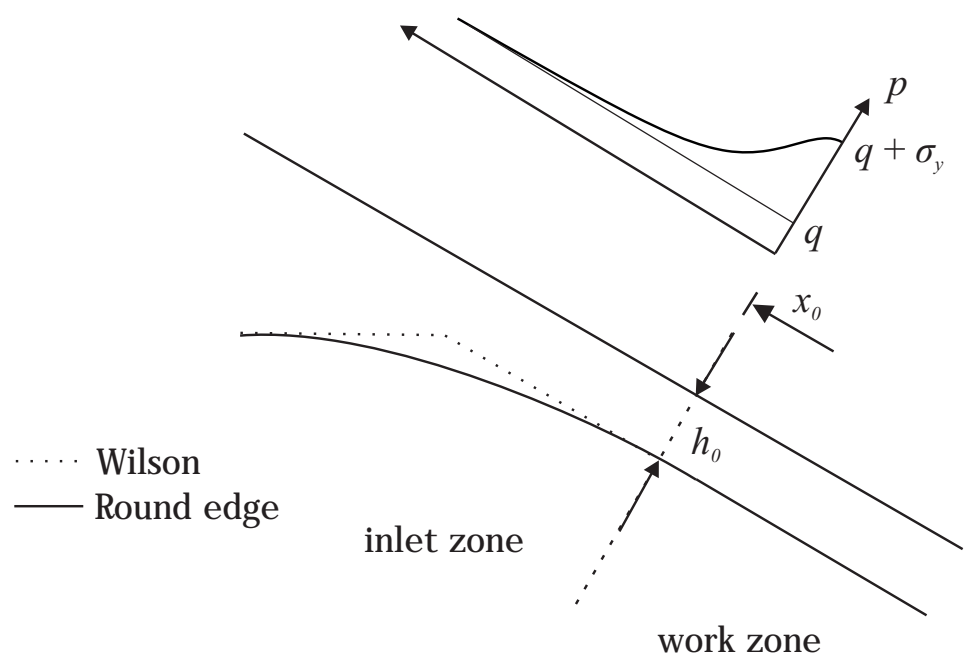

Figure 3.5 Schematic round edge found in residual billets.

\subsubsection{Analytical solution}

When the Barus viscosity model is used this differential equation can be solved analytically. Substituting Barus equation in Eq (3.8) results in

$$
\frac{\partial p}{\partial x}=6 U_{1} \eta_{0} \mathrm{e}^{\gamma p} \frac{h-h_{0}}{h^{3}}
$$


To keep the equations transparent the function $g\left(x^{\prime}\right)$ is defined as

$$
g\left(x^{\prime}\right)=\frac{h\left(x^{\prime}\right)-h_{0}}{h\left(x^{\prime}\right)^{3}} \quad \text { with } x^{\prime}=x-x_{0}
$$

Separating the variables leads to

$$
\mathrm{e}^{-\gamma p} \partial p=6 U_{1} \eta_{0} g\left(x^{\prime}\right) \partial x^{\prime}
$$

Integrating gives

$$
-\frac{1}{\gamma} \mathrm{e}^{-\gamma p}=6 U_{1} \eta_{0} G\left(x^{\prime}\right)+C
$$

where

$$
\begin{gathered}
G\left(x^{\prime}\right)=\int g\left(x^{\prime}\right) d x^{\prime} \\
G\left(x^{\prime}\right)=-\frac{R^{2} x^{\prime}}{\left(2 h_{0} R+x^{\prime 2}\right)^{2}}+\frac{R x^{\prime}}{4 h_{0}\left(2 h_{0} R+x^{\prime 2}\right)}+\frac{\sqrt{2} R \arctan \left(\frac{\sqrt{2} x^{\prime}}{2 \sqrt{h_{0} R}}\right)}{8 h_{0} \sqrt{h_{0} R}}
\end{gathered}
$$

The integration constant can be determined with the boundary condition for $x \rightarrow \infty$ where $p=q$. Substitution of Eq. (3.15) in Eq. (3.13) and using this boundary condition gives,

$$
-\frac{1}{\gamma} \mathrm{e}^{-\gamma q}=6 U_{1} \eta_{0} \cdot \frac{1}{8} \frac{R \sqrt{2} \pi / 2}{h_{0} \sqrt{h_{0} R}}+C
$$

Therefore

$$
C=-\frac{1}{\gamma} \mathrm{e}^{-\gamma q}-\frac{3}{8} U_{1} \eta_{0} \frac{\sqrt{2} \pi R}{h_{0} \sqrt{h_{0} R}}
$$

And thus

$$
-\mathrm{e}^{-\gamma p}=6 \gamma U_{1} \eta_{0} G\left(x^{\prime}\right)-\mathrm{e}^{-\gamma q}-\frac{3}{8} \gamma U_{1} \eta_{0} \frac{\sqrt{2} \pi R}{h_{0} \sqrt{h_{0} R}}
$$

The material starts to deform plastically at the transition point from inlet to work zone, so the other boundary condition is $p=q+\sigma_{y}$ at $x=x_{0}\left(x^{\prime}=0\right)$. With this $h_{0}$ can be determined. 


$$
-\mathrm{e}^{-\gamma\left(q+\sigma_{y}\right)}=6 \gamma U_{1} \eta_{0} G\left(x^{\prime}=0\right)-\mathrm{e}^{-\gamma q}-\frac{3}{8} \gamma U_{1} \eta_{0} \frac{\sqrt{2} \pi R}{h_{0} \sqrt{h_{0} R}}
$$

$G(0)=0$ and thus $\mathrm{h}_{0}$ can be solved to be

$$
h_{0}=\left(\frac{3 \sqrt{2} \pi \gamma U_{1} \eta_{0} \sqrt{R} \mathrm{e}^{\gamma q}}{8\left(1-\mathrm{e}^{-\gamma \sigma_{y}}\right)}\right)^{2 / 3}
$$

From Eq. (3.18) also the pressure can be calculated with

$$
p\left(x^{\prime}\right)=-\frac{1}{\gamma} \ln \left\{-6 \gamma U_{1} \eta_{0} G\left(x^{\prime}\right)+\mathrm{e}^{-\gamma q}+\frac{3}{8} \sqrt{2} \pi \gamma U_{1} \eta_{0} \frac{\sqrt{R}}{h_{0} \sqrt{h_{0}}}\right\}
$$

For the standard dataset defined in Appendix $A$ the central film thickness is now calculated as $h_{0}=5.4 \cdot 10^{-8} \mathrm{~m}$, which is significantly higher than the film thickness calculated with the WW model as described in the previous section. The film thickness divided by the roughness is $h_{0} / R_{q}=8.9 \cdot 10^{-3}$.

However, all the discussed models and calculations performed previously are done with the Barus viscosity model. As mentioned in Section 2.5 the Barus viscosity equation is not very accurate in a high pressure situation, such as hydrostatic extrusion; under these conditions the Roelands relation is more suitable, but it is not possible to solve the Reynolds equation analytically with the Roelands relation as viscosity model. Therefore a numerical solution for the HELM model has been developed as well.

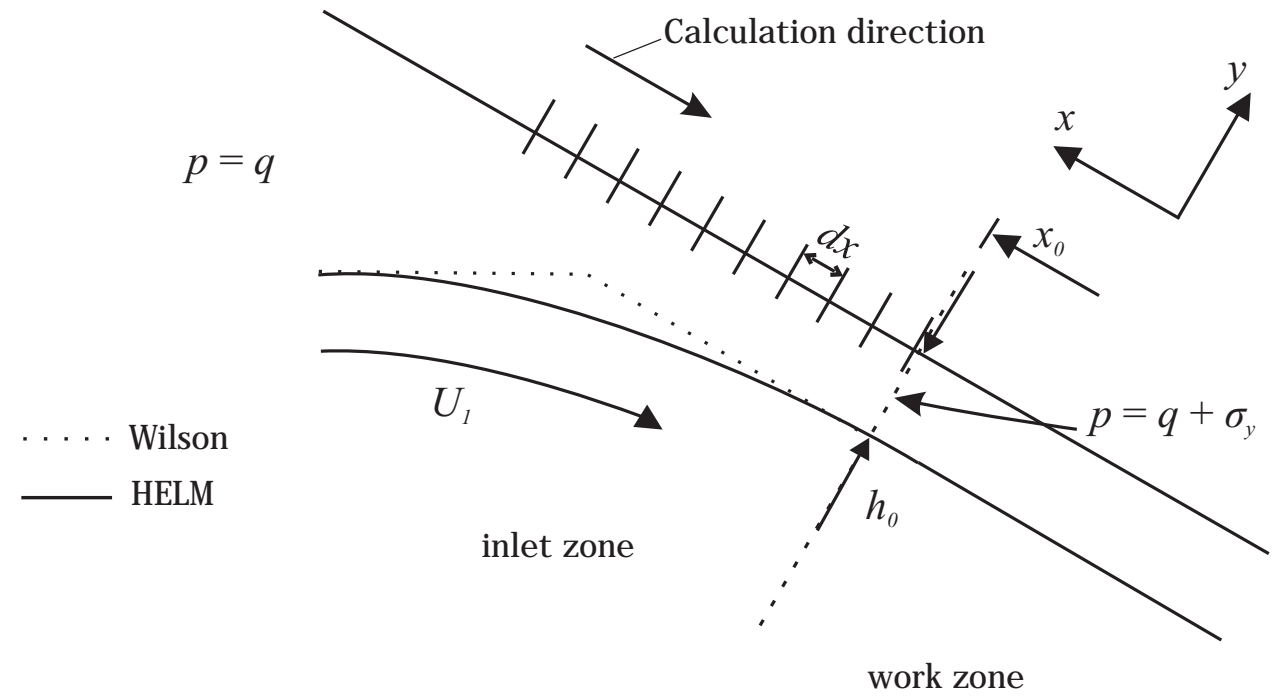

Figure 3.6 Segments finite difference method. 


\subsubsection{Numerical solution}

A finite difference program was written using Matlab, suitable for calculating pressure and central film thickness in the inlet zone for the different viscosity models. To meet the boundary condition at the transition from inlet to work zone the program was written as an iteration loop as described in Figure 3.7.

First the geometry is assumed, e.g. the parabolic function as described in Eq. (3.7), and the central film thickness is estimated. The calculation area is divided into a number of segments specified in advance. Consecutively the pressure is calculated in each of these segments, starting at the hydrostatic pressure for the largest $x$, to the transition from inlet to work zone at $x=x_{0}$, as depicted in Figure 3.6. To meet the other boundary condition the pressure in the last segment $\left(x=x_{0}\right)$ has to be equal to the extrusion pressure plus the yield stress of the billet material $\left(p=q+\sigma_{y}\right)$. If this is the case, the calculation is finished, if not the estimated value of $h_{0}$ is adapted. If the calculated pressure is too high, the estimation of $h_{0}$ is increased and vice versa, until the calculated pressure is within the predefined tolerance range of $1 \mathrm{kPa}$.

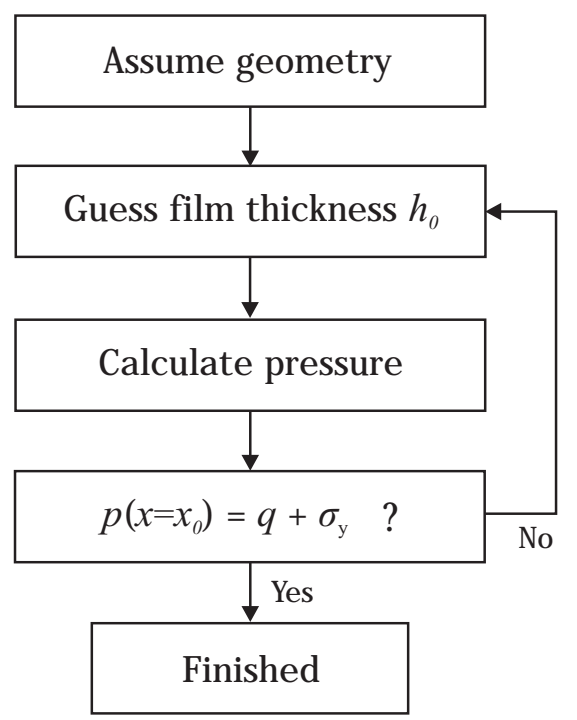

Figure 3.7 Iteration loop of the finite difference model.

The program calculates not only the film thickness and the pressure in the inlet zone but also the viscosity of the hydrostatic extrusion pressure medium. It has to be specified beforehand whether this is done isoviscous or using the models of Barus, Roelands or Nakamura as explained in Section 2.5. Furthermore, it should be noted that in this model only the effect of the pressure and temperature on the viscosity of the oil is taken into account and not the other influences like the effect of the strain rate and temperature on the yield stress of the magnesium.

As an example, Figure 3.8 shows a possible result of these calculations. In Figure 3.8 the transition from inlet to work zone is on the right hand side of the graph $\left(x=x_{0}\right)$ and $x \rightarrow \infty$ is represented on the left hand side of the graph. In the upper half of the graph 
the film thickness is plotted and therefore also the shape of the billet. In the lower half of the plot the pressure in the inlet zone is shown. The pressure rise only takes place at the end of the inlet zone; therefore it is not necessary to incorporate the whole inlet zone in the calculation. In this case the calculation domain is set to a certain length, in this case $1 \mathrm{~mm}$, which is clearly enough. However, this may depend on the parameters of the calculation performed.

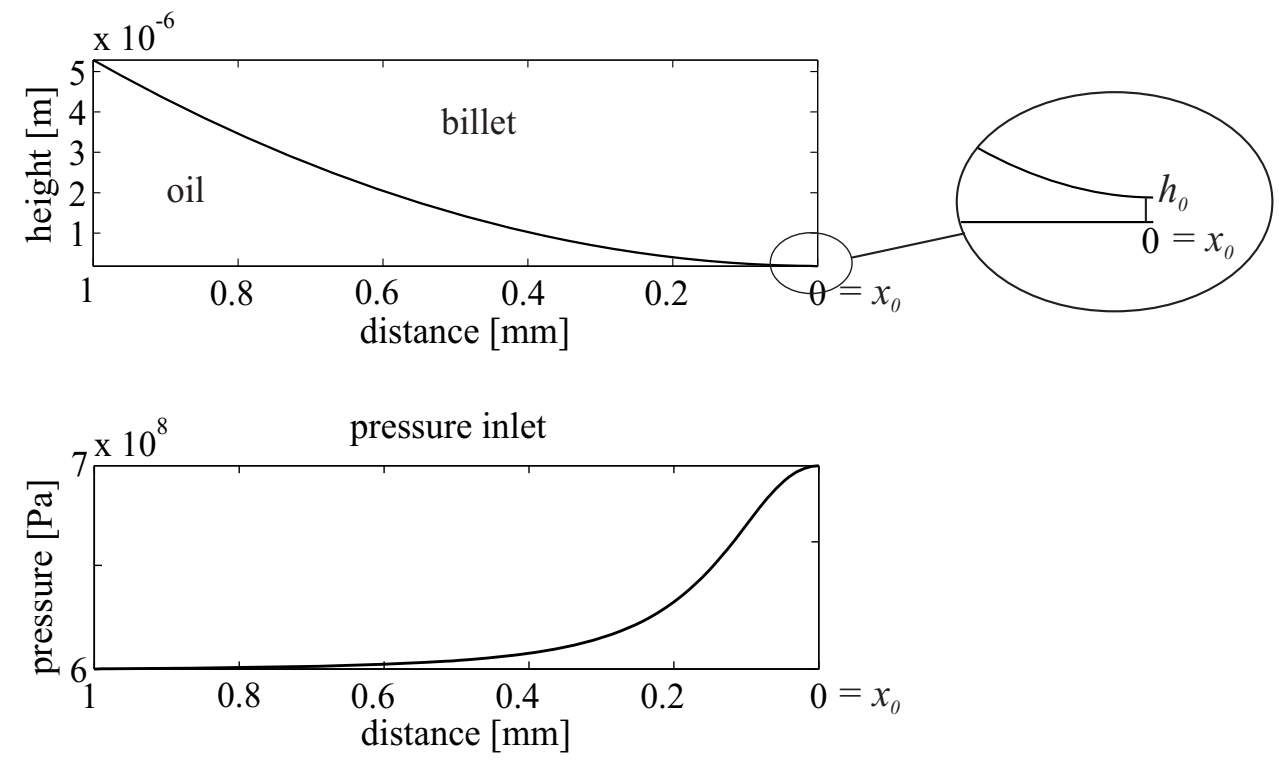

Figure 3.8 Example output of the numerical program.

\subsection{Calculations}

Calculations are performed with both the analytical and the numerical solution of the HELM model to test the performance of the numerical program. Furthermore, the effect of the different viscosity parameters is investigated. And finally the different process parameters in the hydrostatic extrusion process of magnesium are studied. As discussed in Section 3.1.1, $h_{0} / R_{q}$ enables the lubrication regime to be determined, $R_{q}$ being the undeformed roughness of the billet. Therefore in the remainder of chapter this ratio will be plotted instead of the central film thickness.

\subsubsection{Analytical solution versus numerical model}

Initially the analytical solution of the HELM model is compared with the WW model and the numerical solution of HELM. For these calculations the standard dataset (Appendix A) is used, along with the Barus viscosity equation with different viscosity pressure coefficients. The values used are typical values for mineral oil, see for instance [34] and [35]. The results can be found in Table 3.1. The results of both HELM model solutions, analytical and numerical, are very consistent with each other. Furthermore, the pressure is calculated in the last part of the inlet zone with both the analytical and numerical solution of the HELM 
model, as can be seen in Figure 3.9. These results clearly show that the numerical model is in agreement with the analytical solution when the Barus viscosity equation is used.

\begin{tabular}{|l|l|l|l|}
\hline$y\left(\cdot 10^{-8} \mathrm{~Pa}^{-1}\right)$ & WW model & HELM analytical & HELM numerical \\
\hline 0.7 & $4.6 \cdot 10^{-10}$ & $1.9 \cdot 10^{-7}$ & $1.8 \cdot 10^{-7}$ \\
\hline 1.0 & $3.1 \cdot 10^{-9}$ & $6.7 \cdot 10^{-7}$ & $6.7 \cdot 10^{-7}$ \\
\hline 1.5 & $7.7 \cdot 10^{-8}$ & $5.7 \cdot 10^{-6}$ & $5.6 \cdot 10^{-6}$ \\
\hline 2.0 & $1.8 \cdot 10^{-6}$ & $4.7 \cdot 10^{-5}$ & $4.6 \cdot 10^{-5}$ \\
\hline 2.3 & $1.2 \cdot 10^{-5}$ & $1.7 \cdot 10^{-4}$ & $1.6 \cdot 10^{-4}$ \\
\hline
\end{tabular}

Table 3.1 Central film thickness $h_{0}(m)$ for the different inlet zone models for different values for the viscosity pressure coefficient.

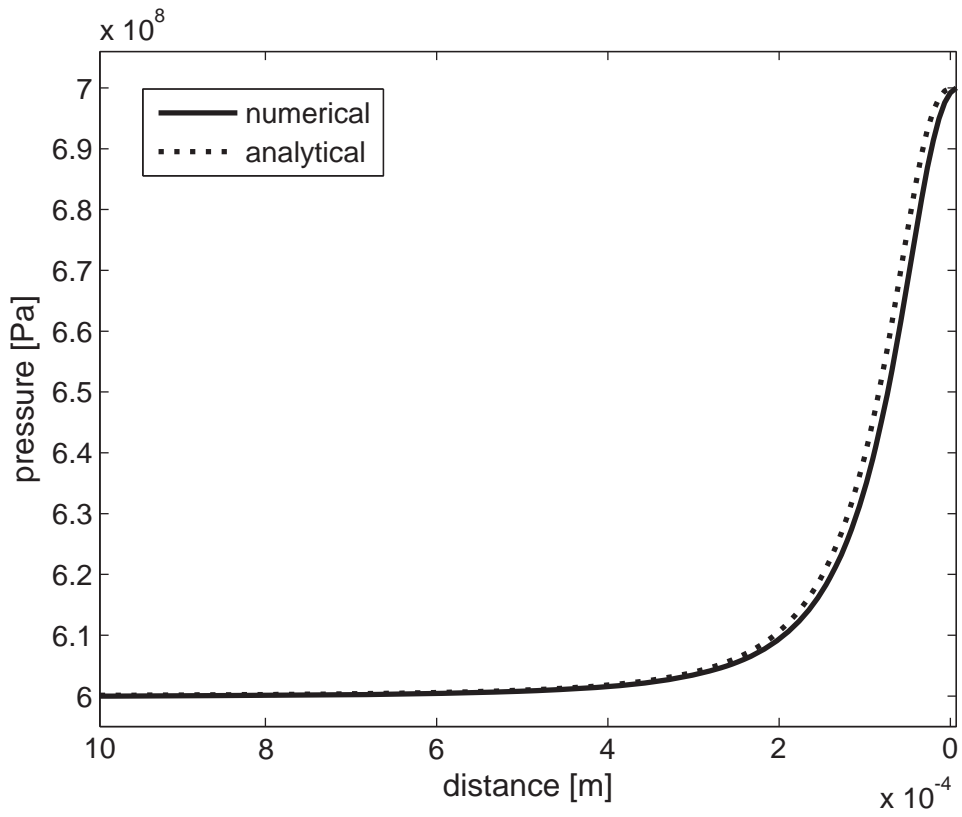

Figure 3.9 Pressure in the inlet zone calculated with both the analytical and numerical model.

In all cases the WW model calculates a significantly lower film thickness than the HELM model. Figure 3.10 shows $h_{0} / R_{q}$ for the two models and for the same range of the pressure viscosity coefficient $y$ as in Table 3.1. It can be seen that for high values of $y$ the HELM model predicts film thicknesses in the range of full film lubrication, in all other cases the values indicate mixed lubrication or boundary lubrication. From Figure 3.10 it can also been seen that the difference between the two models decrease if $y$ increases. This can be explained as follows: it can be seen in both central film thickness solutions Eq. (3.6) and Eq. (3.20) that for a given $\mathrm{R}$ and $\theta$

$$
h_{0} \propto\left(\frac{\gamma \mathrm{e}^{\gamma q}}{1-\mathrm{e}^{-\gamma \sigma_{\mathrm{y}}}}\right)^{n}
$$

In the situation of the WW model $n=1$ and for the HELM model $n=2 / 3$. This results in 


$$
\frac{h_{0}^{\text {HELM }}}{h_{0}^{\mathrm{WW}}} \propto\left(\frac{\gamma \mathrm{e}^{\gamma q}}{1-\mathrm{e}^{-\gamma \sigma_{\mathrm{y}}}}\right)^{-\frac{1}{3}}
$$

which indicates that for an increasing $y$ this ratio is decreasing.

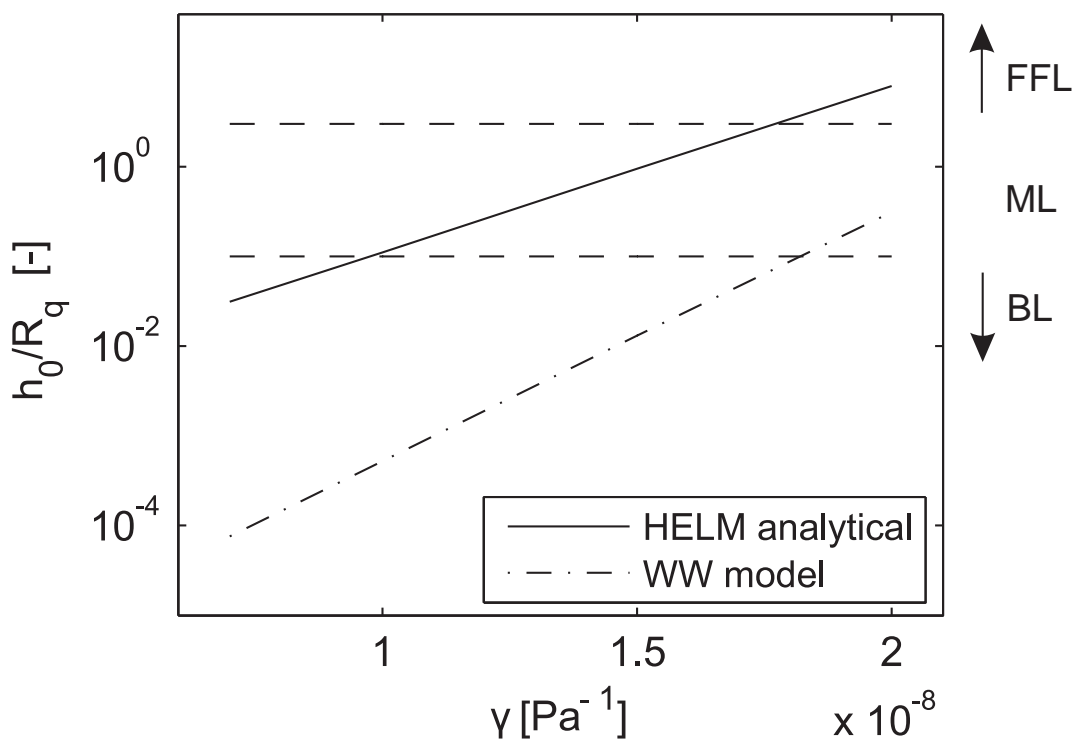

Figure 3.10 Influence of the pressure viscosity coefficient for WW model and HELM model.

\subsubsection{Parameter study of the hydrostatic extrusion process}

With the numerical solution of the HELM model established, the central film thickness for the standard data set defined in Appendix A can be calculated with the Roelands relation as the viscosity model. This gives a central film thickness $h_{0}=2 \cdot 1 \cdot 10^{-8} \mathrm{~m}$ and therefore $h_{0} / R_{q}=3.5 \cdot 10^{-3}$. This value clearly indicates that the system is in the boundary lubrication regime. Based on these results it can be concluded that the $\mathrm{BL}$ regime is present in all hydrostatic pressings for this data set. Varying the process parameters will influence this value, but never above 0.1 which would indicate mixed lubrication regime to be the prevailing lubrication regime. This was previously shown in [33].

As already shown in Figure 3.10, the lubricant properties have a major influence on the results of the film thickness calculations. Therefore, the pressure coefficient of Roelands model $z$ is studied first in Figure 3.11. According to Booser [20] z for castor oil is 0.43, which is a rather low value. Most lubricants have a value between 0.6 and 0.9 ; therefore in the parameter study $z$ is varied between 0.4 and 0.9 . The calculations are done at $a$ lubricant temperature of $150{ }^{\circ} \mathrm{C}$. It can be clearly seen from Figure 3.11 that for higher $\mathrm{z}$ values the film thickness can become great enough for the system to operate in the mixed lubrication regime. 


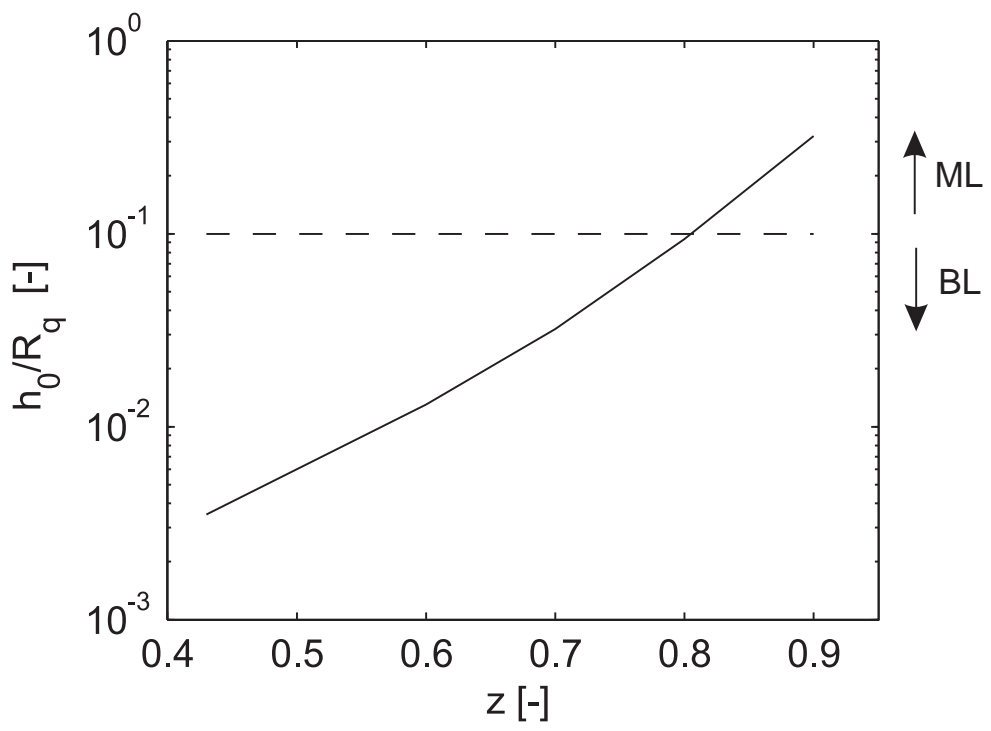

Figure 3.11 Influence of the pressure viscosity coefficient $z$ in Roelands viscosity model, logarithmic scale.

The pressure coefficient $y$ of the Barus equation was already studied in Figure 3.10. There the same conclusion holds good; for relatively high $y$ values it is possible to generate a film thickness that indicates that mixed lubrication is the acting lubrication regime. The conclusion is that when castor oil is used as a pressure medium in the hydrostatic extrusion of magnesium the system operates in the boundary lubrication regime. As discussed previously the best, most consistent surface quality is generated in the mixed lubrication regime. The system might therefore benefit when a different pressure medium is used. Most mineral oils have a Roelands pressure coefficient of $z=0.7$. Therefore this value has been chosen to investigate the effect of using a different oil. When the standard data set is used as defined in Appendix A with this new pressure viscosity coefficient, the central film thickness becomes $h_{0}=1.9 \cdot 10^{-7} \mathrm{~m}$ and therefore $h_{0} / R_{q}=0.032$. Furthermore, several calculations are performed using different process parameters of the hydrostatic extrusion process. For each calculation the standard data set is used and one parameter is varied to investigate its influence on the film thickness. Unless stated otherwise the Roelands viscosity equation is used with a pressure coefficient $z=0.7$.

The first process parameter investigated is the temperature of the lubricant. The oil is brought into the press at room temperature; the billet, however, is heated to approximately $200{ }^{\circ} \mathrm{C}$ before being put into the press. And the die is even warmer, about $350{ }^{\circ} \mathrm{C}$ entering the press. This results in a rapid change in the temperature of the oil in the inlet zone. Due to the effect of the temperature on the viscosity of the oil it is a very important process parameter. In the calculations the temperature is varied between $100{ }^{\circ} \mathrm{C}$ and $250{ }^{\circ} \mathrm{C}$. 


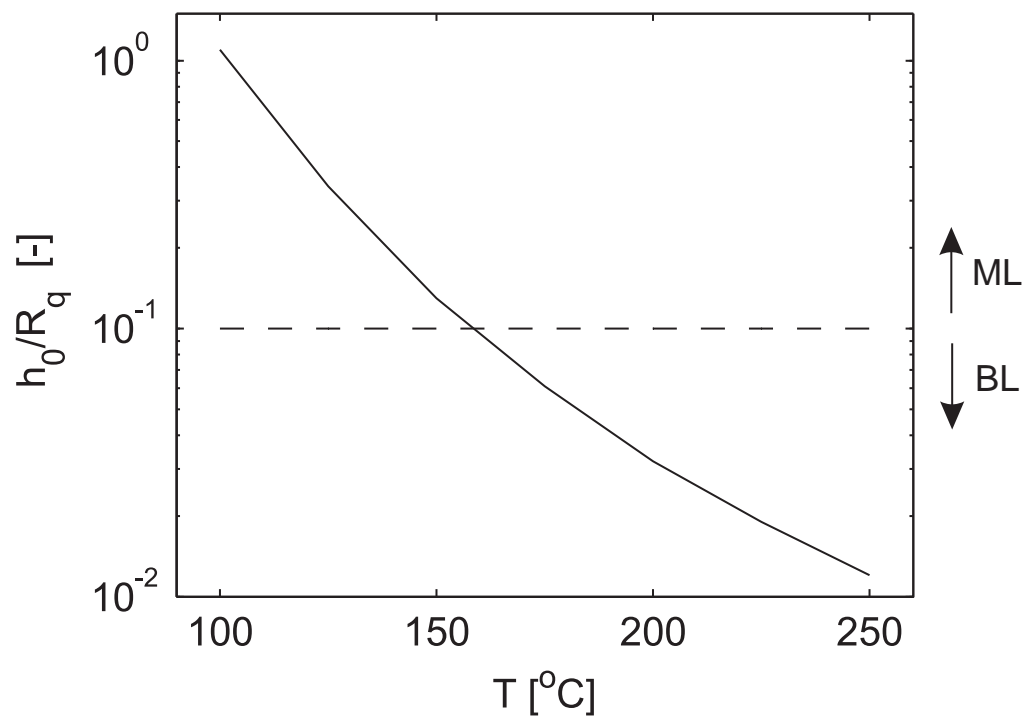

Figure 3.12 Influence of the temperature of the oil.

From Figure 3.12 it can be seen that for lower temperatures, film thickness over roughness values in the order of 0.1 to 1 can be achieved. This is expected because a decrease in oil temperature will result in an increase in base viscosity at atmospheric pressure. It has to be noted, however, that although lower temperatures are beneficial for the film thickness they are unfavourable for the general extrusion performance. As already explained in Section 2.3 magnesium alloys become easier to deform above approximately $200 \stackrel{\circ}{\circ}$ because of the availability of extra slip planes, [12]. Both these effects need to be considered when the oil temperature is chosen.

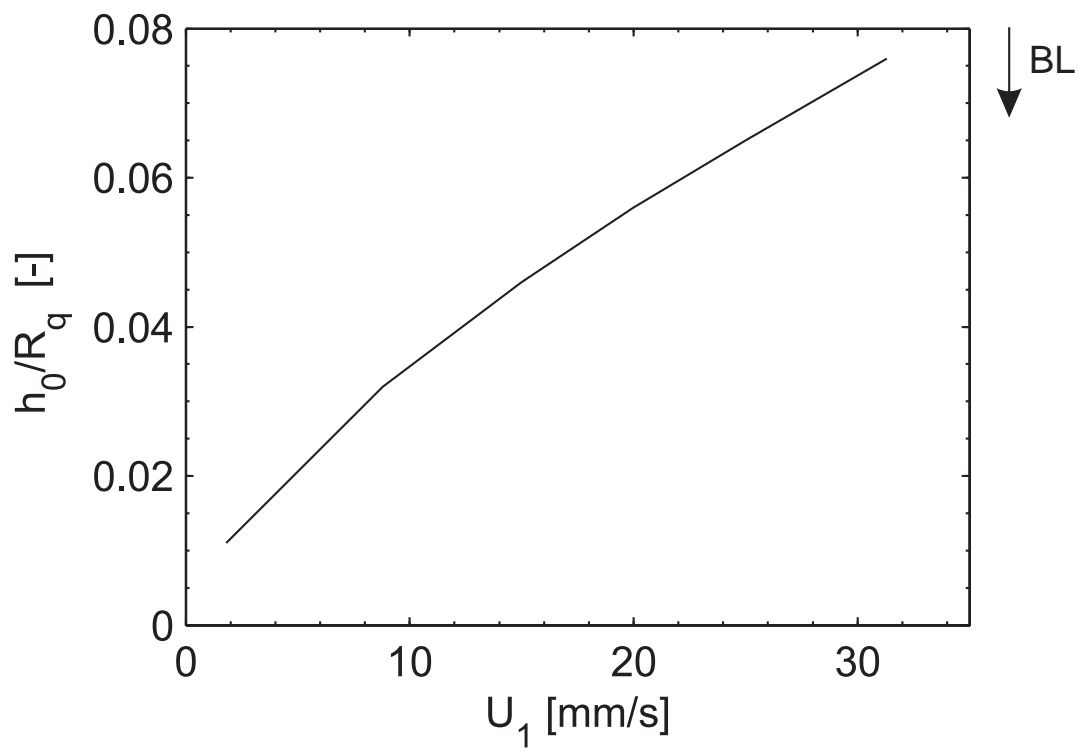

Figure 3.13 Influence of the velocity of the billet $U_{1}$.

The next parameter studied is the velocity of the billet. It is varied between $1.8 \mathrm{~mm} / \mathrm{s}$ and $31.3 \mathrm{~mm} / \mathrm{s}$ : these are actual values used on the 'example' hydrostatic press. From Figure 3.13 it can be seen that an increase in billet velocity results in the film thickness 
increasing. For a high billet velocity the film thickness is edging towards the mixed lubrication regime. Furthermore, it can be seen that the effect of the billet velocity is less than in the WW model, where $h_{0} \sim U_{1}$, and in the HELM model, where $h_{0} \sim U_{1}{ }^{2 / 3}$, as was established in the analytical HELM solution.

The next process parameter studied is the hydrostatic extrusion pressure in the press. In the calculations the hydrostatic pressure $q$ is varied between 0.5 and $1.2 \mathrm{GPa}$; these are typical values used in the hydrostatic extrusion process. From Figure 3.14 it can be seen that an increase in extrusion pressure has a positive effect on the central film thickness. For higher extrusion pressures, approximately above $0.8 \mathrm{GPa}$, the system is in the mixed lubrication regime. For extrusion pressures below this value the system operates in the boundary lubrication regime.

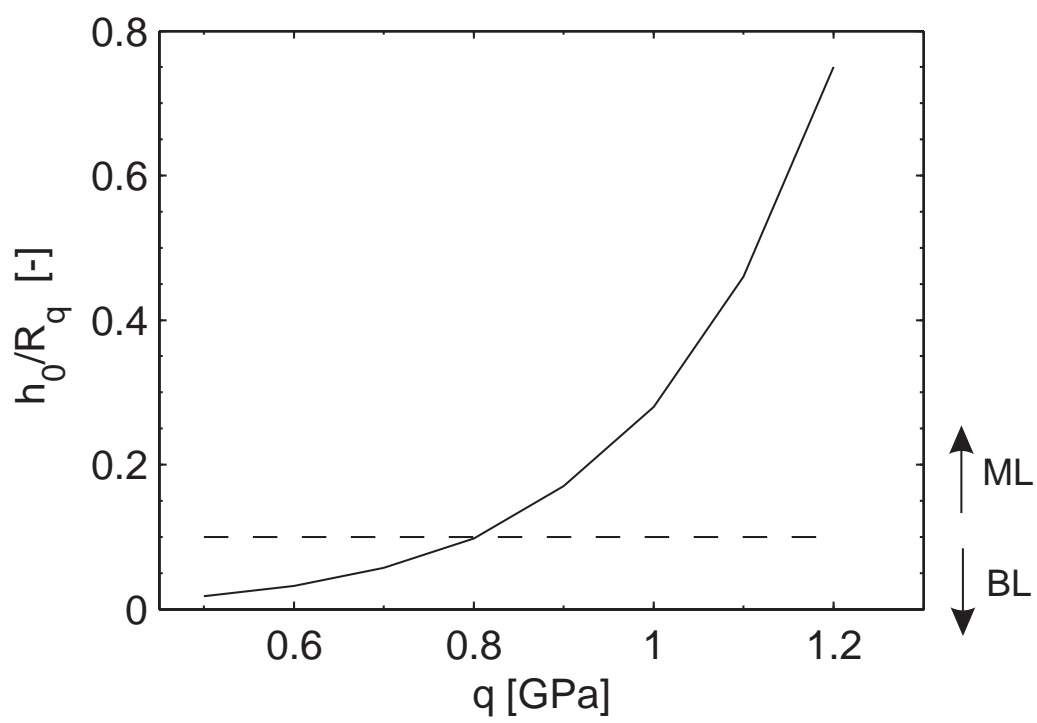

Figure 3.14 Influence of the hydrostatic extrusion pressure $q$.

Finally, the influence of the geometry of the billet is investigated. The round off radius of the billet at the transition from inlet to work zone is not known precisely and may also change during extrusion. To investigate the influence of this parameter a wide range of values is studied. From Figure 3.15 it can clearly be seen that $\mathrm{R}$ has only a rather small influence on the central film thickness. This is consistent with the analytical solution, from which it can be concluded that $h_{0} \sim R^{1 / 3}$. For the whole range of $R$ studied the central film thickness indicates the boundary lubrication regime.

Film thickness calculations were also made for several die angles $\theta$, but no change in $h_{0}$ was found. The explanation for this is that the pressure increase in the inlet zone takes place only in the last part of the inlet zone where the billet is rounded off. Here the die angle is no longer a variable, but the round off radius is, as shown before, of minor influence. 


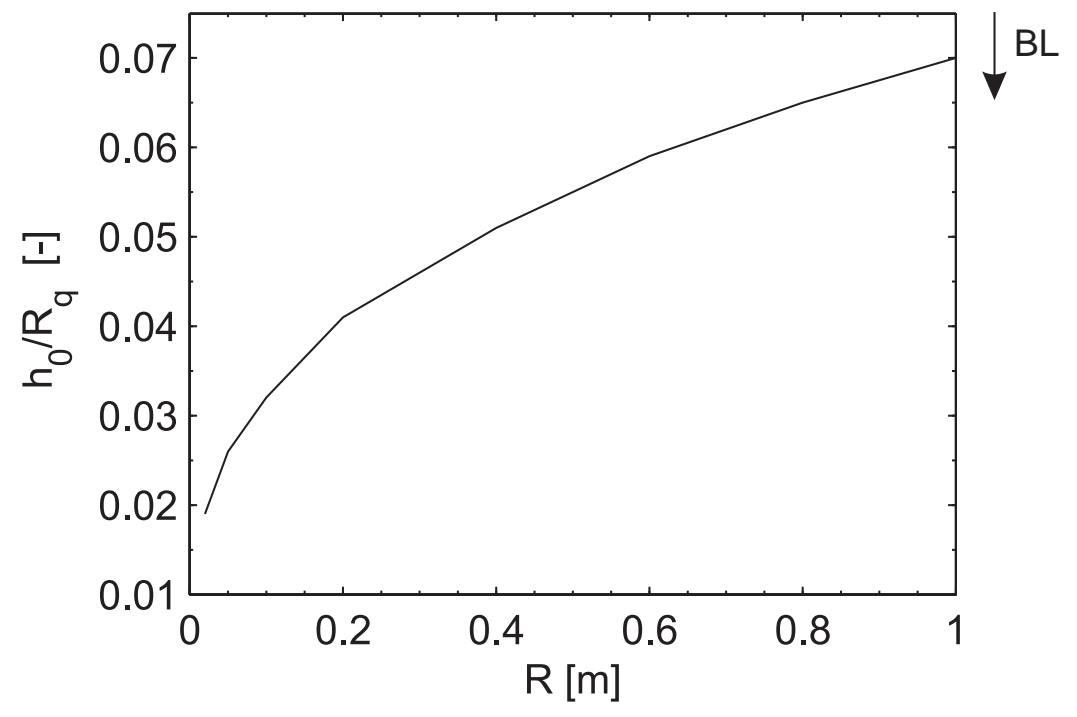

Figure 3.15 Influence of the round off radius $R$ of the billet.

\subsection{Conclusions}

The lubrication in the inlet zone of the hydrostatic extrusion process of magnesium has been modelled. The Wilson and Walowit model for a sharp edge has been extended with a different inlet zone geometry. The observed curvature at the transition from inlet to work zone has been modelled with a parabola: the HELM model. With the use of Barus equation for the viscosity this model is solved analytically. To incorporate the more suitable Roelands model for the viscosity a numerical finite difference solution is created which is programmed in Matlab. This program can be used to perform inlet zone calculations for different viscosity models, different geometries etc. The central film thickness is calculated using the different models. Viscosity and process parameters have been varied to investigate their influence on the lubrication regime the system is in. The conclusions are as follows.

- With castor oil as the pressure medium the WW model predicts, given the standard reference data set, a film thickness in the order of $10^{-10} \mathrm{~m}$. The HELM model with Barus viscosity equation predicts a film thickness in the order of $10^{-7} \mathrm{~m}$, which is significantly higher than the WW model. However, both results clearly show that the billet/ die system operates in the boundary lubrication regime.

- Calculations with the HELM model show that the pressure viscosity coefficient has a very significant effect on the calculated film thickness. This is true for both the Barus and the Roelands viscosity model. Increasing the pressure coefficient $y$ or $z$ results in a central film thickness in the order of the roughness.

- For the currently used castor oil the calculations clearly indicate the BL regime for all extrusion situations. The pressure viscosity coefficient for castor oil is relatively low and this value is of major influence on the results. Therefore calculations are also performed for a pressure viscosity coefficient of $z=0.7$, which is a very common value for mineral oils. 
- For a standard mineral oil with a pressure viscosity coefficient of 0.7 , the calculation shows that for the standard data set the central film thickness is increased by a factor of 10 when compared to the castor oil calculation. This is still just within the $\mathrm{BL}$ regime, however. Investigation of the different process parameters shows that the temperature of the oil and the hydrostatic extrusion pressure are of major influence on the lubrication regime. For temperatures below approximately $160 \stackrel{\circ}{C}$ the system is in the mixed lubrication regime, i.e. $h_{0} / R_{q}>0.1$. However, increasing the hydrostatic pressure is the most realistic option for the system to operate in the ML regime.

- In hydrostatic extrusion of magnesium using a common mineral oil the ML regime is feasible when the temperature of the oil is relatively low, the extrusion pressure relatively high and the extrusion speed relatively high. 


\section{Chapter 4}

\section{Modelling lubrication in the work zone}

The inlet zone calculations of Chapter 3 show that boundary lubrication is the prevailing regime in the inlet zone of the hydrostatic extrusion of magnesium. In the work zone area of the hydrostatic extrusion process the contact conditions change and therefore this conclusion cannot be extended to the work zone area. The roughness of the workpiece decreases significantly in particular towards the outlet of the process, plastic deformation occurs and the velocity of the workpiece material increases towards the exit of the work zone. Due to these effects, there is a possibility that pressure may build-up in the work zone.

In most metal forming processes mixed lubrication is the prevailing lubrication regime in the contact where the actual deformation takes place, [36]. This chapter studies lubrication phenomena in the work zone area of the hydrostatic extrusion process of magnesium, to examine whether or not this is also the prevailing lubrication regime in this case. In this chapter a model is presented to calculate the film thickness in the work zone area incorporating the dominant contact parameters. In Section 4.1 the appropriate equations for the model are derived. Section 4.2 presents the nominal pressure equation for the hydrostatic extrusion process as needed in the lubrication model. Section 4.3 shows the results of this model. In Section 4.4 the numerical implementation of the model is presented. The results of the calculations with the new lubrication model are presented in Section 4.5. In Section 4.6 the percolation threshold is discussed. And finally, conclusions are drawn in Section 4.7.

\subsection{Reynolds equation in conical coordinates}

The lubrication in the work zone area of the hydrostatic extrusion process will be modelled with a full film lubrication model similar to the inlet zone modelling of Chapter 3. The base of this model is the Reynolds equation, the standard version of this equation has been explained in Section 3.2. The Reynolds equation contains three parts: a wedge term, a stretch term and the squeeze effect. In most full film models and mixed lubrication models the wedge effect is the only effect taken into account. This is also done in the inlet zone model described in Chapter 3. However, in the work zone area of the hydrostatic extrusion process, the plastic deformation is quite large and therefore the increase of the velocity 
close to the exit of the die is significant is well. This means that the stretch term could have a significant effect on the film thickness and has to be incorporated in the model. The resulting one-dimensional Reynolds equation is shown in Eq. (4.1).

$$
\frac{\partial}{\partial x}\left(\frac{h^{3}}{\eta} \frac{\partial p}{\partial x}\right)=\frac{U}{2} \frac{\partial h}{\partial x}+\frac{h}{2} \frac{\partial U}{\partial x}
$$

In the model, it is assumed that plastic deformation in the work zone of the hydrostatic extrusion process occurs in a conical die. Until this point the modelling in this work has been done with a one-dimensional flow in a two-dimensional Cartesian coordinate system, implicitly assuming an infinite width of the die. Because of the deformation in the conical section of the die, another description of the flow of the lubricant is required, i.e. a Reynolds equation in a conical coordinate system.

Kim [37] derived a general Reynolds equation for different coordinate systems amongst which is the version in conical coordinates. The general Reynolds equation can be derived from the continuity equation

$$
\frac{1}{r(s)} \frac{\partial}{\partial s}\left(r(s) \rho q_{s}^{\prime}\right)+\frac{1}{r(s)} \frac{\partial}{\partial \psi}\left(\rho q_{\psi}^{\prime}\right)+\frac{\partial}{\partial t}(\rho h)=0
$$

Here, the equations of the flow rate read

$$
\begin{gathered}
q_{\psi}^{\prime}=-\frac{1}{12 \eta} \frac{1}{r(s)} \frac{\partial p}{\partial \psi} h^{3}+\frac{U_{\psi}}{2} h \\
q_{s}^{\prime}=-\frac{1}{12 \eta} \frac{\partial p}{\partial s} h^{3}+\frac{U_{s}}{2} h
\end{gathered}
$$

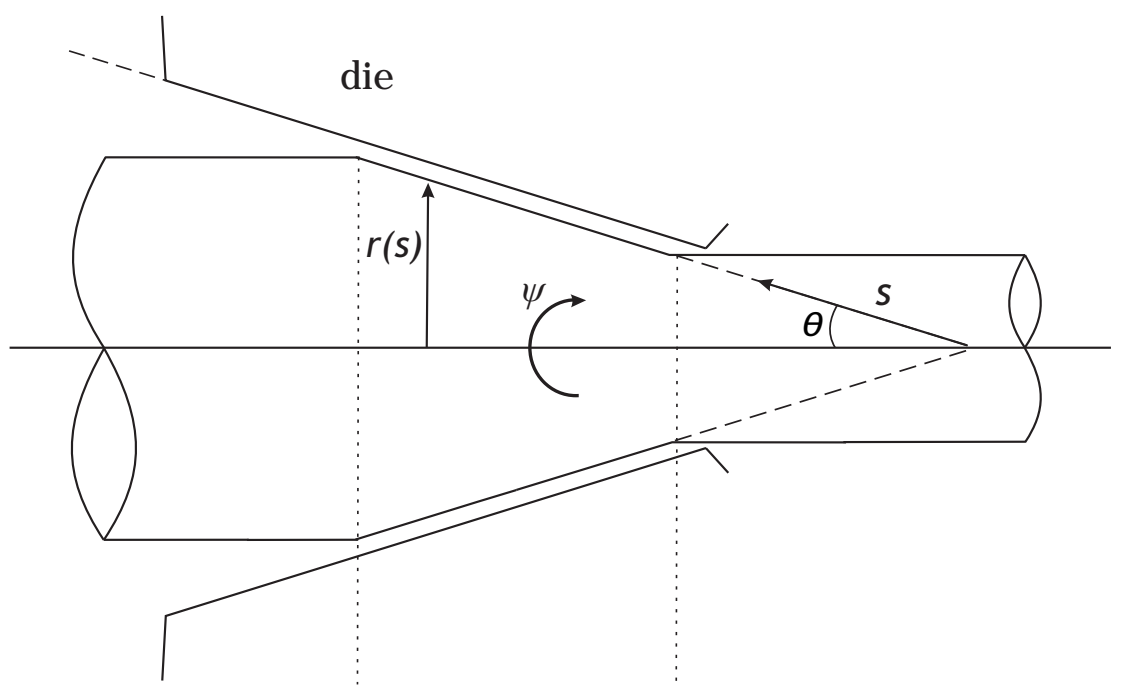

Figure 4.1 Conical coordinate system for hydrostatic extrusion. 
The coordinate system is determined by the definition for $r(s)$. Further, $U_{\psi}$ and $U_{s}$ are the sum velocities of the two surfaces in the $\psi$-direction and the s-direction respectively. The conical coordinate system is depicted in Figure 4.1, in which $r(s)$ is defined as

$$
r(s)=s \sin \theta
$$

The equations of the flow rate, Eq. (4.3) and (4.4), are used in the continuity equation (4.2) assuming $\rho$ is constant, resulting in a general Reynolds equation, formulated in conical coordinates [37].

$$
\begin{aligned}
\frac{1}{r(s)} \frac{\partial}{\partial s}\left(r(s) \frac{h^{3}}{12 \eta} \frac{\partial p}{\partial s}\right) & +\frac{1}{r(s)} \frac{\partial}{\partial \psi}\left(\frac{h^{3}}{12 \eta} \frac{1}{r(s)} \frac{\partial p}{\partial \psi}\right)=\frac{1}{r(s)} \frac{\partial}{\partial s}\left(r(s) \frac{U_{s}}{2} h\right) \\
& +\frac{1}{r(s)} \frac{\partial}{\partial \psi}\left(\frac{U_{\psi}}{2} h\right)+\frac{\partial h}{\partial t}
\end{aligned}
$$

In the hydrostatic extrusion process, the deformation is rotational symmetric which implies that all terms with a derivative to $\psi$ can be neglected. Furthermore, the process is considered stationary and therefore, the time derivative term is also neglected. Then the general Reynolds equation becomes

$$
\frac{\partial}{\partial s}\left(r(s) \frac{h^{3}}{12 \eta} \frac{\partial p}{\partial s}\right)=\frac{\partial}{\partial s}\left(r(s) \frac{U_{s}}{2} h\right)
$$

with $r(s)$ as defined in Eq. (4.5). This leads to

$$
\frac{\partial}{\partial s}\left(s \sin \theta \frac{h^{3}}{12 \eta} \frac{\partial p}{\partial s}\right)=\frac{\partial}{\partial s}\left(s \sin \theta \frac{U_{s}}{2} h\right)
$$

This is rewritten to the final differential equation, neglecting the insignificant term $\frac{\partial h^{3}(s)}{\partial s}$.

$$
\frac{1}{12 \eta s} h^{3}(s) \frac{\partial p}{\partial s}+\frac{1}{12 \eta} h^{3}(s) \frac{\partial^{2} p}{\partial s^{2}}=\frac{1}{2 s} U_{s} h+\frac{1}{2} h \frac{\partial U_{s}}{\partial s}+\frac{U_{s}}{2} \frac{\partial h(s)}{\partial s}
$$




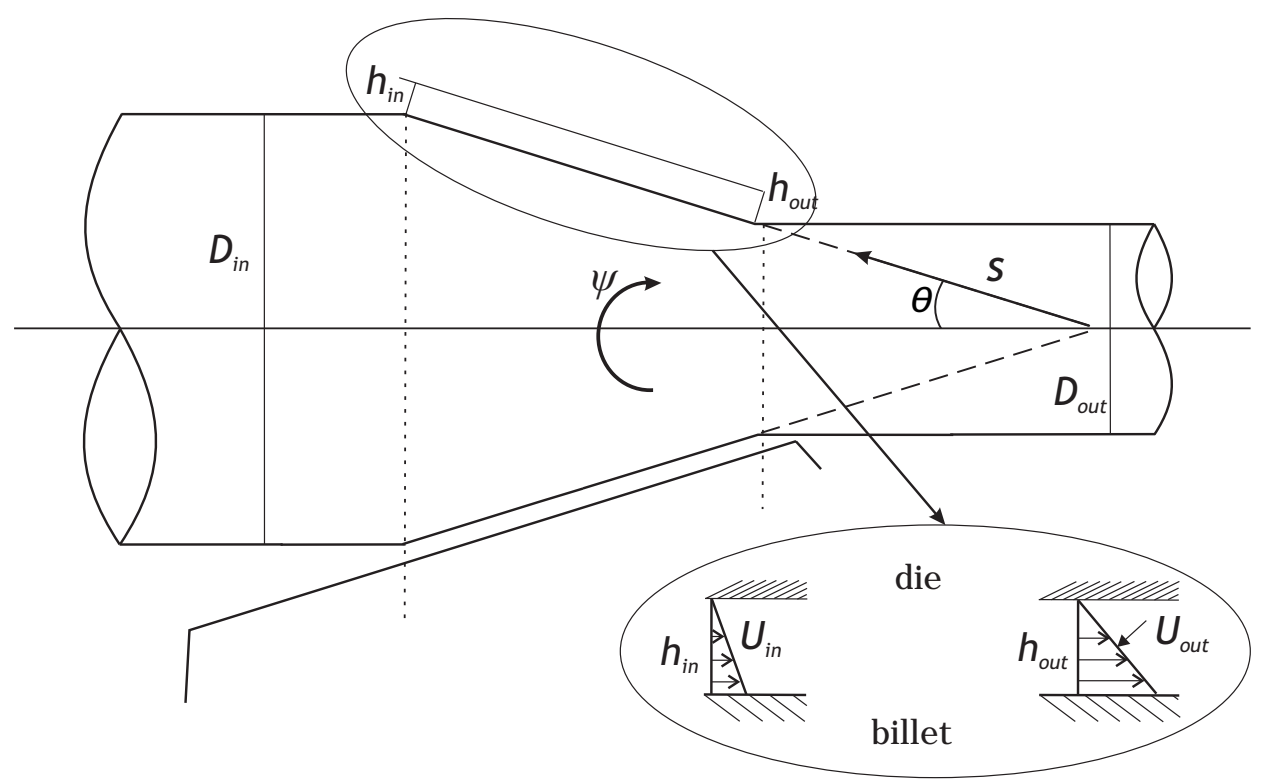

Figure 4.2 Variables used when only Couette flow is present.

In the following section, part of this equation is validated with the calculation of the situation with constant nominal pressure and the velocity $U_{s}$ as in the actual process parameters: assuming Couette flow only. In this case the flow profile over the film thickness is determined by the difference in velocity between the two surfaces of the workpiece and the die, see also Figure 4.2. The total flow at the entry of the work zone area has to be equal to the total flow at the exit of the work zone, as lubricant volume is conserved in the contact ( $\rho$ is assumed to be constant). The flux at the entry is calculated by multiplying the average velocity over the film thickness with the cross sectional area of the lubricant film at the entry of the work zone as shown in Figure 4.2.

$$
\text { Flux }_{\text {in }}=\frac{1}{2} U_{\text {in }} \cdot 2 \pi \cdot \frac{1}{2} D_{\text {in }} \cdot h_{\text {in }}
$$

The flux at the exit of the work zone area is calculated similarly. The velocity of the extrudate material at the exit can be calculated based on conservation of mass of the extrudate material and basic cylindrical geometry as a function of the entry velocity.

$$
U_{\text {out }}=U_{\text {in }} \frac{D_{\text {in }}^{2}}{D_{\text {out }}^{2}}
$$

Equating the flux at the entry to the flux at the exit and using Eq. (4.11) gives a relation between the film thickness at entry and at the exit.

$$
\frac{h_{\text {in }}}{h_{\text {out }}}=\frac{D_{\text {in }}}{D_{\text {out }}}
$$

With a boundary condition at the entry or the exit side of the work zone the film thickness at the other side can be calculated. The boundary condition used will be further explained 
in Section 4.4. In Figure 4.3 the film thickness is shown as calculated with both the conical Reynolds equation (4.9) and the Couette flow equation (4.12) with the standard data set of Table A.5. On the horizontal axis of Figure 4.3 the work zone is depicted, with 0 being the entry of the work zone area and 1 the exit. More information about the numerical implementation of the conical Reynolds equation will be given in Section 4.4.

It can be seen from Figure 4.3 that the resulting film thicknesses are very similar. Varying the process parameters within realistic limits gives similar results. The conclusion therefore is that the velocity terms of Eq. (4.9) determine the film thickness. However, it cannot be concluded, based on these results, that there is no pressure generation in the work zone of the contact. As so far, the nominal pressure is taken to be constant in the work zone, contrary to normal process conditions.

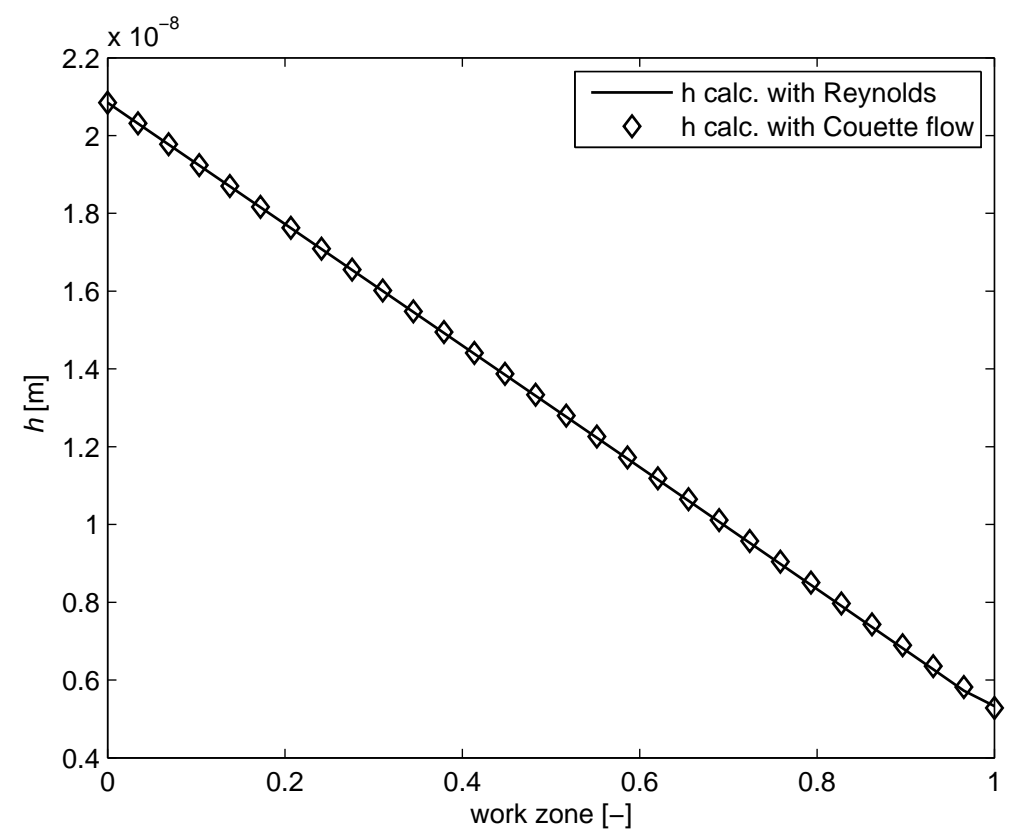

Figure 4.3 Comparison between film thickness $h$ calculated with the conical Reynolds equation (4.9) and the "Couette flow" equation (4.12) using the standard data set.

\subsection{The mechanics of the hydrostatic extrusion process}

One of the inputs for the derived differential equation (4.9) is the nominal contact pressure in the work zone area. This pressure distribution is modelled based on the analysis of Hoffman and Sachs [38]. The geometrical parameters are defined in Figure 4.4. In the analysis the same coordinate system is taken as in the original study of Hoffman and Sachs. Please note that the chosen coordinate system differs from the rest of this work and is therefore only valid for this section of this work. In their analysis, Hoffman and Sachs assume that the frictional force locally obeys Coulomb's law of friction. This means that the tangential stress at a certain location in the contact area is proportional to the normal pressure at that point, and is directed in the opposite direction of the relative motion. The coefficient of friction $\mu$ is considered constant for a given billet and die material and given 
surface conditions and temperature. The coefficient of friction is considered to be independent of the velocity of the billet during extrusion.

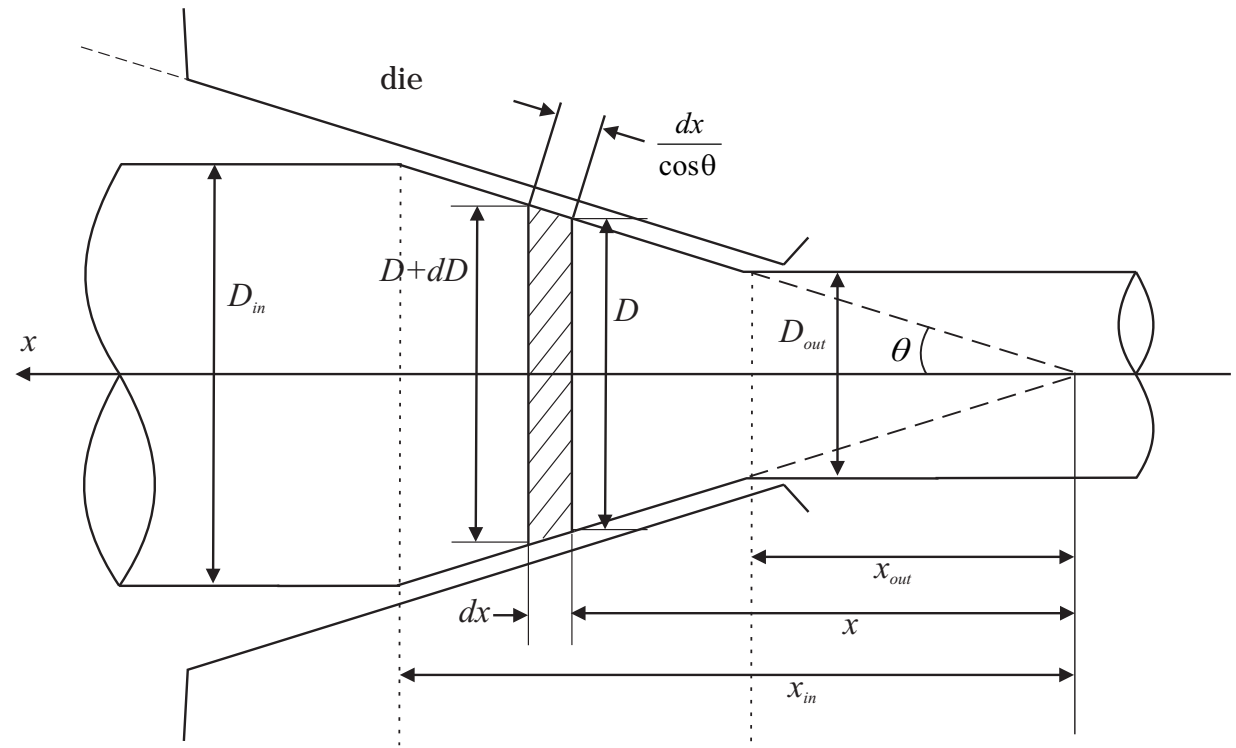

Figure 4.4 Variables used in normal pressure calculation Hoffman and Sachs, [38].

Furthermore, it is assumed that the billet is in a uniform state of stress in all points of a plane perpendicular to the $\mathrm{x}$-axis depicted in Figure 4.4. In the analysis, a cylindrical state of stress is assumed in the whole work zone, with the $x$-direction one of the principal stress directions. The tensile stress $\sigma_{x}$ acts in this principal stress direction. The radial direction perpendicular to the $x$-axis is also a principal stress direction, with $\sigma_{\mathrm{r}}$ the corresponding principal stress. These assumptions work best for small die angles $\theta$ and small values of the friction coefficient $\mu$. In the hydrostatic extrusion process the die angle can be relatively large; however the diameter of the billet is also relatively large. Therefore in reality, deviations from the cylindrical stress state are expected to occur at the edge of the billet due to friction only but it is assumed in the analysis that a cylindrical stress state is maintained over a large part of the cross section.

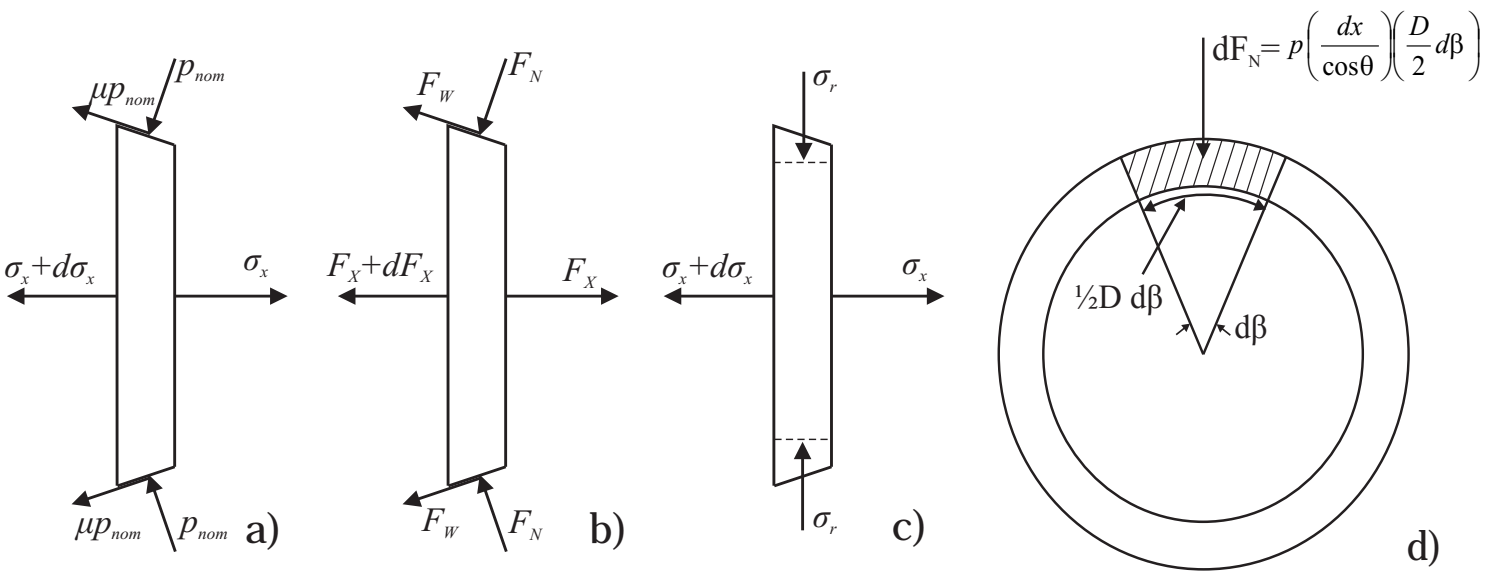

Figure 4.5 The volume element used in the nominal pressure calculation a) the acting stresses b) the acting forces c) the principal stresses and d) a front view of the volume element. 
To calculate the nominal pressure, a volume element is considered in the work zone of the hydrostatic extrusion process bounded by two planes perpendicular to $\mathrm{x}$-axis at distances $\mathrm{x}$ and $x+d x$, see Figure 4.4. For this volume element the force equilibrium in the direction of extrusion, along the $x$-axis, is considered. There are three stresses acting on the element resulting in three forces, see also Figure $4.5 \mathrm{a}$ and $\mathrm{b}$. The resulting force equilibrium becomes, see Figure $4.5 b$

$$
\left(F_{x}+d F_{x}\right)-F_{x}+F_{N x}+F_{W x}=0
$$

in which $F_{\mathrm{Nx}}$ is the component of $F_{\mathrm{N}}$ in the $\mathrm{x}$-direction and $\mathrm{F}_{\mathrm{W} x}$ is the $\mathrm{x}$ component of $\mathrm{F}_{\mathrm{W}}$. The three forces can be calculated as follows:

The difference between the forces on the two transverse planes is calculated as follows

$$
\left(F_{x}+d F_{x}\right)-F_{x}=\left(\sigma_{x}+d \sigma_{x}\right) \cdot \pi\left(\frac{1}{2} D+\frac{1}{2} d D\right)^{2}-\sigma_{x} \pi\left(\frac{1}{2} D\right)^{2}
$$

Rewriting and neglecting higher order terms results in

$$
\left(F_{x}+d F_{x}\right)-F_{x}=\frac{\pi D}{4}\left(D d \sigma_{x}+2 \sigma_{x} d D\right)
$$

The normal pressure on the surface of the volume element in contact with the die (or extrusion medium) is determined by considering a surface element as depicted in Figure $4.5 d$, where two radial planes intersect the conical billet surface with an angle $d B$. The normal load $\mathrm{dF}_{\mathrm{N}}$ on this surface element is

$$
d F_{N}=p_{\text {nom }}\left(\frac{d x}{\cos \theta}\right)\left(\frac{D}{2} d \beta\right)
$$

However, only the axial component is of interest here, which yields

$$
d F_{N x}=p_{\text {nom }}\left(\frac{d x}{\cos \theta}\right)\left(\frac{D}{2} d \beta\right) \sin \theta=p_{\text {nom }} \frac{D}{2} \tan \theta d x d \beta
$$

This is integrated over the total surface area of the volume element in contact with the die, from $B=0$ to $B=2 \pi$.

$$
F_{N x}=\int_{0}^{2 \pi} p_{\text {nom }} \frac{D}{2} \tan \theta d x d \beta=p_{\text {nom }} \pi D \tan \theta d x
$$

Basic geometry gives a relation between $\mathrm{dx}$ and $\mathrm{dD}$ :

$$
\tan \theta=\frac{1}{2} \frac{d D}{d x}
$$


With this relation eq. (4.18) the load on a small volume element is equal to

$$
F_{N x}=\frac{p_{\text {nom }} \pi}{2} D d D
$$

Note $\mathrm{F}_{\mathrm{Nx}}$ is independent of $\theta$.

The frictional force in the direction of extrusion is calculated in a similar way to the normal pressure. The same surface element is considered, and the frictional force on this surface element is

$$
d F_{w}=\mu p_{n o m}\left(\frac{d x}{\cos \theta}\right)\left(\frac{D}{2} d \beta\right)
$$

The axial component yields

$$
d F_{W x}=\mu p_{\text {nот }}\left(\frac{d x}{\cos \theta}\right)\left(\frac{D}{2} d \beta\right) \cos \theta=\mu p_{\text {пот }} \frac{D}{2} d x d \beta
$$

Integrating Eq. (4.22) as before gives

$$
F_{W x}=\int_{0}^{2 \pi} \mu p_{\text {nom }} \frac{D}{2} d x d \beta=\mu p_{\text {nom }} \pi D d x
$$

Equation (4.19) can be used again to eliminate $d x$.

$$
F_{W x}=\frac{\mu p_{\text {nom }} \pi D}{2 \tan \theta} d D
$$

The final equilibrium equation Eq. (4.13) is obtained by substituting the three components Eq. (4.15), Eq. (4.20) and Eq. (4.24).

$$
\frac{\pi D}{4}\left(D d \sigma_{x}+2 \sigma_{x} d D\right)+\frac{p_{\text {nот }} \pi}{2} D d D+\frac{\mu p_{\text {nот }} \pi D}{2 \tan \theta} d D=0
$$

This can be simplified to

$$
D d \sigma_{x}+2 \sigma_{x} d D+2 p_{\text {nom }} d D\left(1+\frac{\mu}{\tan \theta}\right)=0
$$

This differential equation can be solved if $p_{\text {nom }}$ can be expressed in known variables; this can be done with the Tresca yield criterion. Although Hoffman and Sachs, [38], use the nominal pressure $p$ as one of the principal stresses, this is not valid for hydrostatic extrusion because the die angle can become large. The actual principal stresses are indicated in Figure 4.5c. The 'general' Tresca yield criterion gives a relation between the principal stresses and the yield stress $\sigma_{\mathrm{y}}$. 


$$
\frac{\sigma_{1}-\sigma_{3}}{2}=\frac{\sigma_{r}-\sigma_{x}}{2}=\frac{\sigma_{y}}{2}
$$

Because in this case $\sigma_{\mathrm{x}}$ is assumed a tensile stress and $\sigma_{\mathrm{r}}$ a compressive stress, the yield criterion becomes

$$
\sigma_{r}+\sigma_{x}=\sigma_{y}
$$

The principal stress $\sigma_{\mathrm{r}}$ can be calculated by subtracting the components of the forces in the radial direction. First the radial component of the nominal load is of interest, which yields

$$
d F_{N r}=p_{\text {nom }}\left(\frac{d x}{\cos \theta}\right)\left(\frac{D}{2} d \beta\right) \cos \theta=p_{\text {nom }} \frac{D}{2} d x d \beta
$$

This is integrated over the total surface area of the volume element in contact with the die, from $B=0$ to $B=2 \pi$.

$$
F_{N r}=\int_{0}^{2 \pi} p_{\text {nom }} \frac{D}{2} d x d \beta=p_{\text {nom }} \pi D d x
$$

The $d x$ term can be eliminated with the geometry relation Eq. (4.19).

$$
F_{N r}=\frac{p_{\text {nom }} \pi}{2 \tan \theta} D d D
$$

Second, the radial component of the friction force is calculated, using Eq. (4.26).

$$
d F_{W r}=\mu p_{\text {nот }}\left(\frac{d x}{\cos \theta}\right)\left(\frac{D}{2} d \beta\right) \sin \theta=\mu p_{\text {nот }} \frac{D}{2} \tan \theta d x d \beta
$$

Integrating over the total surface area in contact gives $\mathrm{F}_{\mathrm{Wr}}$.

$$
F_{W r}=\int_{0}^{2 \pi} \mu p_{\text {nom }} \frac{D}{2} \tan \theta d x d \beta=\mu p_{\text {nom }} \pi D \tan \theta d x
$$

Again, eliminating the $\mathrm{dx}$ term with the geometry relation Eq. (4.19) gives

$$
F_{W r}=\mu p_{\text {nom }} \pi \frac{D}{2} d D
$$

Now the total force in the radial direction can be calculated by subtracting the components.

$$
F_{r}=F_{N r}-F_{W r}=\frac{p_{\text {nom }} \pi}{2 \tan \theta} D d D-\mu p_{\text {nom }} \pi \frac{D}{2} d D
$$


The radial stress $\sigma_{\mathrm{r}}$ is calculated by dividing the radial force by the area this force is working on.

$$
\sigma_{r}=\frac{F_{r}}{A}=\frac{\frac{p_{\text {nom }} \pi}{2 \tan \theta} D d D-\mu p_{\text {nom }} \pi \frac{D}{2} d D}{\frac{\pi}{2 \tan \theta} D d D}=p_{\text {nom }}(1-\mu \tan \theta)
$$

The area here is $d x \cdot \pi D$, where $d x$ is eliminated with the geometry relation Eq. (4.19). With this result the yield criterion Eq. (4.28) can be calculated in terms of $p_{\text {nom }}$ and $\sigma_{\mathrm{x}}$.

$$
\sigma_{x}+p_{\text {nom }}(1-\mu \tan \theta)=\sigma_{y}
$$

Rearranging leads to

$$
p_{\text {nom }}=\frac{\sigma_{y}-\sigma_{x}}{1-\mu \tan \theta}
$$

The differential equation, Eq. (4.26), can be solved with this result for $p_{\text {nom }}$ and the notation

$$
B=\frac{1}{1-\mu \tan \theta}\left(1+\frac{\mu}{\tan \theta}\right)
$$

Using Eq. (4.38) and Eq. (4.39) the differential equation (4.26) becomes

$$
D d \sigma_{x}+2 \sigma_{x} d D+2 B \sigma_{y} d D-2 B \sigma_{x} d D=0
$$

Separating the variables, this is rewritten to

$$
\frac{d \sigma_{x}}{(B-1) \sigma_{x}-B \sigma_{y}}=\frac{2 d D}{D}
$$

Integrating both sides gives

$$
\ln \left[(B-1) \sigma_{x}-B \sigma_{y}\right]^{(B-1)^{-1}}=\ln D^{2}+C
$$

where $\mathrm{C}$ is a constant of integration. Solving for the axial stress $\sigma_{\mathrm{x}}$ results in

$$
\sigma_{x}=C \frac{D^{2(B-1)}}{B-1}+\frac{B}{B-1} \sigma_{y}
$$

Contrary to the analysis of Hoffman and Sachs the constant of integration $C$ can be determined with the boundary condition at the die entry of the extrusion. Here, $D=D_{\text {in }}$; the stress is known as the hydrostatic pressure $\sigma_{x, \text { in }}=-q$, therefore $C$ can be solved from 


$$
-q=C \frac{D_{i n}^{2(B-1)}}{B-1}+\frac{B}{B-1} \sigma_{y}
$$

Solving for $\mathrm{C}$ gives

$$
C=-q \frac{B-1}{D_{i n}^{2(B-1)}}-\frac{B}{D_{i n}^{2(B-1)}} \sigma_{y}
$$

Finally, this value for the constant $\mathrm{C}$ is added to the solution of the differential equation (4.43).

$$
\sigma_{x}=-q\left(\frac{D^{2}}{D_{i n}^{2}}\right)^{(B-1)}+\frac{B}{B-1} \sigma_{y}\left[1-\left(\frac{D^{2}}{D_{i n}^{2}}\right)^{(B-1)}\right]
$$

The nominal pressure on the surface in the work zone can now be calculated with the yield criterion Eq. (4.38).

$$
p_{\text {nom }}=\frac{1}{1-\mu \tan \theta}\left\{\sigma_{y}+q\left(\frac{D^{2}}{D_{i n}^{2}}\right)^{(B-1)}-\frac{B}{B-1} \sigma_{y}\left[1-\left(\frac{D^{2}}{D_{i n}^{2}}\right)^{(B-1)}\right]\right\}
$$

\subsection{Results for the nominal contact pressure}

To be able to calculate the nominal pressure for the standard data set of hydrostatic extrusion, a friction coefficient $\mu$ is required. The friction coefficient is taken from friction measurements performed on a pin on disk machine on a lubricated contact between magnesium and steel. The measurements are described in Appendix $C$. The friction coefficient used in the calculations is taken to be 0.1 . This is a very typical value for a system where boundary lubrication is the acting lubrication regime.

The nominal pressure for the standard data set of hydrostatic extrusion of magnesium as described in Chapter 2 and Table A. 5 is presented in Figure 4.6 for three different half die angles $\theta$. The corresponding axial stresses in the billet are given in Figure 4.7. The 0 and 1 on the horizontal axis are a normalized coordinate along the x-axis, representing the beginning and end of the work zone. This can be calculated with the variables from Figure 4.4 as follows:

$$
\frac{x_{\text {in }}-x}{x_{\text {in }}-x_{\text {out }}}
$$

It can be seen from these figures that both compressive stresses, the contact pressure $p_{\text {nom }}$ and the axial stress $\sigma_{x}$, decrease in the work zone. For a higher half die angle the nominal 
pressure starts at a higher level at the entry of the work zone; it decreases a little faster in the work zone for a higher die angle.

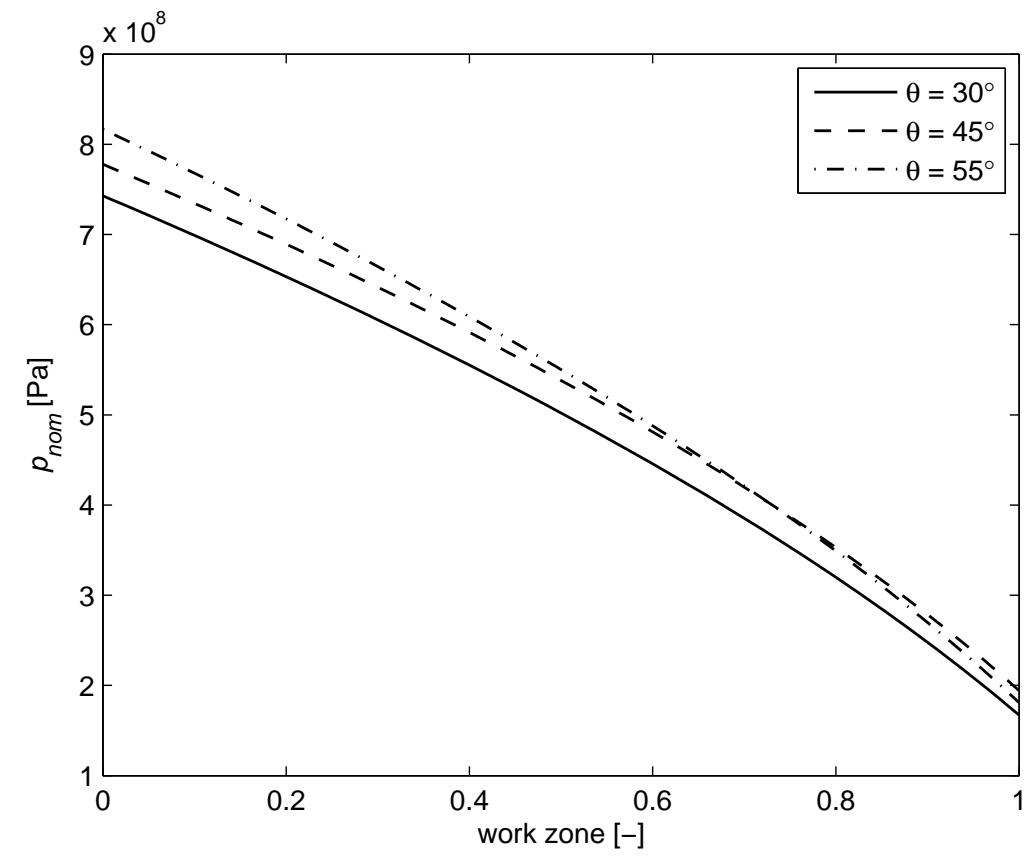

Figure 4.6 Normal pressure in the work zone for different half die angles $\theta$.

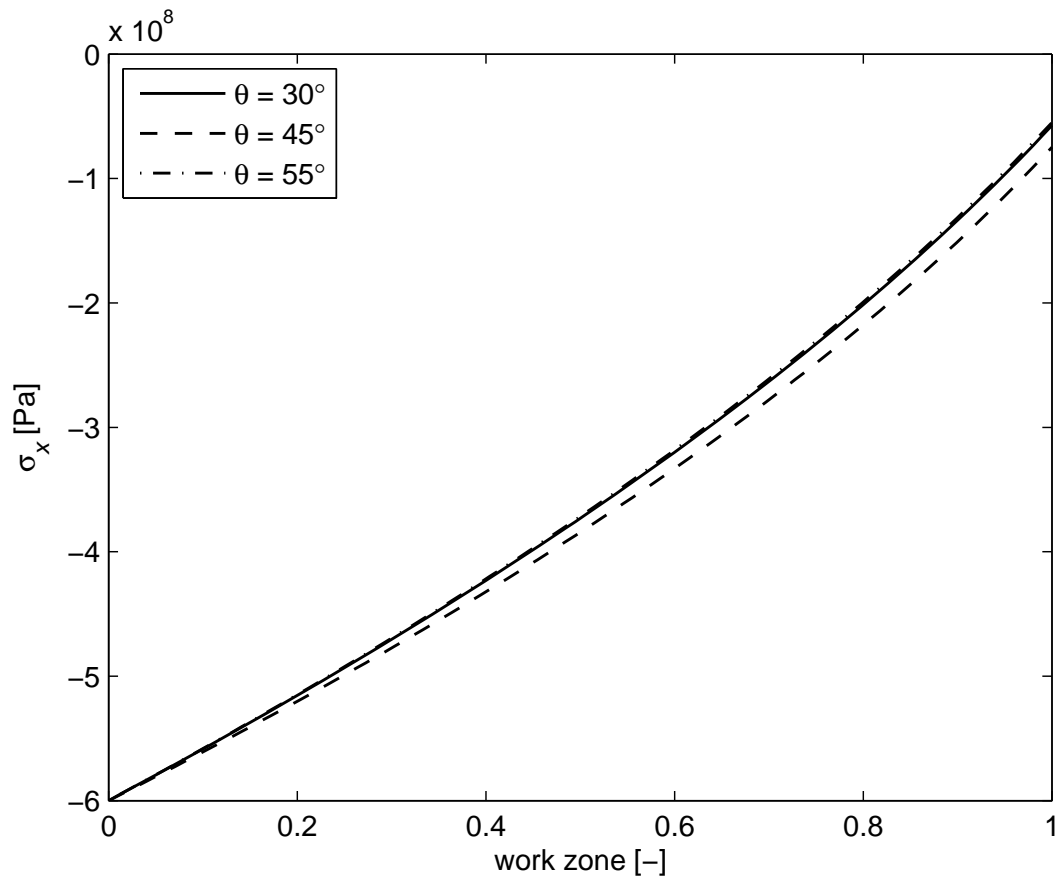

Figure 4.7 Axial stress $\sigma_{\mathrm{x}}$ in the work zone for different half die angles $\theta$.

The results shown in this figure can be explained as follows. The nominal pressure is calculated based on the force equilibrium in the $x$-direction. The axial stress in the billet decreases in the work zone because of the horizontal components of the nominal pressure and the friction force. For higher die angles, these components will have a larger total 
contribution in the $\mathrm{x}$-direction as compared to small die angles. Therefore the axial stress in the billet and also the nominal pressure decrease differently for different die angles. The difference for the nominal pressure at the entry of the work zone can be explained by the flow criterion. The difference between the radial stress and the axial stress in the billet is fixed by the yield stress. The radial stress is formed by the radial components of the friction and the nominal pressure. For a larger die angle these stresses need to be larger in order to have the same radial component.

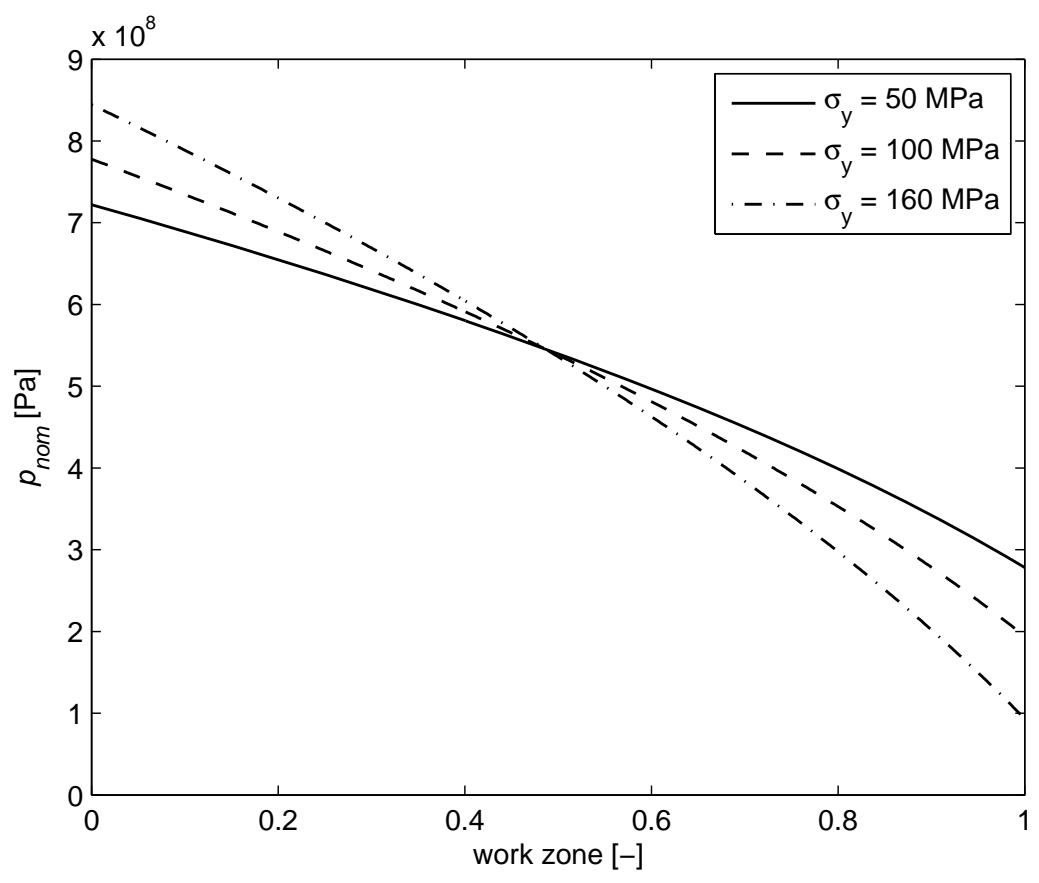

Figure 4.8 Normal pressure in the work zone for different yield stresses $\sigma_{\mathrm{y}}$.

The nominal pressure in the work zone for different yield stresses $\sigma_{\mathrm{y}}$ is given in Figure 4.8. For a higher yield stress the nominal pressure starts higher at the entry of the work zone, but it decreases more sharply than for a lower yield stress. This can be explained as follows. The yield stress determines the difference between the radial and the axial stress. For a higher yield stress the nominal pressure at the entry of the work zone has to be greater and will decrease faster because the friction is proportional to the nominal pressure.

Finally, the nominal pressure for different coefficients of friction is presented in Figure 4.9. Here can be seen that for a higher coefficient of friction the nominal pressure starts at a higher level at the entry of the work zone and decreases faster. This can be explained in a similar way as for the different die angles. The horizontal component of the friction force needs to be compensated by a decrease in axial stress in the billet. If the coefficient of friction is less, the friction force is less and therefore the decrease of the axial stress is less in the work zone. The difference between the radial stress and the axial stress in the billet is fixed by the yield stress and therefore the nominal pressure and the axial stress in the billet are coupled in a similar way. 
The results show that the coefficient of friction $\mu$ has the most significant effect on the results of the nominal pressure, in the range of the variables used.

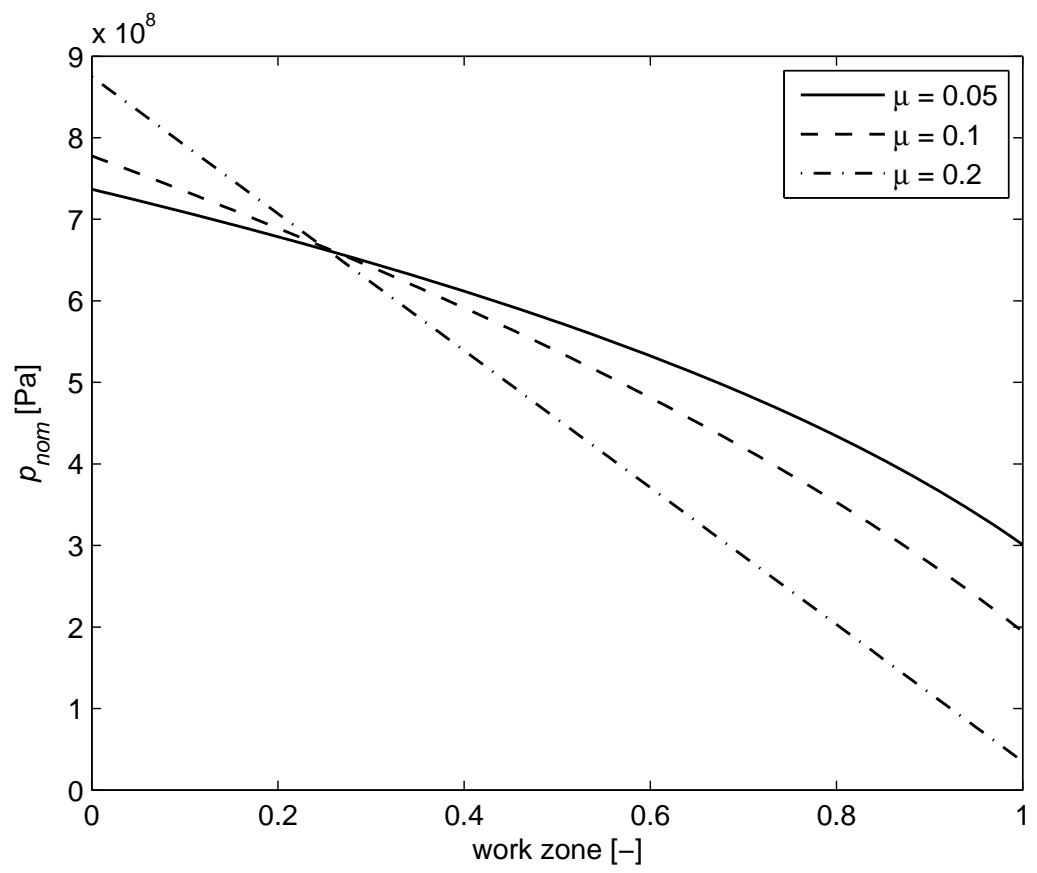

Figure 4.9 Normal pressure in the work zone for different coefficients of friction $\mu$.

If the axial stress in the billet becomes positive at the exit of the extrusion, this means that a tensile stress is required for the extrusion to take place. For wire drawing this is typically the case. However, this is typically not done in the hydrostatic extrusion process. Using this model, a process window can be defined that is bounded by the criterion that $\sigma_{\mathrm{x}}$ $<0$ in the entire work zone. The negative axial stress $\sigma_{\mathrm{x}}$ is determined by the combination of the yield stress, the die angle, the friction coefficient and the other process parameters.

\subsection{Numerical implementation}

As indicated previously, to calculate the film thickness with the Reynolds equation (4.9) a boundary condition is required. This boundary condition for the pressure can be given at the entry or the exit of the work zone area. In Chapter 3 the film thickness at the entry of the work zone was calculated. This value is used as the required boundary condition in the calculations, i.e. for the standard data set $h_{0}=2.1 \cdot 10^{-8} \mathrm{~m}$.

Furthermore, the yield stress of the billet material in the work zone area during extrusion is needed for the calculation. The material model of Li [15], valid for AZ31, as discussed in Section 2.3 is used to calculate the yield stress. This calculation is performed at $300 \stackrel{\circ}{ } \mathrm{C}$ and the strain rate corresponding to the reference data set. This temperature is used based on the simulations of the temperature during the hydrostatic extrusion process by Barton, which is around $300{ }^{\circ} \mathrm{C}$ [39]. The calculated yield stress with the model of $\mathrm{Li}$ is depicted in 
Figure 4.10. Due to the definition of the model of $\mathrm{Li}$, the resulting yield stress in the work zone area is a function with many discontinuities. Since for this temperature the yield stress is approximately constant it is chosen to perform all calculations with the average yield stress value of $\sigma_{\mathrm{y}}=100 \mathrm{MPa}$. This value is confirmed by the work of Zhao, [40], who also performed compressive deformation measurements of AZ31. He too found a yield stress of around $100 \mathrm{MPa}$ for the strains depicted in Figure 4.10.

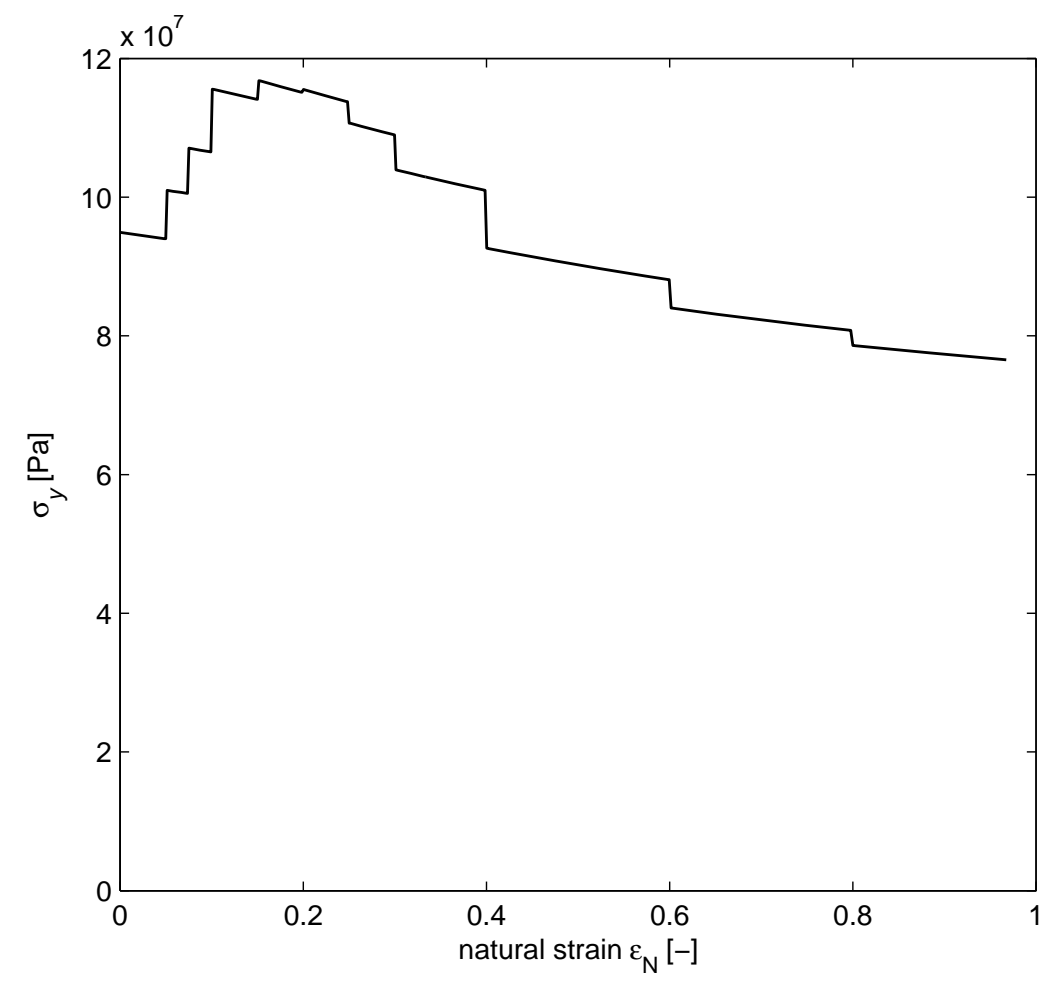

Figure 4.10 Yield stress AZ31 according to the model of Li at 300 ㄷ.

All the calculations have been performed using Matlab. The differential equation (4.9) is programmed using a finite difference approximation technique. In the numerical implementation, a specified number of calculation points (nop) are distributed evenly over the length of the work zone area. This is the s-axis as depicted in Figure 4.1.

The necessary derivatives are approximated using the central discretization method shown in Equations (4.49) and (4.50).

$$
\begin{gathered}
\frac{\partial p_{\text {nom }}\left(s_{0}\right)}{\partial s} \cong \frac{p_{\text {nom }}\left(s_{0}+\Delta s\right)-p_{\text {nom }}\left(s_{0}-\Delta s\right)}{2 \Delta s} \\
\frac{\partial^{2} p_{\text {nom }}\left(s_{0}\right)}{\partial s^{2}} \cong \frac{p_{\text {nom }}\left(s_{0}+\Delta s\right)-2 p_{\text {nom }}\left(s_{0}\right)+p_{\text {nom }}\left(s_{0}-\Delta s\right)}{\Delta s^{2}}
\end{gathered}
$$

For the first and last point in the calculation domain this would require information outside the calculation domain. Calculating these points for the first derivative the forward or backward discretization is used, whatever data information points are available. The first 
and last points of the second derivative are calculated with a forward and backward discretization based on the approximated first derivative.

The calculation starts with a boundary condition at the transition point from the work zone to the outlet zone, as also described earlier in this section.

The number of calculation points (nop) needs to be sufficiently high for the numerical implementation to be stable and accurate. The number of points is checked by increasing nop and checking if the results converge. In Figure 4.3 is already shown that part of the Reynolds equation is checked by comparing the results to the Couette flow equation. This comparison is used to show the effect of the number of calculation points in Figure 4.11. From this figure it can be seen that approximately 200 calculation points are enough to ensure accurate calculation results.

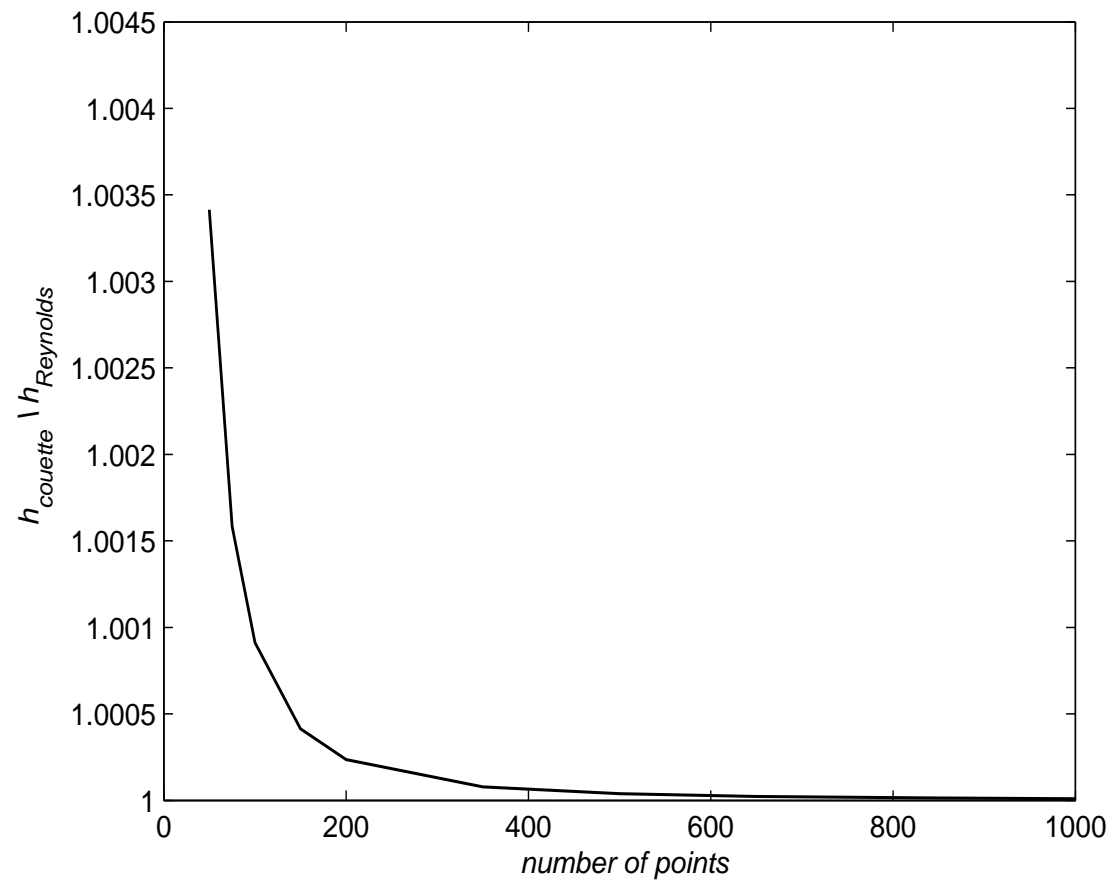

Figure 4.11 The ratio of the "Couette" film thickness over the "Reynolds" film thickness as a function of the number of calculation points.

\subsection{Results}

The film thickness is calculated in the work zone area of the hydrostatic extrusion process based on the standard data set as described in Chapter 2 and Table A.5. The differential equation used (4.9) is explained in Section 4.1, the boundary condition and the numerical implementation are given in Section 4.4. The calculated film thickness found is shown in Figure 4.12. On the horizontal axis the normalised coordinate along the work zone is depicted as mentioned earlier, where 0 is the beginning of the work zone and 1 is the exit end of the work zone. It can be seen from Figure 4.12 that the predicted film thickness in the work zone is very similar to the predicted film thickness with the Couette flow of 
Figure 4.3. This can be explained as follows. For these low film thickness values the terms on the left hand side of Eq. (4.9) become insignificant as these terms contain $\mathrm{h}^{3}$. This results in a situation similar to the calculation results with a constant nominal pressure,

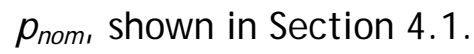

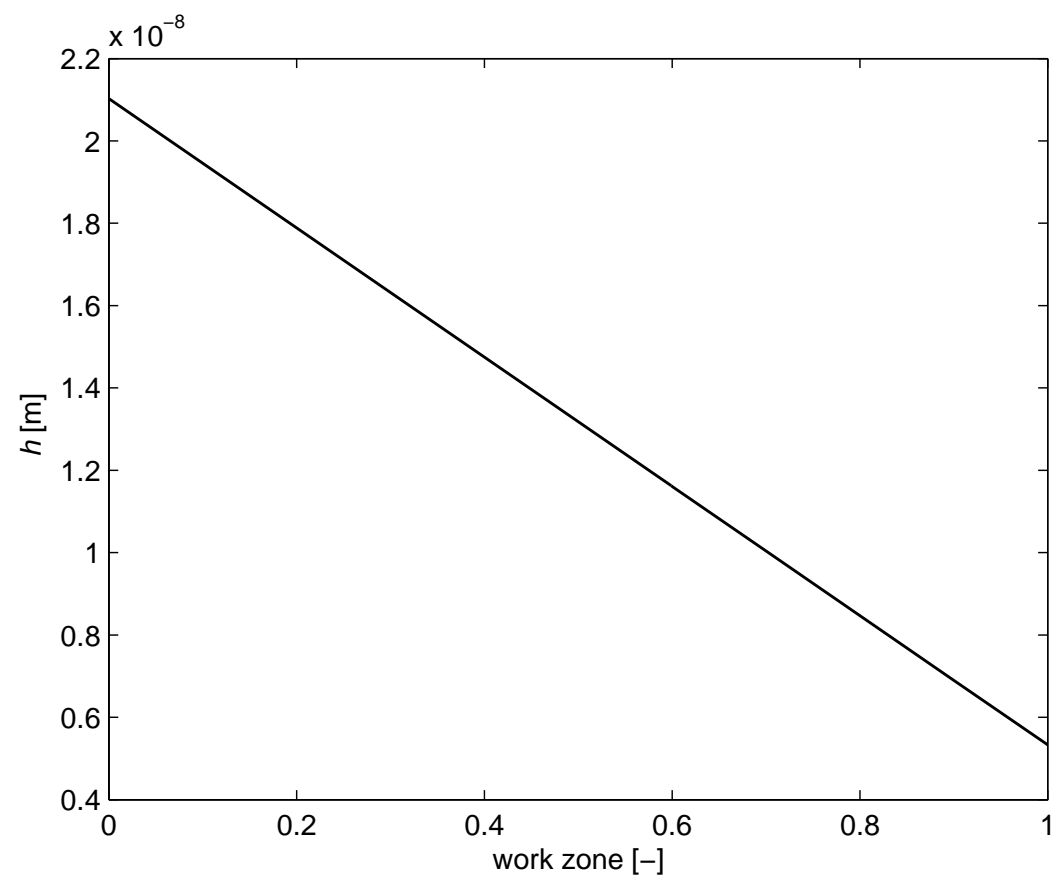

Figure 4.12 Film thickness in the work zone for the standard data set.

The film thickness is compared to the deformed $R_{q}$ roughness value of the workpiece material in the work zone multiplied by 0.1 , which is a good indication for the transition from the mixed lubrication to the boundary lubrication regime [32]. If the film thickness is higher than the dashed line, the system operates in the mixed lubrication regime and if the film thickness is lower than the indicated boundary, the system operates in the boundary lubrication regime. More information about the used roughness values can be found in Appendix C.

It can be seen from Figure 4.13 that the film thickness is below the lubrication mode transition line in the entire work zone. The conclusion therefore is that the prevailing lubrication regime in the work zone of the hydrostatic extrusion process is the boundary lubrication regime.

Since the film thickness for the standard data set is governed by the Couette flow of Eq. (4.12), varying the process parameter, e.g. the die angle and the extrusion speed will not influence the predicted film thickness. The film thickness will be influenced only by varying the extrusion ratio. 


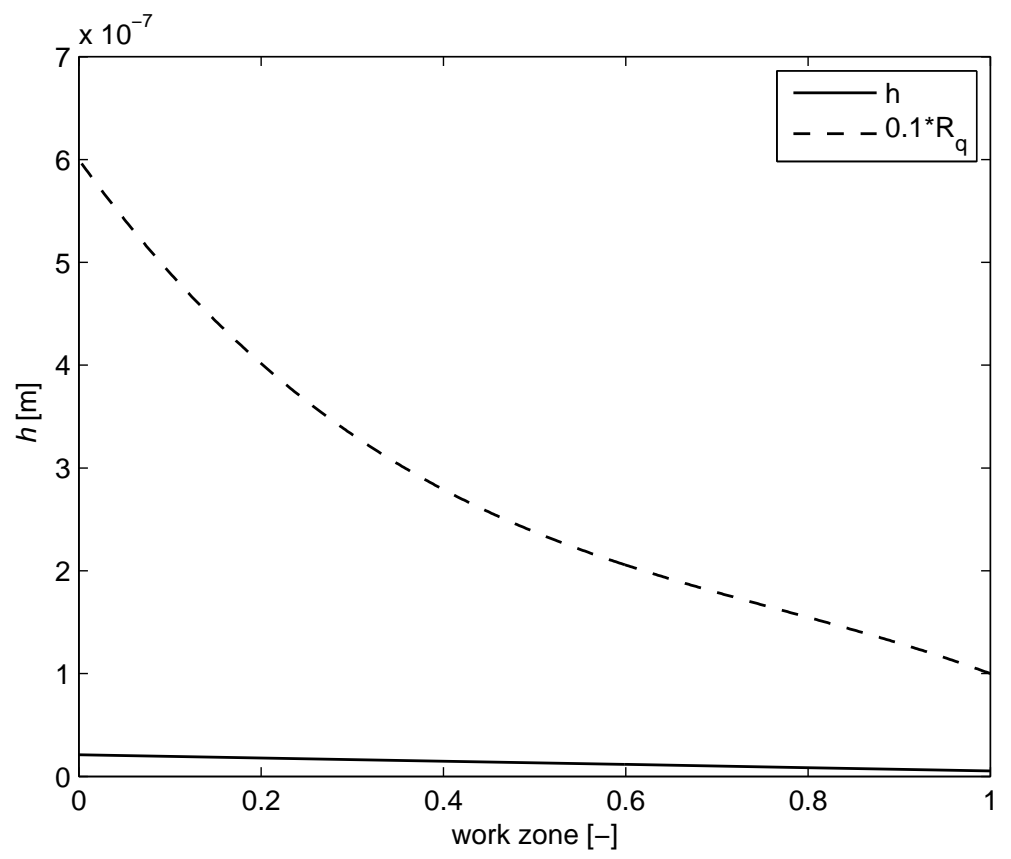

Figure 4.13 Film thickness in the work zone and transition line (dotted) mixed to boundary lubrication $\left(0.1 \cdot \mathbf{R}_{\mathrm{q}}\right)$.

Chapter 3 shows that when a lubricant is used with a higher pressure viscosity coefficient it is possible to have a central film thickness $h_{0}$ in the mixed lubrication regime in the inlet zone. A film thickness calculation was performed with the Roelands pressure viscosity coefficient $z=0.7$ as is used in Chapter 3 , resulting in a central film thickness $h_{0}=1.26 \mu \mathrm{m}$. The results are shown in Figure 4.14 together with the film thickness for this boundary condition calculated with the Couette flow equation. This example calculation is performed with a friction coefficient of $\mu=0.2$. The rest of the process parameters are as in the standard data set of Table A.5. From Figure 4.14 it can be seen that the pressure in the lubricant causes the film thickness to decrease less than with Couette flow only. It can also be seen that both film thickness lines are above the transition from the boundary to the mixed lubrication regime. It has to be noted that the parameter set used here does not represent an actual hydrostatic extrusion, but is shown as an example of what might happen when a different lubricant is used.

The conclusion is that the system acts in boundary lubrication regime, independent of the process parameters used within the appropriate process window. Mixed lubrication can for instance be reached with a lubricant having a higher pressure viscosity coefficient. In the next section, these results will be interpreted in terms of a potential blow-out of the hydrostatic extrusion process. 


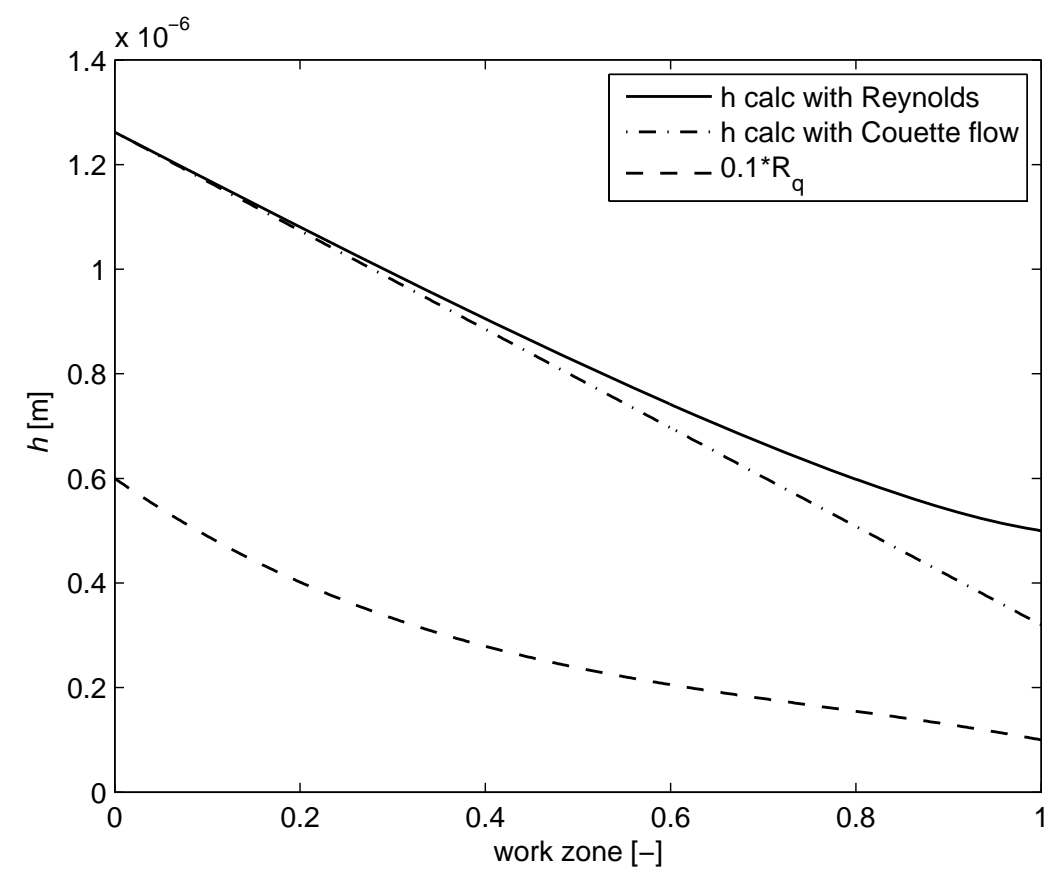

Figure 4.14 Film thickness for a higher viscosity pressure coefficient, $z=0.7$, with Reynolds and Couette flow.

\subsection{Percolation threshold}

One of the phenomena that can occur in hydrostatic extrusion is a blow-out. This happens when there is free flow of the lubricant out of the die and the pressure in the lubricant is greater than the atmospheric pressure. In case of a blow-out, the pressure medium is forced out of the die; this will cause a loss of pressure, and the deformation will stop immediately. This free flow criterion will be investigated in this section.
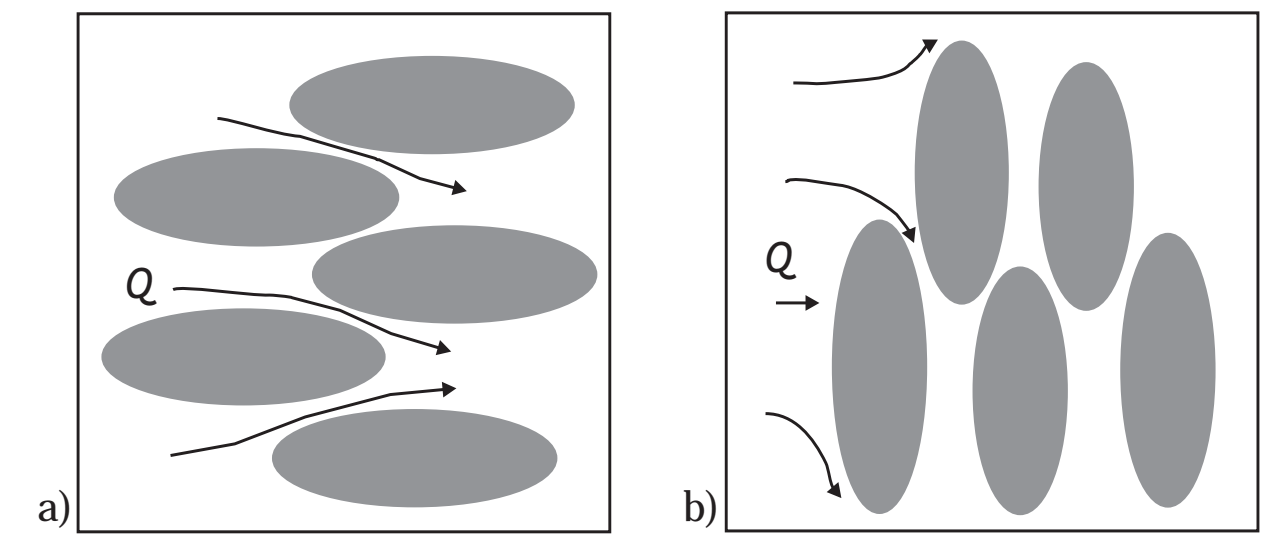

Figure 4.15 Schematic representation of the percolation threshold. a) Longitudinal roughness contact points, where flow is possible between the surfaces. b) Transversal roughness contact points, which are blocking the flow between the contacting surfaces.

The free flow criterion at the die exit can be modelled using the percolation threshold. For this the surfaces in contact are modelled as a "porous medium", with areas of contact surrounded by areas of non-contact. For a low ratio of area in contact, $a$, the lubrication 
can flow between the areas of contact. With an increasing ratio of area in contact, thereby increasing nominal pressure, the percolation threshold is reached when the lubricant can no longer flow between the contacting areas, as is visualized in Figure 4.15.

Lo [41] derived the percolation threshold for several roughness patterns using this "porous medium" model. He found that for an isotropic roughness no flow is possible for a fraction of area in contact higher than 0.675 . This value changes significantly for surfaces with an anisotropic roughness. The anisotropy of a surface roughness can be characterized by the Peklenik number as explained by Patir [42]. The Peklenik number is defined as the ratio of the $\lambda_{0.5}$ in both surface directions, where $\lambda_{0.5}$ is the length at which the auto-correlation function of a profile reduces to $50 \%$ of its original value, [42].

$$
\gamma=\frac{\lambda_{0.5 x}}{\lambda_{0.5 y}}
$$

For an isotropic surface roughness this results in a Peklenik number of 1 . For $y<1$ the roughness is transverse, so with wavelengths perpendicular to the velocity vector. This situation is depicted in Figure 4.15b. For a longitudinal roughness the wavelengths are in the direction of the velocity and $y>1$. The turned billet has a transverse roughness and will therefore have a small Peklenik number. Extrusion products have Iongitudinal surface roughness and thus a high Peklenik number, although the billet surface is mostly transverse in nature due to the turning operation done on the billet before extrusion. The roughness changes through the work zone from transversal to longitudinal, so $y$ will change from a value $<1$ to a value $>1$ in the work zone. Lo [41] states that for transversal roughnesses where $y$ is equal to $1 / 3,1 / 6$ and $1 / 9$ the pressure driven (Poiseuille) flow disappears for contact ratios of respectively $0.35,0.23$ and 0.19 . These values are significantly lower than for an isotropic roughness. For longitudinal roughnesses the fraction of area in contact for which the pressure flow starts to disappear will be even higher than $a=0.675$ for an isotropic roughness. The fraction of area in contact for an isotropic roughness is used in this work as a lower limit for the ratio in contact at the exit of the hydrostatic extrusion process at which there is no blow-out.

With this fraction of area in contact $a$, the resulting separation $d$ can be calculated, as is explained in Section 2.3.2.

$$
\alpha=\int_{d}^{\infty} \varphi(z) d z
$$

The separation is defined as the distance between the mean lines of the surfaces. By definition the separation becomes negative for fraction of contact area higher than 0.5 for a Gaussian surface. The film thickness needs to be positive for all situations, therefore a suitable relation between film thickness and separation is required for the high values of 
the fraction of the area in contact as in the work zone exists. Here, the definition of the average film thickness as presented by Patir [42] is used.

$$
h_{T}=\frac{\int_{-\infty}^{d}(d-z) \varphi(z) d z}{\int_{-\infty}^{\infty} \varphi(z) d z}
$$

Physically, the equation means that the volume in the valleys below the separation $d$ is integrated and divided by the total surface area. Calculating the separation and the average film thickness for $a=0.675$ and a roughness of $R_{q}=1.0 \mu \mathrm{m}$ gives an average film thickness $h_{T}=0.21 \mu \mathrm{m}$ as the upper limit for the no free flow criterion at the exit of the work zone area. The $R_{q}$ value given at the exit of the work zone area is explained further in Appendix C. The conclusion is that the results of Section 4.5 are in agreement with the percolation threshold. The calculated film thicknesses at the exit of the work zone are below the percolation threshold, therefore there is no risk of a blow-out.

It has to be noted that these calculations are based on the observation that there is a longitudinal roughness at the exit end of the work zone and the Peklenik number is larger than 1. If the transversal roughness would stay intact in the entire work zone the percolation threshold changes significantly and the upper limit for the fraction of area in contact would then be in the order of 0.2 or 0.3 . In this situation the percolation threshold film thickness increases significantly. Consequently, if a lubricant film is present, the roughness of the billet will have a greater tendency to stay intact. For aluminum billets it has indeed been observed that there is a transversal roughness in the entire work zone area; this effect has not been seen for magnesium billets.

\subsection{Conclusions}

To be able to calculate the film thickness in the work zone area of the hydrostatic extrusion process a lubrication model has been formulated. This model is based on the full film lubrication assumption utilizing the Reynolds equation. This differential equation is adapted to make it suitable for the geometry of the work zone area of the hydrostatic extrusion process. The model is numerically implemented using Matlab with a finite difference method and a boundary condition at the inlet of the work zone of the hydrostatic extrusion process based on the analysis of the inlet zone explained in Chapter 3. Furthermore, the nominal pressure in the work zone area of the hydrostatic extrusion process is modelled and calculated. The conclusions are as follows.

- The calculated film thickness is compared to $0.1 \cdot R_{q}$ of the deformed workpiece surface, to be able to distinguish between the boundary and mixed lubrication regime. The conclusion is that in the entire work zone the system acts clearly in the boundary lubrication regime. 
- Due to the low film thickness, the full film lubrication model behaves as if Couette flow is present. Consequently, changing the process parameters does not influence the predicted film thickness significantly.

- When a different lubricant is used with a higher pressure viscosity coefficient it is possible for the system to act in the mixed lubrication regime.

- An upper limit for the film thickness at the outlet of the work zone has been defined based on the percolation threshold. 


\section{Chapter 5}

\section{Contact in hydrostatic extrusion}

In the hydrostatic extrusion process, the actual metal forming takes place in the work zone of the extrusion process. As shown in the previous chapter the film thickness in the work zone area suggests that boundary lubrication is the prevailing lubrication regime as the film is too thin to separate the surfaces. Consequently, to determine the contact conditions in the work zone a contact model is required. The contact model provides a link between process parameters like normal load, bulk strain, material properties and roughness of the extrudate and the real area of contact.

Firstly, in Section 5.1 an overview is given of some contact models in literature. In Section 5.2 a contact model suitable for hydrostatic extrusion of magnesium is presented. In Section 5.3 the input parameters needed for the contact model at micro level will be given. In Section 5.4 calculations will be performed with the existing contact model. The contact model of Westeneng is extended in Section 5.5. The bulk strain effect is added to the contact model in Section 5.6 and a parameter study is performed with this model in Section 5.7. Finally, conclusions will be drawn in Section 5.8 .

\section{1 Literature}

In literature, many contact models for rough surfaces can be found. A review of these models is written by Liu [43]. The first step in a contact model is the modelling of the geometrical properties of the surfaces. In the earlier models the rough surfaces have been described statistically. In Greenwood [44] and de Rooij [45], the summits of the asperities are considered to be spherical with a constant radius. The height of the summits is modelled with a Gaussian height distribution function, where the mean is given by the mean plane of summits and the standard deviation by the standard deviation of the summit heights. Two key aspects of these models are that the summits of the asperities are spherical and that the absence of asperity interactions is assumed. Later, also elliptical paraboloids and other summit shapes have been considered, see [43] for further reference.

According to Greenwood and Williamson [46], the different contact models can be classified based on the mode of deformation of the summits, these deformation modes can be either plastic, elastic or elasto-plastic. 
In Westeneng [47] several numerical contact models are mentioned where each surface location is described by a number of bars. The deformation caused by the loaded elements is superimposed in order to deduce the geometry of the deformed surface. In contrast to most contacts where the asperities deform elastically, in metal forming processes, such as hydrostatic extrusion the deformation is by nature plastic, both in the bulk of the material and at asperity level.

Bulk deformation is actually very significant for the surface deformation in forming processes as has already been shown by Wilson and Sheu [48] and Sutcliffe [49]. Asperities deform more easily when bulk strain is present. Therefore, the real area of contact is increased under the influence of bulk strain. Both Wilson and Sheu [48] and Sutcliffe [49] developed a contact model including bulk strain for wedge-shaped asperities with equal height. Wilson and Sheu use the upper bound method to investigate the deformation of wedges parallel to the direction of the uniaxial bulk strain. Sutcliffe uses the slip line theory for wedges perpendicular to the direction of bulk strain. Kimura and Childs [50] later incorporated more bulk strain effects, but they also used a uniform wedge-shaped roughness profile. Further work was done by Westeneng [47], who introduced a contact model including bulk strain effects suitable for any asperity geometry assuming a statistically rough surface.

Another important aspect is volume conservation, meaning that the volume of the flattened asperities has to be equal to the volume corresponding to the rise of the valleys. Pullen and Williamson developed a contact model with volume conservation [51]. Traditional stochastic models are derived for summit contacts. They overestimate the fraction of area in contact for high loads, i.e. surface deformation models predict a saturation of the fraction of area in contact, $a$, at 1 . To overcome this problem the model of Pullen and Williamson is developed taking the total surface into account, They also performed experiments with a specimen of aluminium in a confined container. A range of loads is applied to this surface, such that the pressure varies from 0 to 4 times the hardness of the material. After each loading experiment a profile of the surface of the specimen is studied along the same track. They observed that the displaced material reappears as a uniform rise of the valleys even for low loads. Based on an energy-balance relation expressions are derived to give a relation between load, separation and fraction of area in contact. The most relevant result is the relation between the dimensionless load, $\mathrm{W}^{*}$, and the fraction of real area of contact, $a$.

$$
W^{*}=\frac{\alpha}{1-\alpha}
$$

The model does, however, have an important shortcoming: bulk deformation due to inplane tensile stress is not included, as their model describes the situation of the material being in a confined container. 
Westeneng [47] developed a contact model for deep drawing which incorporates bulk deformation, volume conservation, asperity persistence and can be used for any asperity geometry. This model can also be applied to the hydrostatic extrusion process and will be expanded in this chapter. For this reason, the theory behind the contact model of Westeneng is explained in Section 5.2.

The contact model explained in this chapter is a micro scale model. However, it requires input parameters at macro level, such as nominal pressure $p_{\text {nom }}$ and strain $\varepsilon$ in the work zone area. The output of the contact model consists of micro scale parameters like the separation $d$ and the rise of the valleys $U$, which will be explained in the next section. These micro scale parameters are used to calculate the macro fraction of the real contact area $a$ at every location in the work zone of the hydrostatic extrusion process, see also Figure 5.1.
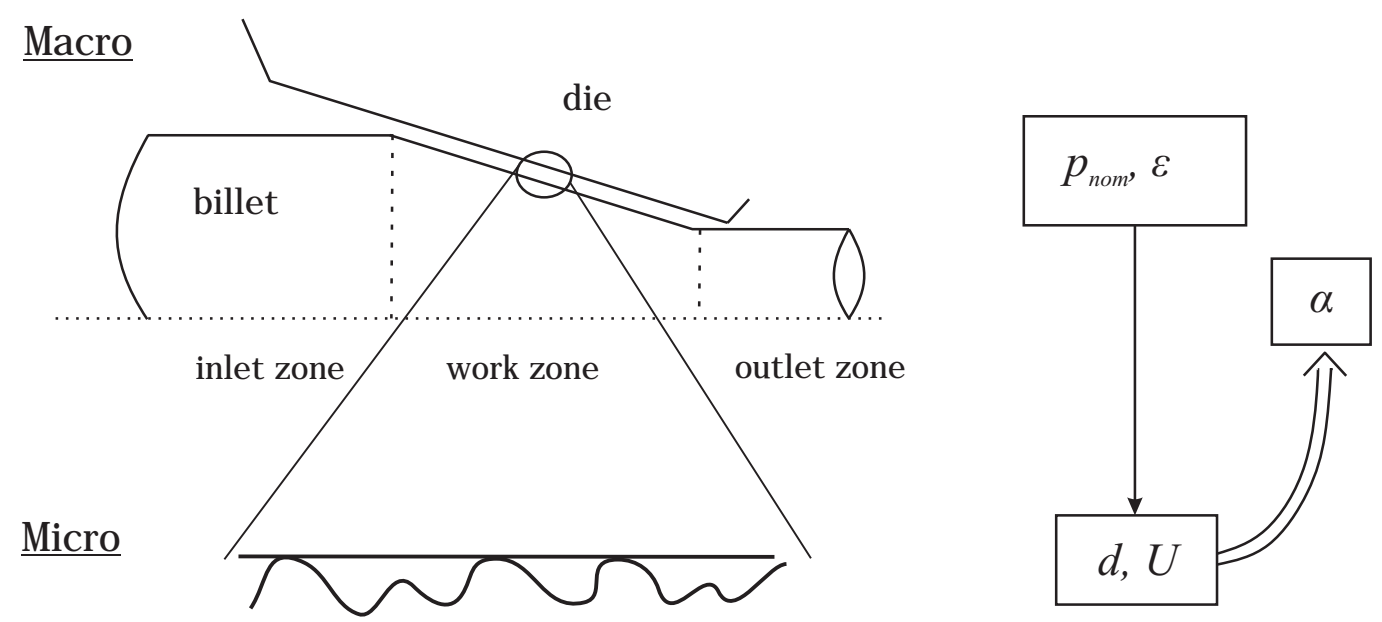

Figure 5.1 Macro and micro scale modelling.

\section{2 Contact between workpiece and die at micro level}

In this section, the model of Westeneng will be discussed in some detail, as the model is extended to higher contact pressures in Section 5.5. The contact model of Westeneng [47] consists of two parts, the first part incorporates the effect of normal loading and the second part adds the effect of bulk strain. The first part will be explained in this section and the effect of bulk strain later in Section 5.6.

The normal loading part of the contact model is based on an energy analysis. Westeneng assumes the deformation to be fully plastic, which in the work zone of the hydrostatic extrusion process is a good assumption. The model is based on a rough soft surface in contact with a hard smooth surface, as is the case in most metal forming processes. As in the model of Pullen and Williamson, volume conservation is assumed. This means that the volume of the indented asperities is equal to the volume of the rise of the valleys. Furthermore, it is assumed that the valleys rise with a constant value $U$. This is validated 
with experiments of Pullen and Williamson [51] as explained earlier. The surface heights are represented by bars. The situation is visualized in

Figure 5.2.

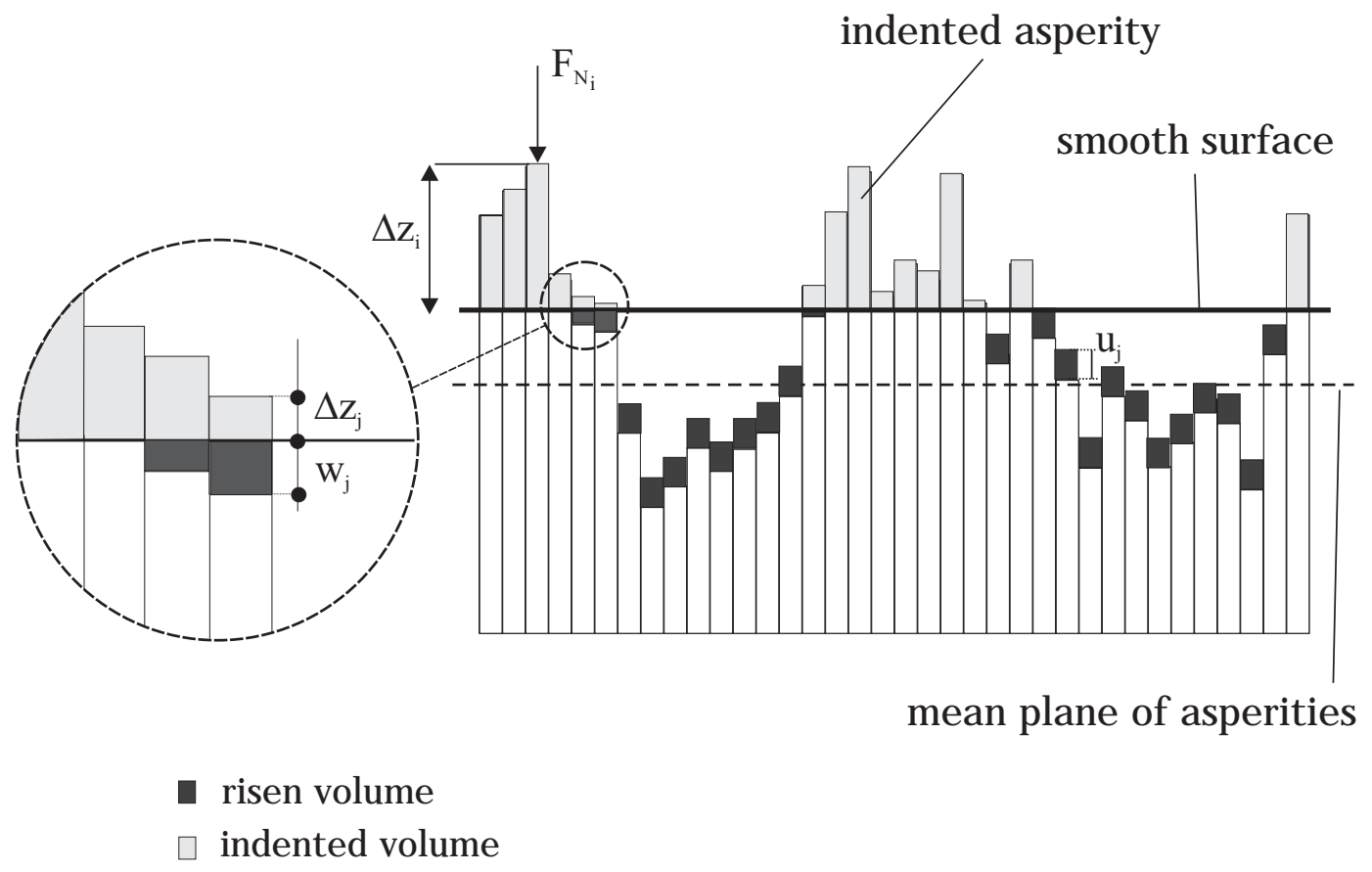

Figure 5.2 Asperities represented by bars in contact with a smooth surface, [47].

The number of bars flattened by the smooth surface is $\mathrm{N}^{*}$. The height of the indentation of a bar is called $\Delta \mathrm{z}_{\mathrm{i}}$ for $\mathrm{i}=1,2 \ldots \mathrm{N}^{*}$. The normal force carried by each bar is called $\mathrm{F}_{\mathrm{Ni}}$. The model is based on an energy balance with four energy contributions. The first external energy component is the work needed to indent the $\mathrm{N}^{*}$ bars, amounting to

$$
W_{e x t}^{\mathrm{N}^{*}}=\sum_{i=1}^{N^{*}} F_{N_{i}} \Delta z_{i}
$$

As stated earlier, the assumption is that all asperities which are not in contact rise with the same value $U$. However, for some asperities this would mean they rise above the contacting level. These asperities are only able to rise the distance $w_{j}$ where $w_{j} \leq U$. For these bars some work is needed to prevent a rise $\Delta z_{i}=U-w_{j}$ to keep the rising bars below the smooth surface. The number of bars that come into contact because of the rising of the valleys is called $\mathrm{N}^{* *}$. This leads to

$$
W_{e x t}^{\mathrm{N}^{* *}}=\sum_{j=1}^{N^{* *}} F_{N_{j}} \Delta z_{j}
$$

The total external energy is 


$$
W_{e x t}=W_{e x t}^{N^{*}}+W_{e x t}^{N^{* *}}=\sum_{k=1}^{N} F_{N_{k}} \Delta z_{k}
$$

where $\mathrm{N}$ is the total number of bars in contact with the smooth surface ( $\left.\mathrm{N}=\mathrm{N}^{*}+\mathrm{N}^{* *}\right)$. For further details the reader is referred to [47].

The total external energy applied is used for two internal energy contributions. One part of the energy is absorbed by the indented asperities $W_{\text {int }}^{a b s}$ and the remaining part of the energy is needed to raise the valleys $W_{\text {int }}^{\text {rise }}$. Because of the assumed ideal plastic deformation the real pressure in the indented bars is equal to the hardness. Therefore the energy used for flattening can be calculated as follows

$$
W_{\mathrm{int}}^{a b s}=\sum_{k=1}^{N} H \Delta A \Delta z_{k}
$$

where $\mathrm{H}$ tis he hardness of the billet material and $\Delta \mathrm{A}$ is the area of each bar.

To calculate $W_{\text {int }}^{\text {rise }}$ an asperity persistence parameter $\eta$ is introduced, which determines how much energy is required to lift up the valleys. The effect of asperity persistence is that the material in the valleys of the surface becomes more difficult to deform when the fraction of area in contact increases, see Childs [52]. This results in the effect that not all asperities flatten when a large normal load is applied. This also means that the real pressure in an asperity can be higher than the hardness. This phenomenon cannot be explained by work hardening of the asperities because it also takes place for non-work hardening materials. When $\eta=0$ no energy is needed to raise the valleys. When $\eta=1$ a maximum amount of energy is required to raise the valleys, therefore $0 \leq \eta \leq 1$.

The energy contribution for the rise, $W_{\text {int }}^{\text {rise }}$, is calculated as the sum of the energy needed to raise the $\mathrm{N}^{* *}$ bars which touch the smooth surface after applying the load and to raise the $\mathrm{M}$ bars which are not in contact with the smooth surface.

$$
W_{\mathrm{int}}^{\text {rise }}=\eta\left(\sum_{m=1}^{M} U H \Delta A+\sum_{j=1}^{N^{* *}} w_{j} H \Delta A\right)
$$

To be able to solve the energy balance equation an extra equation is needed. The assumed volume conservation can be used, see also Figure 5.3. The volume conservation is written as

$$
\underbrace{\sum_{m=1}^{M} U \Delta A}_{V_{\uparrow 1}}+\underbrace{\sum_{j=1}^{N * *} w_{j} \Delta A}_{V_{\uparrow 2}}=\underbrace{\sum_{i=1}^{N^{*}} \Delta z_{i} \Delta A}_{V_{\downarrow}}
$$




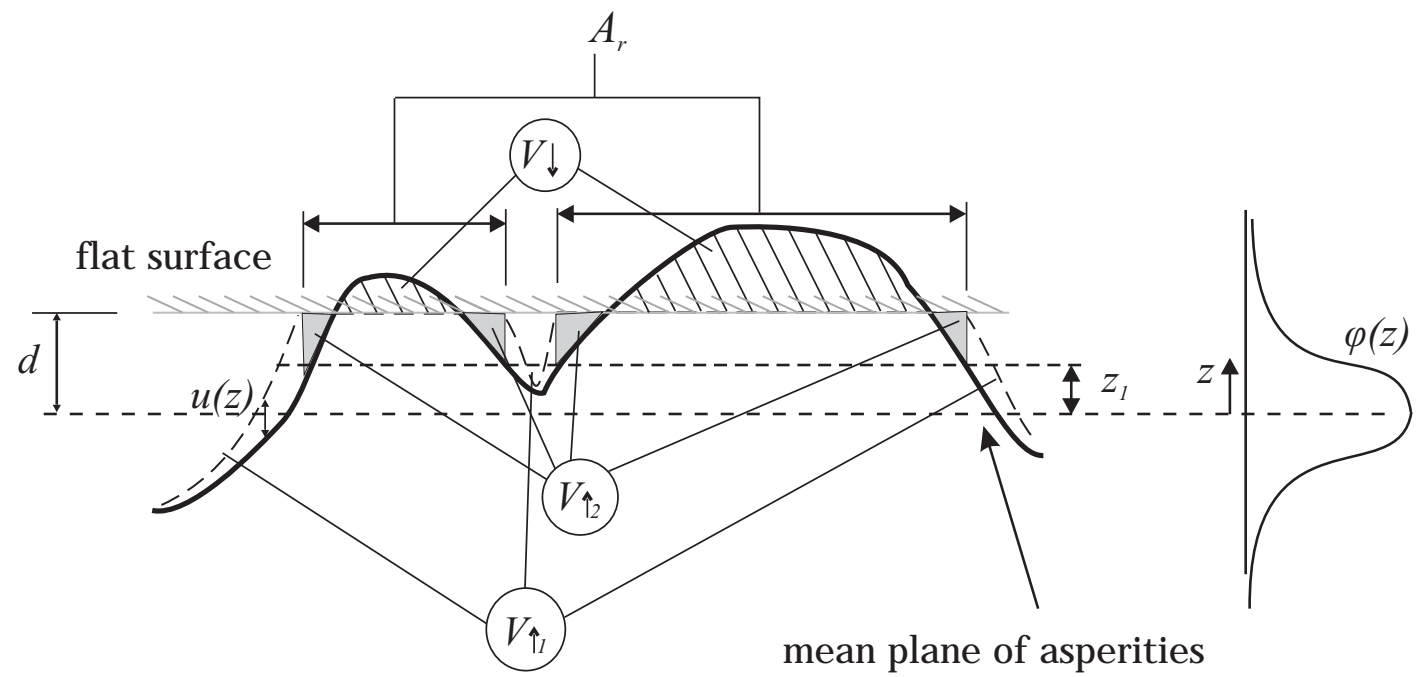

Figure 5.3 The rough surface in contact with the smooth surface with stochastic variables, taken from [47].

To reformulate the energy balance and volume conservation equations into properties of a rough surface, several stochastic variables are introduced, see Figure 5.3. In this figure $\varphi(z)$ is the normalised height distribution function of the asperities of the rough surface, and $d$ is the separation, i.e. the distance between the smooth surface and the mean plane of the asperities of the rough surface. Further, $z_{1}$ is the minimum height of a bar, that comes into contact with the smooth surface after the normal load is applied. This value can be obtained from the condition

$$
z_{1}+U=d
$$

The volume conservation equation (5.7) can now be written as

$$
A_{\text {nom }} \int_{-\infty}^{z_{1}} U \phi(z) d z+A_{\text {nom }} \int_{z_{1}}^{d}(d-z) \phi(z) d z=A_{\text {nom }} \int_{d}^{\infty}(z-d) \phi(z) d z
$$

This can be rewritten without further assumptions as

$$
U(1-\alpha)=\int_{d-U}^{\infty}(z-d) \phi(z) d z
$$

Furthermore an energy factor $\zeta_{1}$ and two shape factors $\zeta_{2}$ and $\zeta_{3}$ are introduced. The energy factor is defined as

$$
\zeta_{1}=\frac{\sum_{k=1}^{N} F_{N_{k}} \Delta z_{k}}{\hat{\Delta} z_{k} F_{N}}
$$

where $\hat{\Delta} z_{k}$ is the maximum indentation of the rough surface. With $\zeta_{1}$ the external energy equation (5.4) can be rewritten as 


$$
W_{e x t}=\zeta_{1} F_{N} \hat{\Delta} z_{k}
$$

The shape factors $\zeta_{2}$ and $\zeta_{3}$ are defined as

$$
\begin{gathered}
\zeta_{2}=\frac{\sum_{k=1}^{N} \Delta z_{k}}{N \hat{\Delta} z_{k}} \\
\zeta_{3}=\frac{\sum_{i=1}^{N^{*}} \Delta z_{i}}{N^{*} \hat{\Delta} z_{k}}
\end{gathered}
$$

They are called shaped factors because their value is influenced by the asperity height distribution and thus the 'shape' of the surface. Using $\zeta_{2}$ and writing $N \Delta A=A_{r}$, the internal absorbed energy, Eq. (5.5), can be written as

$$
W_{\text {int }}^{a b s}=\zeta_{2} H A_{r} \hat{\Delta} z_{k}
$$

Without further assumption the internal rise energy Eq. (5.6) can be rewritten with $\zeta_{3}$ and the volume conservation equation (5.10) as

$$
W_{\text {int }}^{\text {rise }}=\eta \zeta_{3} H\left(A_{r}-N^{* *} \Delta A\right) \hat{\Delta} z_{k}
$$

Now, equating the external energy equation (5.4) to the sum of Eq. (5.15) and Eq. (5.16) gives the final energy balance equation.

$$
\frac{F_{N}}{H}=\frac{\zeta_{2}}{\zeta_{1}} A_{r}+\frac{\zeta_{3}}{\zeta_{1}} \eta\left(A_{r}-N * * \Delta A\right)
$$

As described by [47] there is a relation between $\zeta_{1}, \zeta_{2}, \zeta_{3}$ and $\xi$ using this and the definition of $a \mathrm{Eq}$. (5.17) can be written as

$$
P=\frac{p_{\text {nom }}}{H}=\xi\left(1+\eta \frac{\int_{d}^{\infty}(z-d) \varphi(z) d z}{\int_{d-U}^{d}(z+U-d) \varphi(z) d z+\int_{d}^{\infty}(z-d) \varphi(z) d z}\right)
$$

With $\xi$ defined as

$$
\xi=\frac{\int_{d-U}^{\infty} F_{N}(z) \varphi(z) d z \cdot\left(\int_{d-U}^{d}(z+U-d) \varphi(z) d z+\int_{d}^{\infty}(z-d) \varphi(z) d z\right)}{\int_{d-U}^{d} F_{N}(z)(z+U-d) \varphi(z) d z+\int_{d}^{\infty} F_{N}(z)(z-d) \varphi(z) d z}
$$

A system of equations is created to solve $a, \mathrm{~d}$ and $\mathrm{U}$ simultaneously, see also Figure 5.4. 


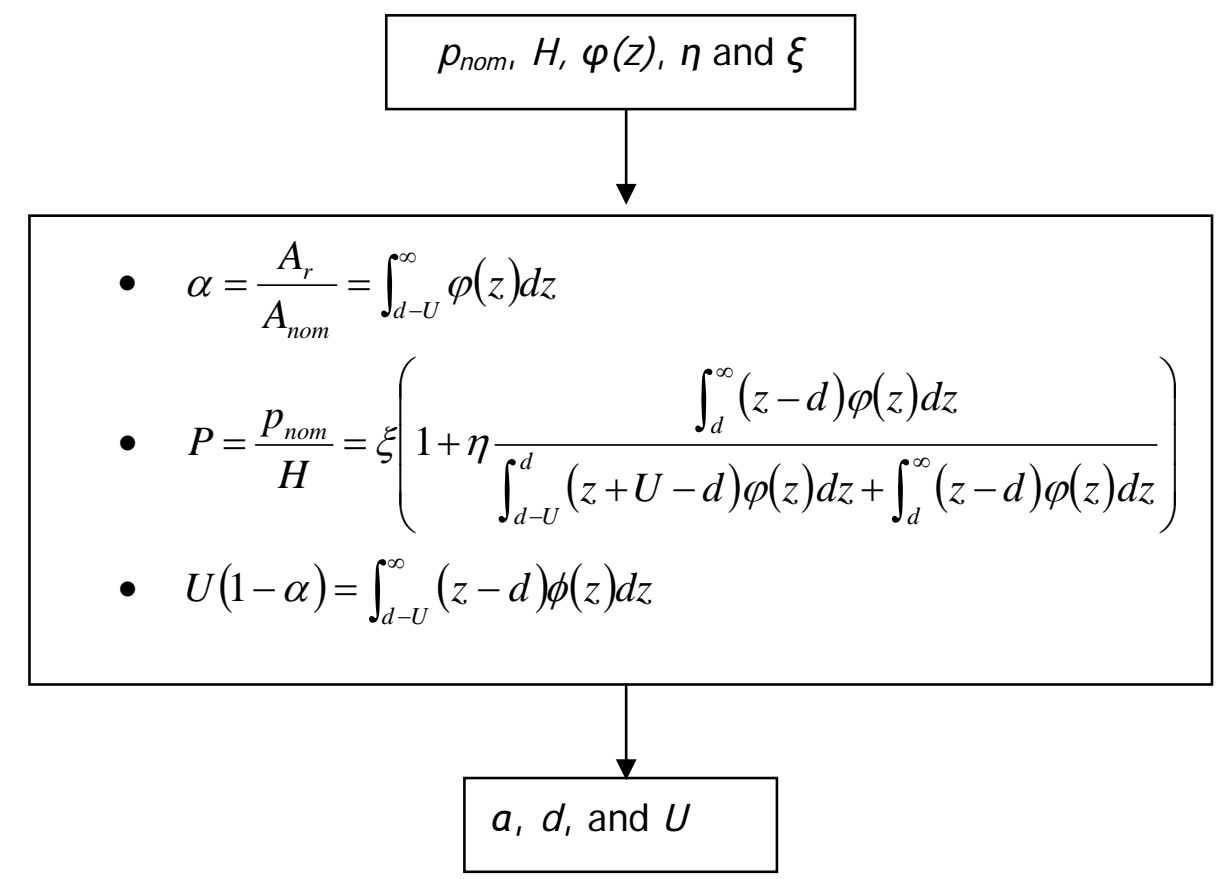

Figure 5.4 Calculation scheme for ideal plastic deformation.

As can be seen in Figure $5.4 \xi$ is needed to solve the system of equations. However, $\xi$ is a function of $d, U$ and $F_{N}(z)$, therefore additionally an expression for $F_{N}(z)$ is needed. Westeneng [47] proposes the use of a general power law in the form of

$$
F_{N}(z)=B \Delta z^{n}
$$

where

$$
\Delta z= \begin{cases}z-d & \text { for } z>d \\ z-d+U & \text { for } d-U \leq z<d\end{cases}
$$

$\mathrm{B}$ and $\mathrm{n}$ are assumed to be constants greater than zero. They are called indentation parameters, because they determine the amount of indentation of an asperity carrying a normal load. There is an obvious discontinuity in Eq. (5.21) at $z=d$. For bars with a height a little bit lower than $d$, energy is needed to keep the bar below the smooth surface for they tend to raise an amount $U$. The amount of energy absorbed is equal to the energy needed to indent a bar with a height $d+U$. For asperities with a height a little higher than $d$, almost no energy is needed for indentation.

If Eq. (5.20) is substituted in Eq. (5.19) the following relation for $\xi$ is acquired. 


$$
\begin{aligned}
\xi(d, U, n)= & \left(\int_{d-U}^{d}(z+U-d)^{n} \varphi(z) d z+\int_{d}^{\infty}(z-d)^{n} \varphi(z) d z\right) \\
& \frac{\left(\int_{d-U}^{d}(z+U-d) \varphi(z) d z+\int_{d}^{\infty}(z-d) \varphi(z) d z\right)}{\int_{d-U}^{d}(z+U-d)^{n+1} \varphi(z) d z+\int_{d}^{\infty}(z-d)^{n+1} \varphi(z) d z}
\end{aligned}
$$

As can be seen $\xi$ is independent of the constant B. With Eq. (5.22) the system of equations in Figure 5.4 can be solved. All the required parameters needed to calculate $a, d$, and $U$ are given in the next section.

\subsection{Input parameters in more detail}

To be able to use the contact model of Westeneng as described in the previous section in the work zone of the hydrostatic extrusion process several input parameters are needed. The nominal pressure has already been explained in Section 4.2; the rest of the input parameters will be discussed in this section. For reasons of convenience the parameters needed in the rest of this chapter will also be explained here. These parameters will be used as described in this section as reference unless noted otherwise.

\section{Parameter $\mathbf{n}$}

The parameter $n$ is needed to calculate the normal force acting on a bar $F_{N}(z)$ so as to be able to calculate $\xi$. Westeneng states that for an ideal plastically deforming spherical asperity with radius $B, F_{N}$ equals

$$
F_{N}(z)=2 \pi \beta H \Delta z
$$

Comparing to Eq. (5.20) this leads to $n=1$ and $B=2 \pi B H$. It is expected that the value for $n$ will be close to 1 , see [47].

\section{Asperity persistence parameter $\eta$}

The asperity persistence parameter $\eta$ varies between 0 and 1 . When $\eta=0$ no energy is needed to raise the valleys and $\eta=1$ means a maximum amount of energy is needed to lift up the valleys. Normally the persistence increases with an increasing load, [47]. Therefore the persistence parameter is to be taken as dependent on the load, in the form of $\eta=P, P$ as defined in Figure 5.4. However, $n$ can never be higher than 1 , therefore it is defined as follows.

$$
\eta= \begin{cases}P & \text { for } P \leq 1 \\ 1 & \text { for } P>1\end{cases}
$$




\section{Surface roughness $\varphi(z)$}

The surface roughness is modelled with a roughness density function $\varphi(z)$ as a Gaussian distribution with a mean equal to zero and standard deviation $\sigma$ as discussed in Section 2.3.2. This results in

$$
\varphi(z)=\frac{1}{\sqrt{2 \pi \sigma^{2}}} e^{\frac{-x^{2}}{2 \sigma^{2}}}
$$

where $\sigma=6.0 \mu \mathrm{m}$, which is the measured RMS value of a magnesium billet.

\section{Material properties $\sigma_{\mathrm{y}}$ and $\mathrm{H}$}

The contact model as described before requires material properties. As explained in the previous chapter a fixed yield stress is used, $\sigma_{y}=100 \mathrm{MPa}$. The hardness $\mathrm{H}$ of the magnesium billet can be related to the yield stress as $H=2.8 \cdot \sigma_{y}$. This relation has been shown to be approximately valid for metals, [53].

\section{Half asperity distance I}

Parameter I is the half asperity distance needed for the bulk strain calculations in the Section 5.7. It can be calculated from the total amount of asperities per unit area Q using

$$
l=\frac{1}{2 \sqrt{Q \alpha}}
$$

This can be done in two different ways, one with a fixed value for I and one depending on $a$. In the first method the fraction of real area of contact from the normal loading model $a_{\mathrm{L}}$ is used to calculate I and this fixed value is used for all bulk strain calculations. However $a$ will change with increasing strain and therefore also I. This can be incorporated in the model by updating I in each step of $\mathrm{d} \varepsilon$ when the new $a$ is calculated. The value of $\mathrm{Q}$ is taken from roughness measurements of a residual billet as already described in Section 2.3.2 and is equal to $\mathrm{Q}=3 \cdot 10^{9} \mathrm{~m}^{-2}$.

\section{Width of a bar $\sqrt{\Delta A}$}

Measured roughness data is input for the model. One of the important characteristics of roughness information is the pixel size. The dimensions of the bars as defined by Westeneng are determined by this roughness information, the bar size is taken to be equal to the pixel size in the contact model. As can be seen in Figure 2.5, the roughness measurement is performed with 350 pixels over a length of $867.4 \mu \mathrm{m}$. This means that the distance between 2 pixels and therefore also the distance between 2 bars is $2.5 \mu \mathrm{m}$, so the width of a bar, equal to $\sqrt{\Delta A}$, is also $2.5 \mu \mathrm{m}$.

\section{Length of a calculation domain $L_{d}$}

For each calculation performed in Matlab a number of points (nop) have to be specified. This defines the number of calculation areas used. The total calculation length $L$, which is 
in this case the length of the work zone area, is divided into nop calculation domains $L_{d}$. For each calculation domain the area is divided into bars as explained in Section 5.2.

$$
L_{d}=\frac{L}{n o p}
$$

The nop is an input parameter of the calculation and can therefore vary and is adapted to balance calculation time and convergence. Typical values for nop are 200 and 500.

\section{Number of bars $\mathbf{Q}_{\mathbf{b}}$}

The amount of bars in a calculation domain, $Q_{b}$, is required for the extended contact model as will be explained in Section 5.5. It can be calculated from the width of a bar $\sqrt{\Delta A}$ and the length of a calculation domain $L_{d}$.

$$
Q_{b}=\frac{L_{d}}{\sqrt{\Delta A}}
$$

\section{Strain $\varepsilon$}

The strain $\varepsilon$ is required in the contact model. Strain can be defined in two ways, nominal strain and natural strain. The nominal strain in one direction is defined as the length difference divided by the original length.

$$
\varepsilon=\frac{\Delta l}{l_{\text {original }}}=\frac{l_{\text {end }}-l_{\text {original }}}{l_{\text {original }}}
$$

In the hydrostatic extrusion process with a conical die this can be calculated from the geometry as follows.

$$
\varepsilon=\frac{A_{\text {in }}-A_{\text {out }}}{A_{\text {in }}}=\frac{\pi R_{\text {in }}^{2}-\pi R_{\text {out }}^{2}}{\pi R_{\text {in }}^{2}}=1-\frac{R_{\text {out }}^{2}}{R_{\text {in }}^{2}}
$$

However, for larger strains, which are present in hydrostatic extrusion, it is better to use the definition of natural strain or true strain.

$$
\varepsilon_{N}=\ln (1+\varepsilon)
$$

Here, the axisymmetrical equivalent plastic strain is used, as presented by Avitzur [54]. For a deforming rod the natural strain becomes

$$
\varepsilon_{N}=\ln \left(\frac{R_{\text {in }}^{2}}{R_{\text {out }}^{2}}\right)=2 \ln \left(\frac{R_{\text {in }}}{R_{\text {out }}}\right)
$$


The strain can now be calculated in each point in the work zone by using the current radius of the extruded material as the end radius, $\mathrm{R}_{\text {out }}$, in the above equation.

\subsection{Results with the contact model of Westeneng}

With the contact model as described in Section 5.2, the parameters described in Section 5.3 and the model of Section 4.2 and the standard data set defined in Chapter 2 a calculation is performed in the work zone of the hydrostatic extrusion process. These calculations are made for a wide range of pressures to be able to compare the results with the experimental and theoretical results of Pullen and Williamson [51], as described at the beginning of this chapter. They mention in their study that they used aluminium for their experiments. It is not specified which alloy is used, therefore a standard soft aluminium is assumed with a yield stress of $100 \mathrm{MPa}$.

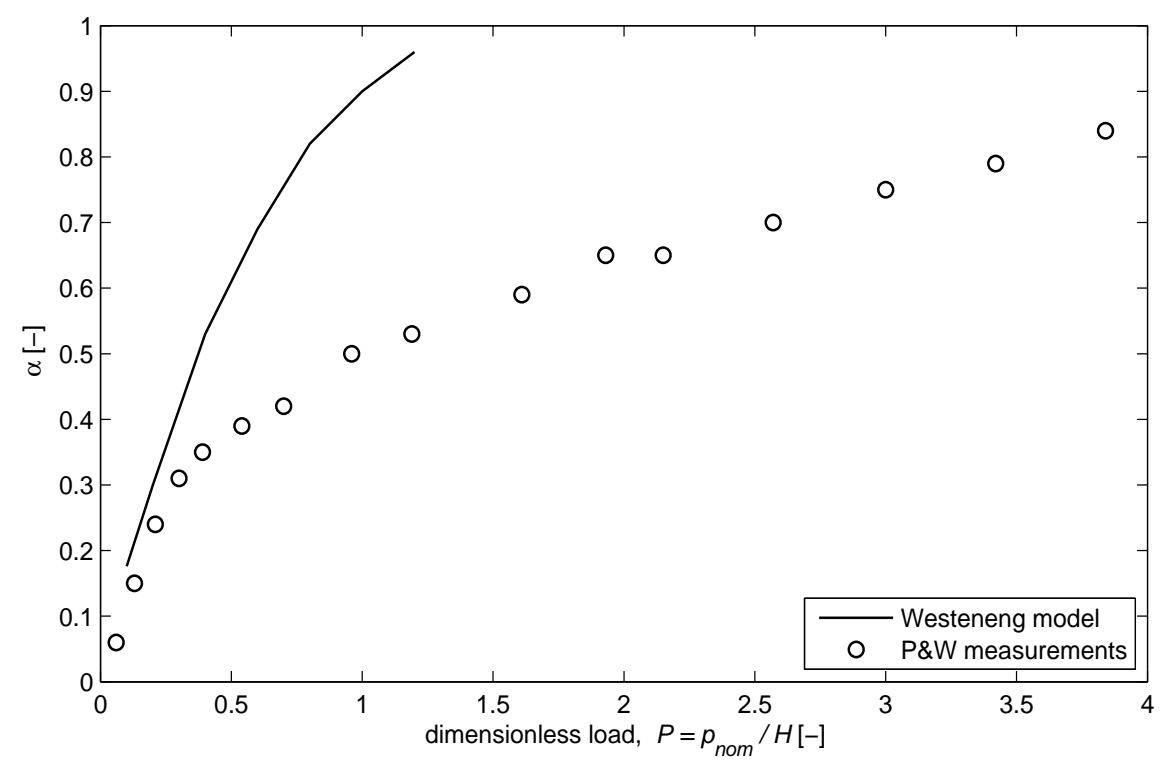

Figure 5.5 The fraction of real contact area $a$ as a function of the dimensionless load for the Westeneng model (normal loading) and the Pullen and Williamson measurements; based upon Figure 4 of [51].

Some of these results are shown in Figure 5.5. The predicted fraction of real contact area $a$ in the work zone is given for the Westeneng model and the Pullen and Williamson measurements. It can be seen that $a$ is predicted to be higher with the Westeneng model; and indeed for high pressures the difference is significant. The pressure range that occurs in the hydrostatic extrusion process is approximately the same as shown in Figure 5.5. Therefore these results of the Westeneng contact model show that this model is not suitable for the hydrostatic extrusion process in its current form.

\subsection{Extended contact model}

As shown in the previous section the contact model of Westeneng in its current form is not suitable for the high pressures which are common in the hydrostatic extrusion process. 
Therefore the contact model of Westeneng will be adapted to fit the results of Pullen and Williamson [51], as shown in Figure 5.5, more accurately over the whole pressure range depicted. To do this, in the contact model of Westeneng a shear stress between the bars will be incorporated. The choice here is that the strength of the interface between the bars is calculated according to the yield criterion of von Mises [55], which results in the following relation between hardness and shear strength, $k$.

$$
k=\frac{H}{3 \sqrt{3}}
$$

The area on which this shear stress works will be taken as equal to the width of a bar, $\sqrt{\Delta A}$, where $\Delta A$ is the cross area of one bar as defined by Westeneng, multiplied by a certain height $\mathrm{S}$. To be able to incorporate this effect in the energy relations of the contact model of Westeneng a distance needs to be specified over which the shear stresses are acting. This height $S$ is used as a fitting parameter to fit this extended contact model on the measurements of Pullen and Williamson, as mentioned before. Furthermore, it is assumed that only the bars which are in contact with the counter surface contribute to this shearing effect. The bars which are not in contact with the counter surface all rise with the same amount $U$, which means there is no shearing effect between these bars. It has to be noted that each bar has four sides on which this shearing effect may take place. However, if four sides were to be taken into account for each bar, each shearing movement would be calculated twice, once for each of the two bars it influences. This effect is compensated by calculating two sides for each bar in the calculations.

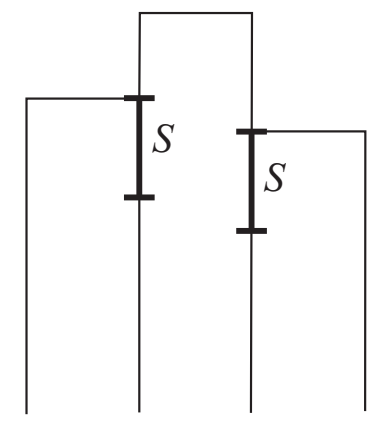

Figure 5.6 Shear term between the bars working on surface $S$.

With the above assumption an extra energy term is defined which is added to the internal absorbed energy equation, Eq. (5.5), of the original Westeneng contact model.

$$
W_{\mathrm{int}}^{a b s}=\sum_{k=1}^{N} H \Delta A \Delta z_{k}+2 \sum_{k=1}^{N} k \sqrt{\Delta A} S \cdot S
$$

As in Westeneng this can be rewritten ${ }^{1}$ as

\footnotetext{
${ }^{1}$ This is allowed only if the cross area of the bars is square.
} 


$$
W_{\mathrm{int}}^{a b s}=\varsigma_{2} H A_{r} \hat{\Delta} z_{k}+2 k A_{r} \frac{S^{2}}{\sum_{k=1}^{N} \sqrt{\Delta A}}
$$

The internal energy required for the rise of the valleys stays the same as in the original Westeneng model. This also holds for the external energy needed to indent the asperities. Therefore the total energy equation becomes

$$
\begin{gathered}
W_{e x t}=W_{\mathrm{int}}^{a b s}+W_{\mathrm{int}}^{r i s e} \\
\zeta_{1} F_{N} \hat{\Delta} z_{k}=\zeta_{2} H A_{r} \hat{\Delta} z_{k}+2 k A_{r} \frac{S^{2}}{\sum_{k=1}^{N} \sqrt{\Delta A}}+\eta \zeta_{3} H\left(A_{r}-N^{* * \Delta A}\right) \hat{\Delta} z_{k}
\end{gathered}
$$

Rewriting and using the relations between $\zeta_{1}, \zeta_{2}, \zeta_{3}$ and $\xi$ as given by Westeneng [47] gives

$$
\frac{F_{N}}{H}=\xi A_{\text {nom }}+2 k \frac{A_{r}}{H} \frac{S^{2}}{\sum_{k=1}^{N} \sqrt{\Delta A} \hat{\Delta} z_{k}}+\eta \xi c(d, U) \cdot\left(A_{r}-N^{* *} \Delta A\right)
$$

To obtain the required relation for pressure instead of force, this relation is divided by $A_{\text {nom. }}$

$$
\frac{p_{\text {nот }}}{H}=\xi+2 k \alpha \frac{S^{2}}{H \sum_{k=1}^{N} \sqrt{\Delta A}} \frac{F_{N}}{\sum_{k=1}^{N} F_{N k} \Delta z_{k}}+\eta \xi c(d, U) \cdot\left(\alpha-\frac{N^{* *} \Delta A}{A_{\text {nот }}}\right)
$$

Equivalent to Westeneng this is equal to

$$
\frac{p_{\text {nom }}}{H}=\xi\left(1+\eta c(d, U)\left[\alpha-\int_{d-U}^{d} \varphi(z) d z\right]\right)+2 k \alpha \frac{S^{2}}{H \sum_{k=1}^{N} \sqrt{\Delta A}} \frac{F_{N}}{\sum_{k=1}^{N} F_{N k} \Delta z_{k}}
$$

where

$$
\frac{F_{N}}{\sum_{k=1}^{N} F_{N k} \Delta z_{k}}=\frac{Q_{b} \int_{d-U}^{\infty} F_{N}(z) \varphi(z) d z}{\int_{d-U}^{\infty} F_{N}(z) \Delta z \varphi(z) d z}
$$

As in the original model, $\Delta z$ is defined in Eq. (5.21), $\xi$ is given by Eq. (5.22) and $\mathrm{Q}_{b}$ is the total number of bars per calculation domain. The new pressure relation Eq. (5.40) contains a geometry term which is calculated as follows.

$$
\sum_{i=1}^{N} \sqrt{\Delta A}=\sqrt{\alpha} L_{d}
$$

The length of a calculation domain $L_{d}$, is explained in Section 5.3. 


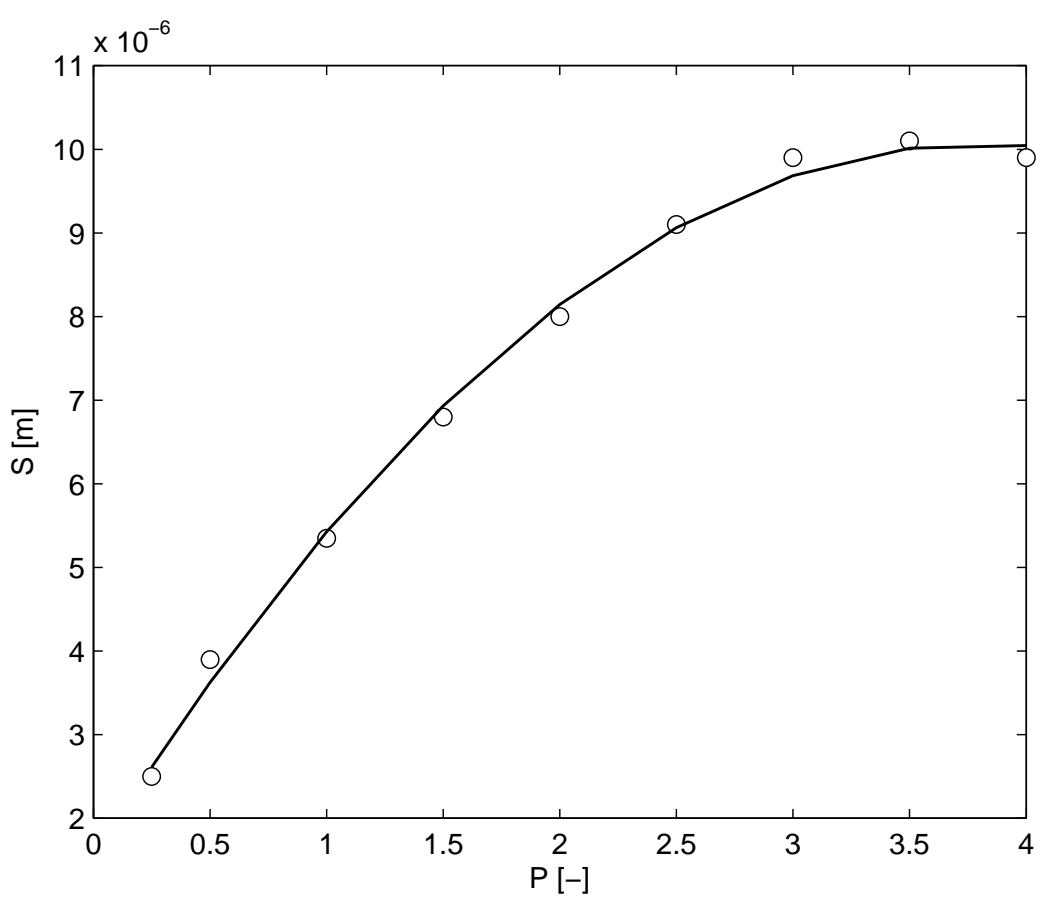

Figure 5.7 Shearing height $S$ as a function of the dimensionless load $P$. The dots represent the measurements of Pullen and Williamson, the line the fit function Eq. (5.43).

The calculation scheme of the contact model as depicted in Figure 5.4 is adapted with this new pressure relation, Eq. (5.40). Finally this extended contact model is fitted on the experimental data of Figure 5.5 of Pullen and Williamson [51] in a pressure range of 0 to 4 times the hardness. As mentioned earlier Pullen and Williamson do not specify the exact aluminium alloy used in their experiments. As noted before, for the fitting calculations a standard soft aluminium is assumed with a yield stress of $100 \mathrm{MPa}$. For 9 pressures in the specified pressure range the contact model is fitted on the experimental data by varying $\mathrm{S}$. With these nine points a curve fit is calculated using Matlab, see Figure 5.7.

$$
S=-0.590 \cdot 10^{-6} P^{2}+4.49 \cdot 10^{-6} P+1.53 \cdot 10^{-6}
$$

It can be seen in Figure 5.7 that at higher pressures the area on which strain occurs is higher. The shear height $S$ increases with increasing load and saturates at a value of approximately $1 \cdot 10^{-5} \mathrm{~m}$ which is in the order of the surface roughness. Consequently, the values of $\mathrm{S}$ obtained in the fit are physically relevant.

\subsection{Bulk strain effect}

The presence of bulk strain influences the surface roughness and the friction between tool and workpiece. Because of the plastic bulk deformation of the workpiece material the asperities deform more easily. This can be expressed as a decreasing effective hardness and an increasing real area of contact compared to the situation with only normal loading. As mentioned earlier, contact models including bulk strain have been developed for wedge-shaped asperities. Wilson and Sheu [48] assume wedge-shaped asperities with a 
constant slope and a strain direction parallel to the orientation of the asperities. The length of the asperities is much larger than the width, therefore a plane-stress situation is assumed. Wilson uses an upper bound analysis, which results in an overestimated effective hardness and an underestimated real area of contact.

Sutcliffe [49] developed a contact model for the same geometry of the asperities, except that the strain is directed perpendicular to the direction of the asperities. Sutcliffe uses a slipline analysis which will underestimate the effective hardness and therefore overestimate the real area of contact, [49].

However, the actual geometry of the surface during hydrostatic extrusion of the billet does not consist of wedge-shaped asperities. Therefore Westeneng [47] introduces an extension to his contact model to model the influence of bulk strain for any surface geometry. The contact situation can be seen in Figure 5.8.

Westeneng assumes that the application of the normal load results in a roughness distribution $\varphi_{L}(\mathrm{z})$, a separation $\mathrm{d}_{\mathrm{L}}$ and a rise of the valleys $\mathrm{U}_{\mathrm{L}}$. When the material is subjected to a bulk strain the material shows additional flattening. This is expressed as an additional rise of the valleys $U_{s}$, resulting in a separation $d_{s}$. In the bulk strain phase volume conservation is also assumed.

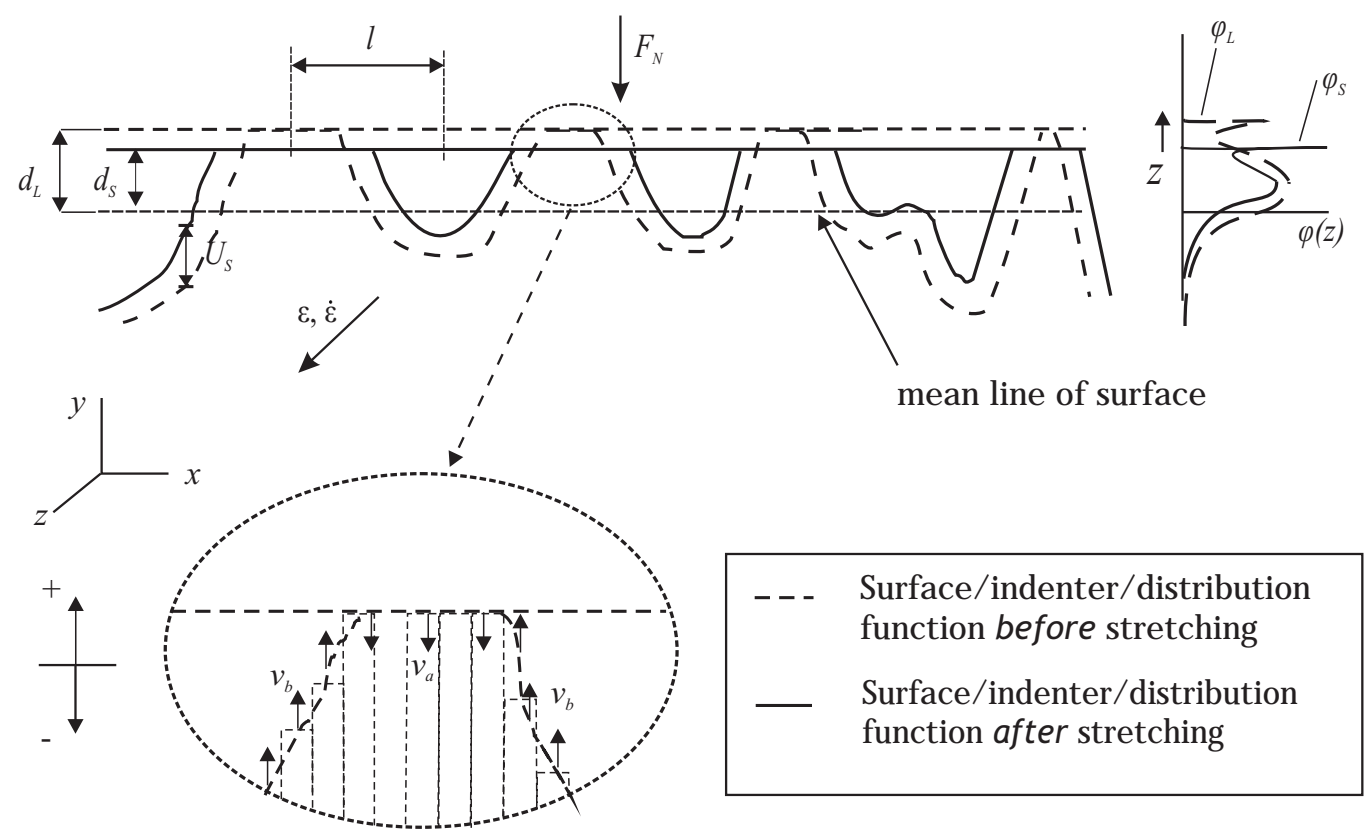

Figure 5.8 The contact between the rough billet and the smooth die with the effect of the bulk strain, picture taken from [47].

The starting point is again that the asperities are represented with bars. A fraction of real area of contact is defined for this asperity as $\hat{\alpha}$. The change of $\hat{\alpha}$ as a function of the nominal strain $\varepsilon$ can, for an infinitesimally small change of strain $\varepsilon$, be written as $d \hat{\alpha} / d \varepsilon$. The unit time of the strain is defined as $t_{s}$ and the flattening distance $w_{S}$ corresponds to 
the definition of flattening speed $v_{a}+v_{b}$ by [48], see also Figure 5.8. Now $d \hat{\alpha} / d \varepsilon$ can be written as

$$
\frac{d \hat{\alpha}}{d \varepsilon}=\frac{d \hat{\alpha}}{d w_{S}} \frac{d w_{S}}{d t_{S}} \frac{d t_{S}}{d \varepsilon}
$$

The flattening distance is defined as

$$
w_{S}=d_{L}-d_{S}+U_{S}
$$

Using this, the first term of the right hand side of Eq. (5.44) can be written as

$$
\frac{d \hat{\alpha}}{d w_{S}}=\frac{d \hat{\alpha}}{d\left(U_{S}-d_{S}\right)}
$$

Defining $v_{a}$ as the indentation speed and $v_{b}$ as the upward speed of the free surface as defined in Figure 5.8, the second term of Eq. (5.44) can be written as

$$
\frac{d w_{S}}{d t_{S}}=v_{a}+v_{b}
$$

Combining these results Eq. (5.44) can now be written as

$$
\frac{d \hat{\alpha}}{d \varepsilon}=\frac{d \hat{\alpha}}{d\left(U_{S}-d_{S}\right)} \frac{v_{a}+v_{b}}{\dot{\varepsilon}}
$$

Now the definition of the non-dimensional strain rate $E$ of Wilson [48] is used.

$$
E=\frac{\dot{\varepsilon} l}{v_{a}+v_{b}}
$$

Where $\mathrm{I}$ is the mean half asperity spacing as also depicted in Figure 5.8 and explained in Section 5.3. Equation (5.48) can now be written as

$$
\frac{d \hat{\alpha}}{d \varepsilon}=\frac{l}{E} \frac{d \hat{\alpha}}{d\left(U_{S}-d_{S}\right)}
$$

To calculate the non-dimensional strain rate $E$ the non-dimensional effective hardness $H_{\text {eff }}$ is required. This is calculated with the definition of Wilson [48].

$$
H_{\text {eff }}=\frac{p_{\text {nom }}}{\alpha k}
$$

The relation between the effective hardness and the non-dimensional strain rate $E$ is defined differently by several people. Here the numerical analysis of Korzekwa [56] is 
used, because this gives a better representation also for higher non-dimensional strain rates $\mathrm{E}$. The numerical results are fitted by Westeneng [47] as a function of $a$ and $\mathrm{H}_{\text {eff }}$.

$$
\begin{aligned}
& \frac{1}{E}=-0.0163-0.0428 \ln (\alpha)+0.986 H_{\text {eff }}-0.0196 \ln ^{2}(\alpha)-0.487 H_{\text {eff }}^{2}- \\
& 0.329 H_{\text {eff }} \ln (\alpha)+0.0676 H_{\text {eff }}^{3}-0.0522 H_{\text {eff }}^{2} \ln (\alpha)-0.0967 H_{\text {eff }} \ln ^{2}(\alpha)
\end{aligned}
$$

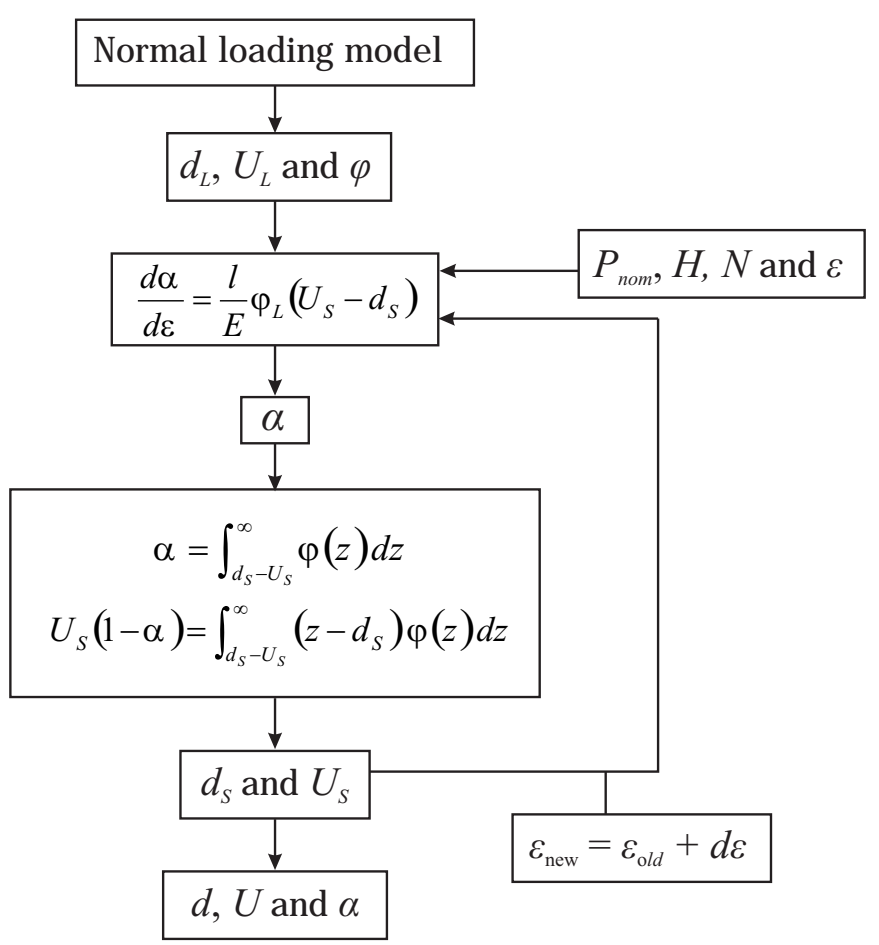

Figure 5.9 Flow chart of the contact model including bulk strain, based upon [47].

Going back to Eq. (5.50), it is assumed here that the fraction of real contact area $\hat{\alpha}$ of one asperity is equal to the total fraction of real contact area $a$. This assumption of Westeneng is made so to be able to use the general information known about the relation between a and $U_{s}, d_{s}$. If this is assumed, the definition of $a$ is given by

$$
\alpha=\int_{d_{S}-U_{S}}^{\infty} \varphi_{L}(z) d z
$$

This relation can be differentiated with respect to $\left(U_{S}-d_{S}\right)$ giving

$$
\frac{d \alpha}{d\left(U_{S}-d_{S}\right)}=\varphi_{S}\left(U_{S}-d_{S}\right)
$$

When this result is substituted into Eq. (5.50) a simple relation for $\mathrm{da} / \mathrm{d} \varepsilon$ is obtained.

$$
\frac{d \alpha}{d \varepsilon}=\frac{l}{E} \varphi_{L}\left(U_{S}-d_{S}\right)
$$


Finally the bulk strain results can be calculated according to the flow chart depicted in Figure 5.9. The strain is incrementally increased with steps $d \varepsilon$. In each step the change in $a$ is calculated and the new separation and rise of the valleys $d_{s}$ and $U_{s}$ are calculated with this new $a$. These values are used as inputs for the increment $d \varepsilon$ until the final strain is reached.

\subsection{Parameter study}

The extended contact model, i.e. including the shear term, is applied to the work zone of the hydrostatic extrusion process. Since the bulk strain part of the contact model is incremental, the calculation is stopped when an $a$ of 0.99 is reached. First a calculation is done with and without bulk strain to show its effect. For this calculation the pressure is set to a constant $p_{n o m} / H=0.5$. In Figure 5.10 the fraction of area in contact is plotted as a function of the natural strain, both for normal loading and for normal loading plus bulk strain effect. It can be seen here that the bulk strain has a significant effect on the contact area. For a natural strain of 0.5 , a already increases from 0.4 to almost 0.9 , for $\mathrm{p}_{\text {nom }} / \mathrm{H}=0.5$.

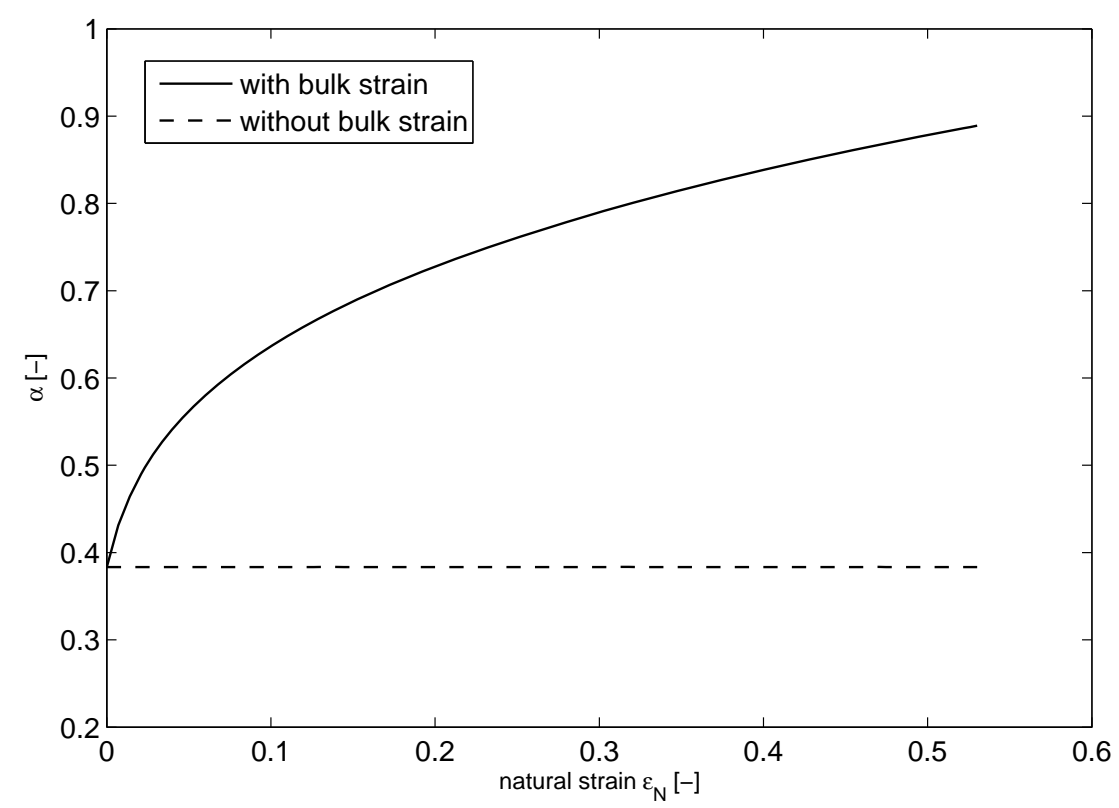

Figure 5.10 The fraction of real contact area as a function of the natural strain for $\mathbf{p}_{\text {nom }} / \mathbf{H}=\mathbf{0 . 5}$.

In the rest of this section calculations are performed for the work zone of the hydrostatic extrusion process, including the nominal contact pressure variations in the work zone as described in Section 4.3. The process parameters can be found in the reference dataset as described in Table 2.6. In Figure 5.11 is he nominal pressure in the work zone for these parameters and this material model shown. The 0 and 1 on the horizontal axis represent the beginning and end of the work zone. 


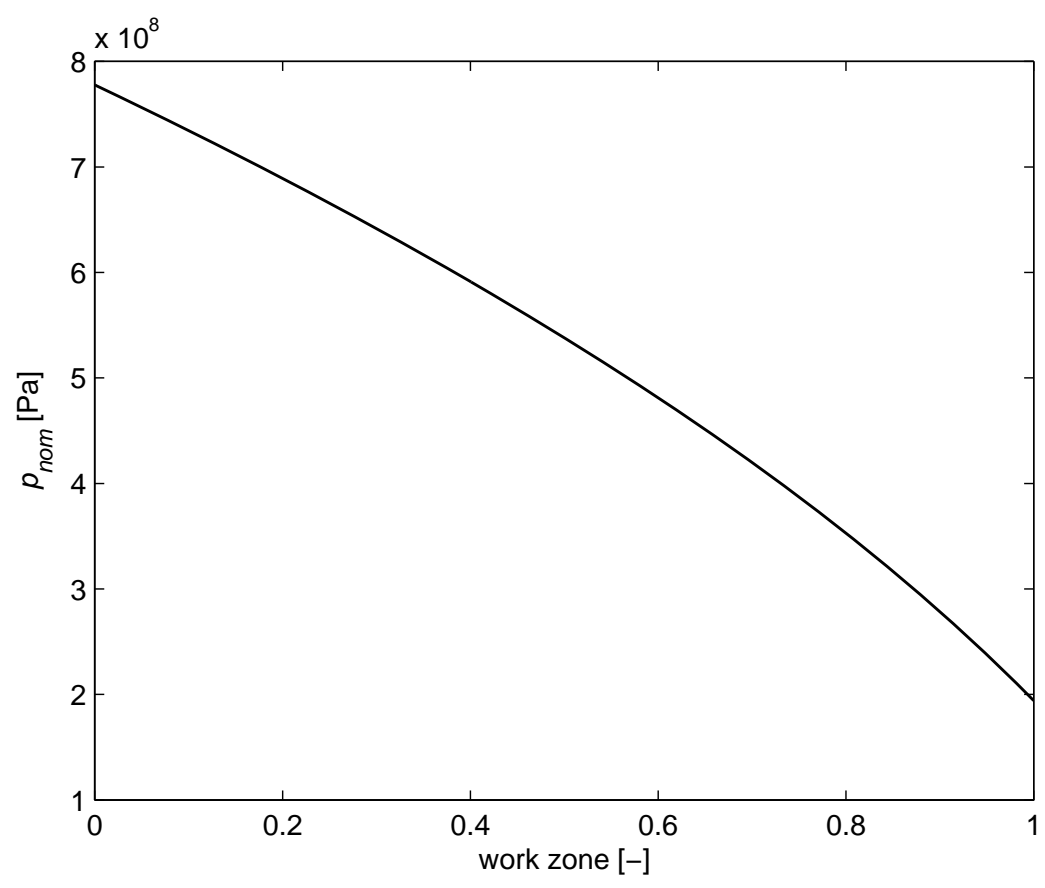

Figure 5.11 Nominal pressure in the work zone of the hydrostatic extrusion process for the reference data set.

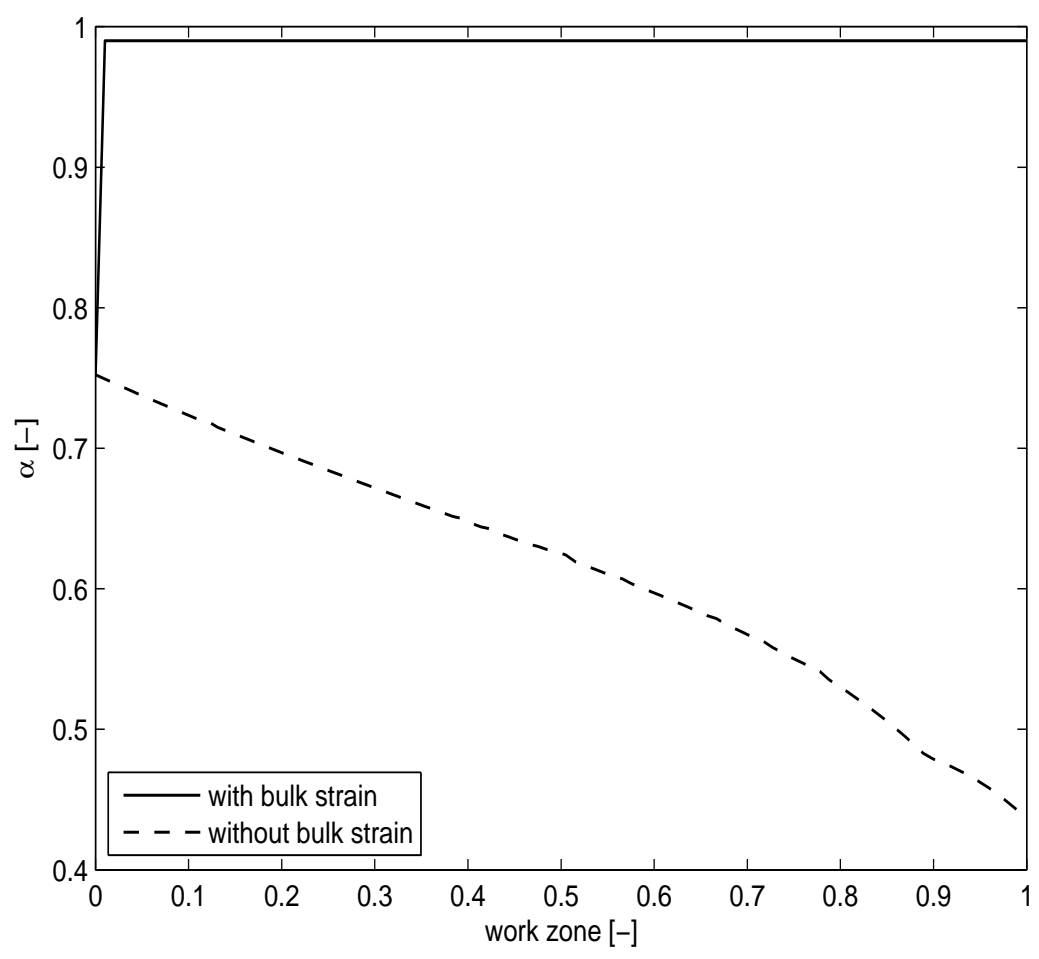

Figure 5.12 Fraction of real contact area for the reference data set.

The resulting fraction of real contact area for this dataset is presented in Figure 5.12; both $a$ after the first part of the contact model and $a$ including the bulk strain effect. It can be concluded from the figure that the fraction of real contact area increases very rapidly to 
the limiting value in the calculation of 0.99 and stays constant in the entire work zone. The fraction of real contact area without the bulk strain effect decreases in the work zone because of the decreasing nominal pressure. However the increasing bulk strain compensates this effect in the entire work zone.

It has to be noted that in the hydrostatic extrusion process there is oil in the contact between billet and die. For the contact condition used this means it is very likely that oil is being trapped in some of the valleys of the roughness as well. This trapped oil will develop a hydrostatic pressure and prevent these valleys from rising. Therefore the fraction of real contact area will most probably be less than 1 . This effect is not incorporated in the contact model.

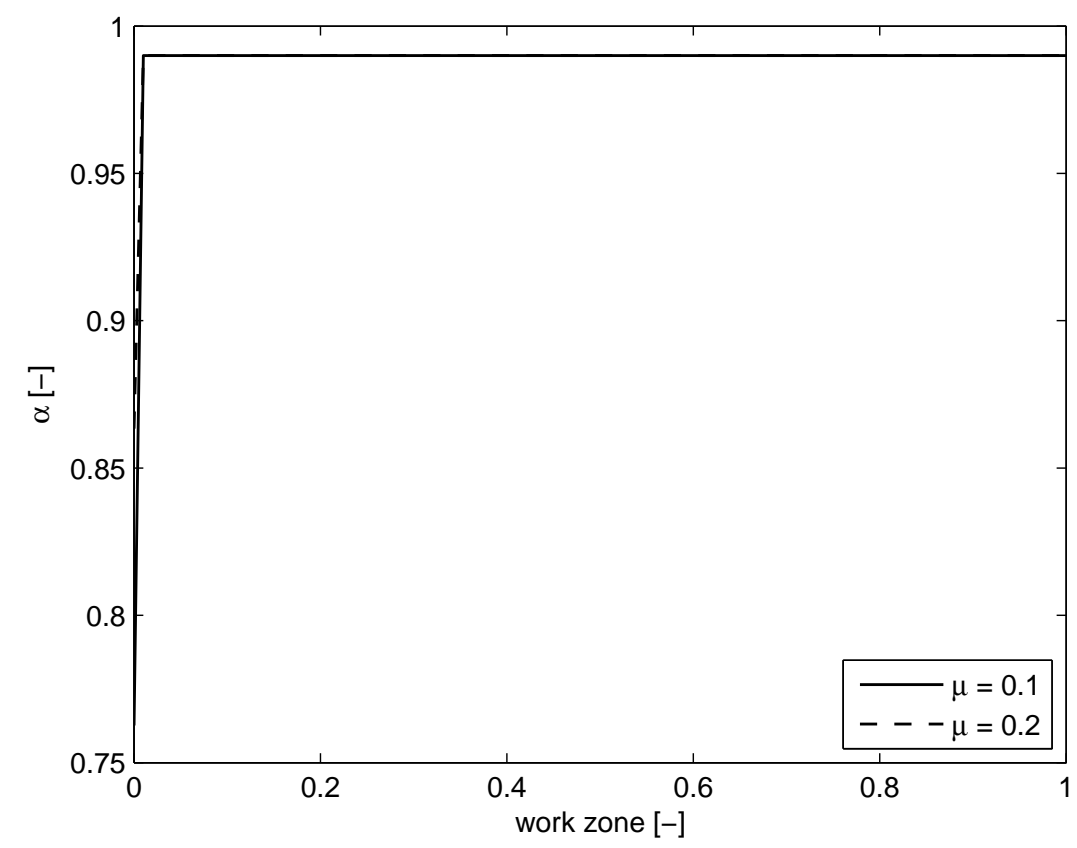

Figure 5.13 Influence of the friction coefficient on the fraction of real contact area.

Next, the influence of several process parameters is investigated. Firstly, the influence of the coefficient of friction $\mu$ is investigated, the results can be seen in Figure 5.13 . The coefficient of friction has a lot of influence on the nominal pressure in the extrusion process as is explained in Section 4.3. For a high coefficient of friction the nominal pressure is higher at the entry of the work zone, but it also decreases faster towards the exit. The fraction of real contact area is almost the same for both friction coefficients. It increases very rapidly to almost 1 and stays constant in the entire work zone.

Furthermore, the influence of other process parameters on the fraction of real area of contact is investigated. The hydrostatic extrusion pressure $q$ is varied between 0.6 and $0.8 \mathrm{GPa}$. The semi die angle $\theta$ is varied between 30 and 550. The yield stress $\sigma_{\mathrm{y}}$ is varied between 80 and $150 \mathrm{MPa}$. And finally, the roughness of the billet material $\mathrm{R}_{\mathrm{q}}$ is varied 
between 3 and $10 \mu \mathrm{m}$. The results are all similar to the previous results and are therefore not shown.

To investigate the effect of the amount of bulk strain a calculation is also performed for a rather low extrusion ratio. A billet is extruded from $73 \mathrm{~mm}$ diameter to $68 \mathrm{~mm}$ diameter, resulting in an extrusion ratio of 1.15 . The rest of the process parameters are as the standard data set, see Table 2.6. The resulting fraction of real contact area $a$ both after normal loading and including the bulk strain effect can be found in Figure 5.14. It can be seen that the results are very similar to the results for the standard data set of Figure 5.12. The real area of contact increases to almost 1 a bit further in the work zone area and is constant in the rest of the work zone area.

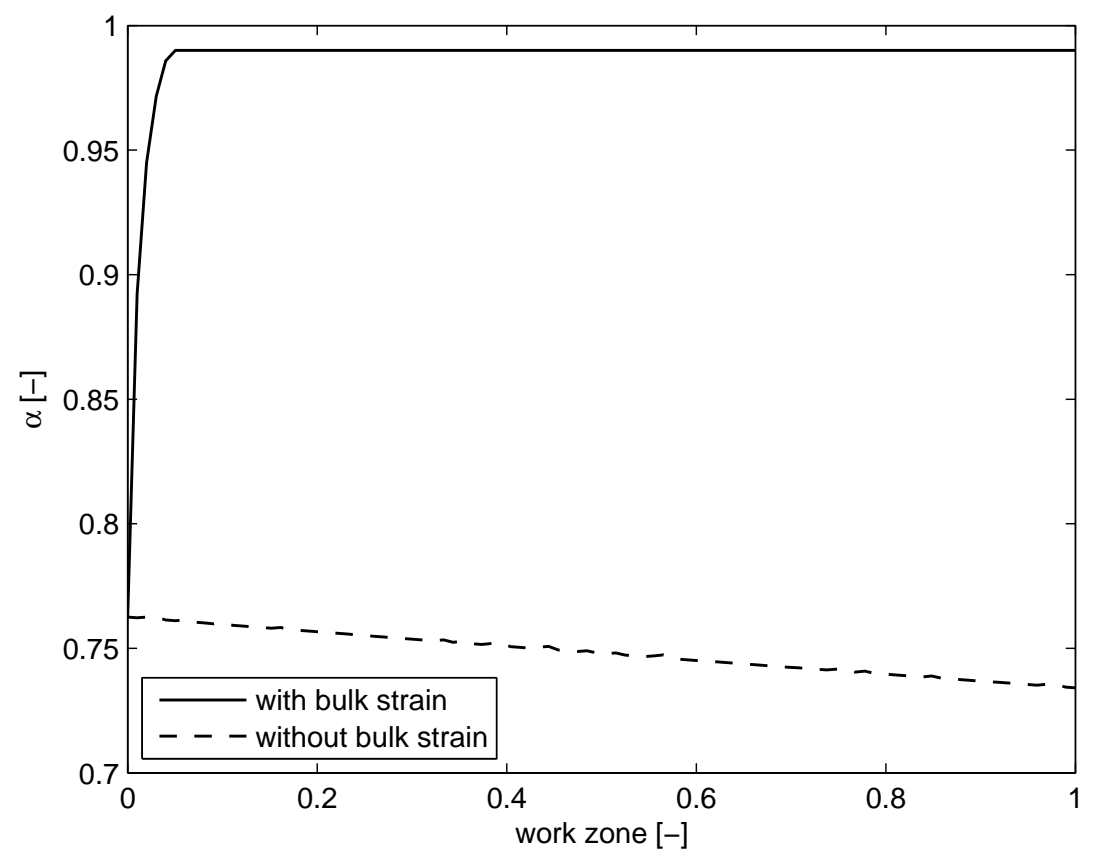

Figure 5.14 The fraction of real contact area for an extrusion from 73 to $68 \mathrm{~mm}$ diameter.

Finally, a simulation is performed with the same low extrusion ratio as mentioned above and the hydrostatic extrusion pressure is reduced to $10 \%$ of its original value. The resulting real area of contact can be found in Figure 5.15. The simulated conditions here are very close to wire drawing process conditions as will be further discussed in Chapter 6 . It can be seen from Figure 5.15 that the calculated real area of contact both after normal loading and including the bulk strain effect are significantly lower than in the previous calculations. The results show that the calculated real area of contact in hydrostatic extrusion is very high due to the high nominal pressure in combination with the high bulk strain. 


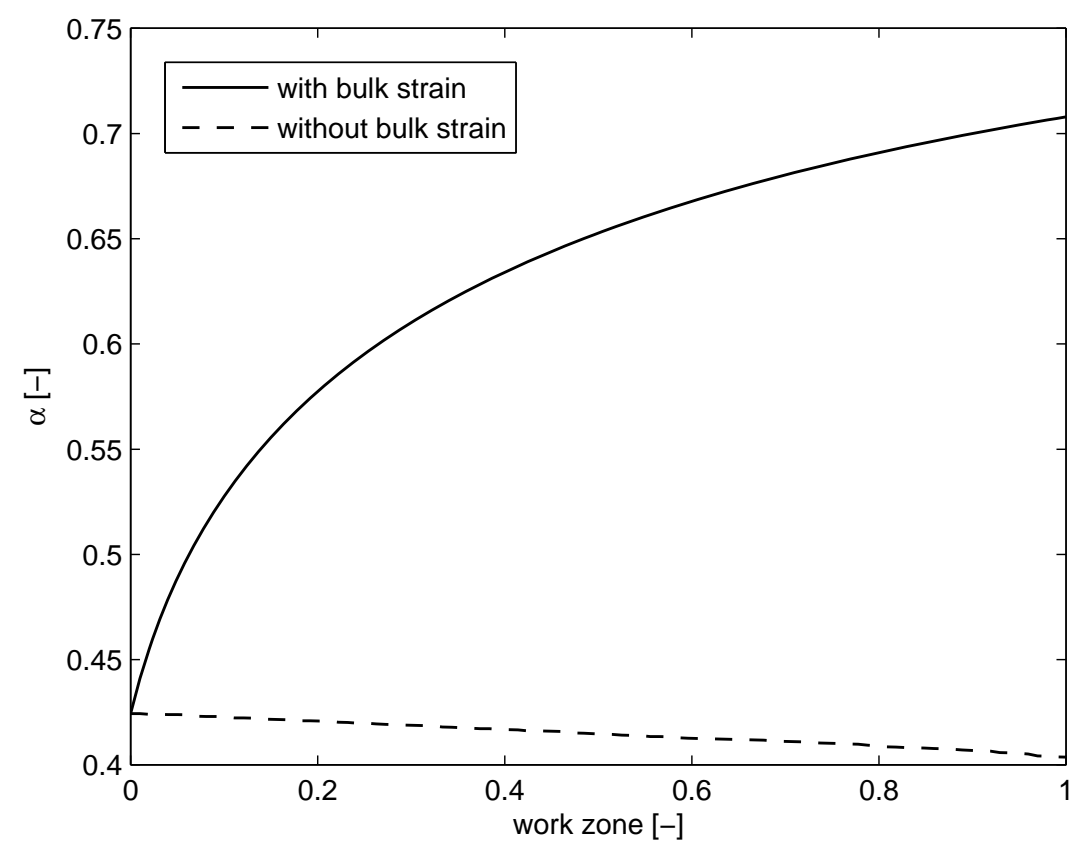

Figure 5.15 The fraction of real contact area for an extrusion from 73 to $68 \mathrm{~mm}$ diameter with a reduced hydrostatic pressure of $60 \mathrm{MPa}$.

\subsection{Conclusions}

To be able to simulate the contact between the billet and the die in the hydrostatic extrusion a contact model is developed. This contact model includes bulk strain effects and is suitable for any surface roughness geometry. The work zone of the hydrostatic extrusion process is simulated with this contact model.

- The developed contact model, including shear, is fitted to the measured results of Pullen and Williamson up to pressures in the order of four times the hardness, as required for the hydrostatic extrusion process.

- The bulk strain part of the Westeneng model is added to the extended normal loading part of the contact model to incorporate the influence of the bulk strain.

- Results show that the fraction of real area in contact $a$ increases rapidly to almost one and stays constant in the entire work zone area for typical hydrostatic extrusion conditions.

- For low extrusion ratios and low extrusion pressures, the fraction of area in contact is increasing towards the exit of the extrusion process and reaches values around $a=0.5$ to $a=0.7$. These contact conditions in the work zone are similar to, for instance, the condition in the wire drawing process. 


\section{Chapter 6}

\section{Application to wire drawing}

The lubrication and contact models developed for hydrostatic extrusion in this work can also be used for other axisymmetrical forming processes. Examples of such processes are rod drawing, tube drawing with a moving or stationary mandrel and wire drawing with or without a mandrel. As an example, in this chapter the model is applied to the wire drawing process without a mandrel. In the first section the wire drawing process is explained. Section 6.2 explains the models needed for the wire drawing process. In Section 6.3 a case from literature will be analysed using the developed theory for the drawing of an aluminium wire with oil used as lubricant. In Section 6.4 a case is investigated with a stainless steel wire and sodium stearate soap as lubricant. Finally, conclusions will be drawn in Section 6.5.

\subsection{Production process}

In the wire drawing process a wire is pulled through a die in order to reduce the diameter of its cross-section. The die can have different shapes, but here only a conical die is studied. This process can be performed submerged in a lubricant, dry where the wire is pulled through a box of lubricant or using a solid lubricant like a polymer or a soft metal. In wire drawing the die angles and the reductions per pass are small: die angles in the order of 80 and reductions in the range 10 to $50 \%$ In industry, wire drawing is usually a multi-pass process, where the wire is pulled through a series of dies to reduce the wire to its desired final diameter. All kinds of material can be drawn, e.g. different kinds of steel, aluminium and copper. The wires produced are used in many applications, such as fencing, concrete reinforcement, electrical wiring, musical instruments and shopping carts.

A schematic wire drawing process and the variables used in this chapter can be seen in Figure 6.1. The principal differences between the wire drawing process and the hydrostatic extrusion process are the small die angles and reduction ratios in wire drawing, and the method of applying the deformation force. In hydrostatic extrusion the force is applied by compressing the original billet, in wire drawing a tensile stress is applied to the drawn wire. Sometimes in the wire drawing process not only is a tensile stress applied to the wire at the exit of the die but also a lower tensile stress is applied to the wire at the entry side of the die. This phenomenon is called back-pull and will be discussed in more detail in the 
next section. In this chapter the wire drawing process with a conical die is studied with sufficient lubricant present in the contact between wire and die.

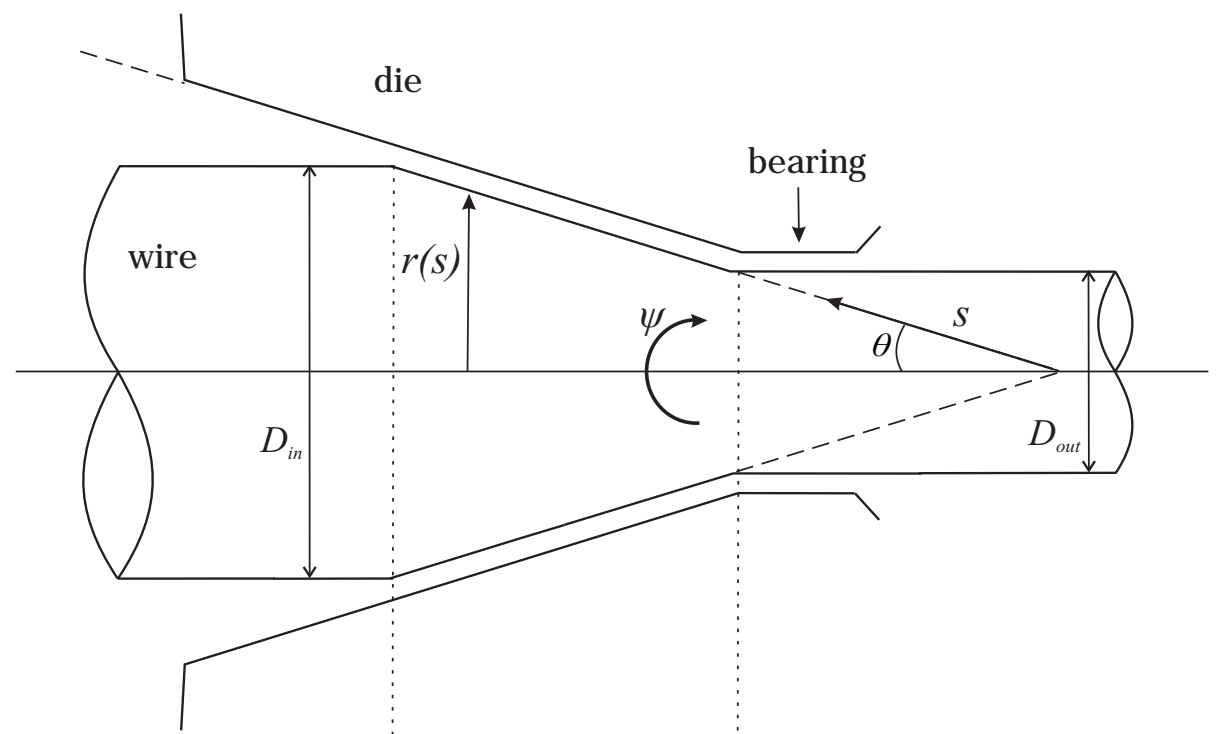

Figure 6.1 Schematic wire drawing process with its variables.

\subsection{Modelling friction in wire drawing}

The friction phenomena in the wire drawing process are modelled in a similar way to the hydrostatic extrusion process. This means that an inlet zone simulation is performed to calculate the central film thickness $h_{0}$ at the entry of the work zone. The film thickness between wire and die in the work zone of the wire drawing process is modelled based on the full film lubrication assumption, as was done in Chapter 4 of this work. After that a contact simulation is performed to calculate the ratio of area in contact in the work zone. The results of these calculations will give a good estimate of the friction phenomena that may take place in the wire drawing process.

The inlet film thickness calculation can be performed with the analytical solution of Eq. (3.20), if the viscosity of the lubricant is modelled using the Barus equation, Eq. (2.10). If the viscosity is modelled with Roelands relation, Eq. (2.11), the numerical iteration depicted in Figure 3.7 is used.

The film thickness in the work zone of the wire drawing process is modelled based on the same assumptions as in Chapter 4. Similar to the hydrostatic extrusion process a conical die is assumed, therefore also a conical coordinate system is used, as can be seen in Figure 6.1. The Reynolds equation in conical coordinates as derived in Chapter 4 is used to model the film thickness between billet and die in the work zone area of the wire drawing process, as given below. 


$$
\frac{1}{12 \eta s} h^{3}(s) \frac{\partial p}{\partial s}+\frac{1}{12 \eta} h^{3}(s) \frac{\partial^{2} p}{\partial s^{2}}=\frac{1}{2 s} U_{s} h+\frac{1}{2} h \frac{\partial U_{s}}{\partial s}+\frac{U_{s}}{2} \frac{\partial h(s)}{\partial s}
$$

The central film thickness from the inlet film thickness calculation is used as the required boundary condition to solve this differential equation.

The fraction of real area in contact is calculated using the developed contact model which is presented in Chapter 5. The flow chart of the numerical simulation of the contact model is depicted in Figure 5.9.

To perform these simulations of the film thickness several input parameters are required, e. g. the viscosity of the lubricant $\eta$, the round off radius from inlet to work zone $R$ and the nominal pressure in the contact between wire and die $p_{\text {nom. }}$. The derivation of the latter will be discussed here first.

The nominal contact pressure between wire and die $p_{\text {nom }}$ is modelled based on the slab method explained in Section 4.2. A cross-sectional element of the wire is considered and the force equilibrium on this element is derived as is shown for hydrostatic extrusion in Figure 4.4 and Figure 4.5. The formulas derived for the hydrostatic extrusion process can be used directly if the boundary condition is adapted. When the back-pull tension stress is applied as the boundary condition the nominal stress and the axial stress in the work zone of the wire drawing process are:

$$
\begin{gathered}
\sigma_{x}=\sigma_{b}\left(\frac{D^{2}}{D_{i n}^{2}}\right)^{(B-1)}+\frac{B}{B-1} \sigma_{y}\left[1-\left(\frac{D^{2}}{D_{i n}^{2}}\right)^{(B-1)}\right] \\
p_{\text {nот }}=\frac{1}{1-\mu \tan \theta}\left\{\sigma_{y}+q\left(\frac{D^{2}}{D_{i n}^{2}}\right)^{(B-1)}-\frac{B}{B-1} \sigma_{y}\left[1-\left(\frac{D^{2}}{D_{i n}^{2}}\right)^{(B-1)}\right]\right\}
\end{gathered}
$$

Here is $\sigma_{\mathrm{b}}$ the back-pull stress, $\sigma_{\mathrm{y}}$ the yield stress and $\mathrm{B}$ is defined as

$$
B=\frac{1}{1-\mu \tan \theta}\left(1+\frac{\mu}{\tan \theta}\right)
$$

where $\mu$ is the friction coefficient and $\theta$ is the semi die angle. More information about the wire drawing process can be found in [57].

The nominal pressure and the axial stress are calculated based on the parameter set given in Table 6.1, (the first case study of Section 6.3). The axial stress is depicted in Figure 6.2 for three different back-pull tensions. On the horizontal axis the work zone is depicted, where 0 represents the entry and 1 the exit of the work zone area. Figure 6.3 shows the 
corresponding nominal pressures for the three different back-pull tensions. As can be clearly seen from both figures, increasing the back-pull tension increases the draw stress and lowers the nominal pressure in the work zone area, Eq. (6.2) and (6.3).

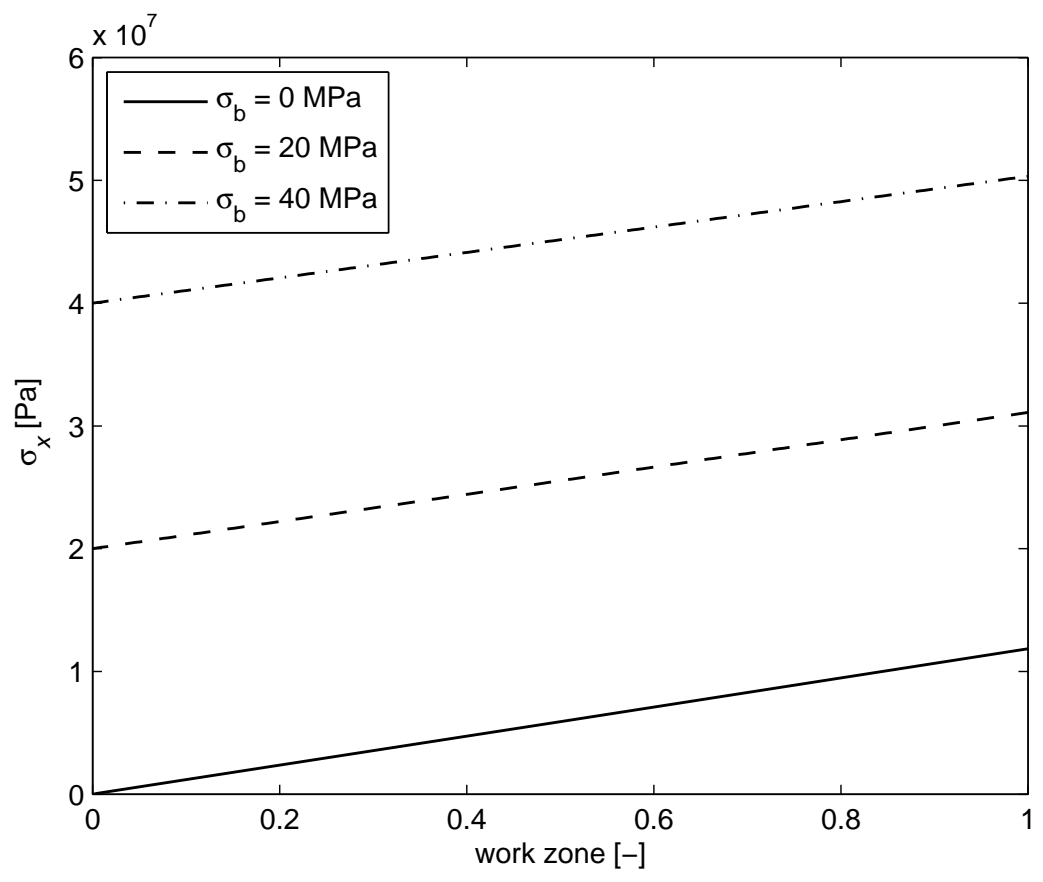

Figure 6.2 The axial stress in the work zone area of the wire drawing process for different backpull tensions.

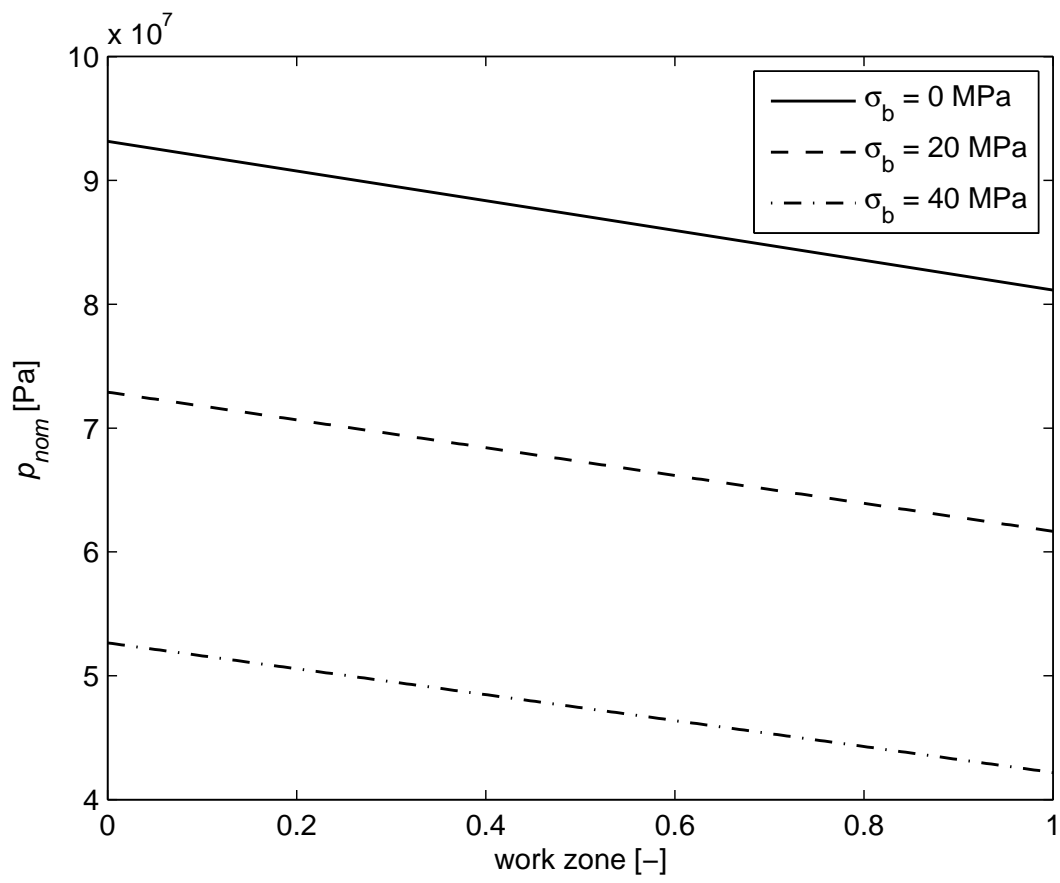

Figure 6.3 The nominal contact pressure in the work zone of the wire drawing process for three different back-pull tensions. 
For the inlet zone calculations the radius of the round edge $\mathrm{R}$ is required. For the wire drawing process the round-off radius is estimated to be $R=0.2 \mathrm{~m}$. The contact model requires a value for the roughness of the wire. Unfortunately, in the literature cases studied in the following sections the roughness is not given. Therefore the roughness of the wire when entering the work zone is estimated to be $R_{q}=2.5 \mu \mathrm{m}$. The other process parameters are taken from the cases presented in literature and will be put forward in the following sections.

\subsection{Literature case 1}

The first wire drawing case studied are experiments performed by Valberg [58]. The wire drawing experiments were performed with a softened aluminium AA6082 wire and the system is lubricated with the oil ESSO ENL 212. The process parameters used in these experiments are given in Table 6.1; the experiments are assumed to take place at $\mathrm{T}=40 \stackrel{\circ}{\circ} \mathrm{C}$.

\begin{tabular}{|l|l|l|}
\hline Symbol & Value & Description \\
\hline$\theta$ & 10 o & semi die angle \\
\hline$D_{\text {in }}$ & $9.04 \mathrm{~mm}$ & wire diameter inlet \\
\hline$D_{\text {out }}$ & $8.63 \mathrm{~mm}$ & wire diameter outlet \\
\hline$U$ & $1 \mathrm{~mm} / \mathrm{s}$ & wire velocity outlet \\
\hline$\sigma_{\mathrm{b}}$ & $0 \mathrm{MPa}$ & back tension \\
\hline$\eta_{0}$ & $119 \mathrm{mPa} \cdot \mathrm{s}^{1}$ & viscosity ENL 212 at 40 ㅇ C \\
\hline $\mathrm{z}$ & $0.6^{2}$ & Roelands pressure viscosity coefficient \\
\hline$\sigma_{\mathrm{y}}$ & $90 \mathrm{MPa}$ & average yield stress AA6082 \\
\hline$\mu$ & 0.07 & friction coefficient \\
\hline $\mathrm{F}_{\mathrm{d}}$ & $1.5 \mathrm{kN}$ & drawing force \\
\hline
\end{tabular}

Table 6.1 Process parameters from the experiments of Valberg [58].

The yield stress of the softened AA6082 was determined by tensile testing, i.e. $90 \mathrm{MPa}$ and the increase in yield stress is modelled using a power-law relation, of [58]

$$
\sigma=k \cdot \varepsilon^{n}
$$

where the strength coefficient is $k=175.15 \mathrm{MPa}$ and the strain hardening exponent $\mathrm{n}$ is 0.16 , batch 1 of [58].

The viscosity of the lubricant is modelled using the Roelands relation, Eq. (2.11), with the parameters $\eta_{0}$ and $z$ as in Table 6.1. The nominal contact pressure in the work zone of the

\footnotetext{
${ }^{1}$ Value obtained from Exxonmobil

${ }^{2}$ Estimated value based on standard mineral oil
} 
wire drawing process is calculated using Eq. (6.3) and depicted as the solid line in Figure 6.3.

For these experiments the central film thickness is calculated numerically to be $h_{0}=1.7 \cdot 10^{-8} \mathrm{~m}$. As explained previously the film thickness divided by the surface roughness gives a good indication of the lubrication regime. The roughness of the wire at the entry of the inlet zone, $R_{q}=2.5 \mu \mathrm{m}$. In the inlet zone this results in $h_{0} / R_{q}=6.8 \cdot 10^{-3}$; this value is lower than 0.1 and therefore it can be concluded that the acting lubrication regime is boundary lubrication.

The film thickness in the work zone area is calculated using the conical Reynolds equation as discussed in the previous section. The film thickness in the inlet zone is used as the boundary condition. The calculated film thickness in the work zone is shown in Figure 6.4. The film thickness decreases slightly in the work zone. The surface roughness of the wire also decreases in the work zone. An estimated value of the surface roughness of the final wire is $R_{q}=0.1 \mu \mathrm{m}$. This leads at the outlet to $h_{0} / R_{q}=0.16$, which is slightly above the transition from the boundary to the mixed lubrication regime. The conclusion therefore is that the system is most likely acting in the boundary lubrication regime, however for a smooth wire mixed lubrication is possible.

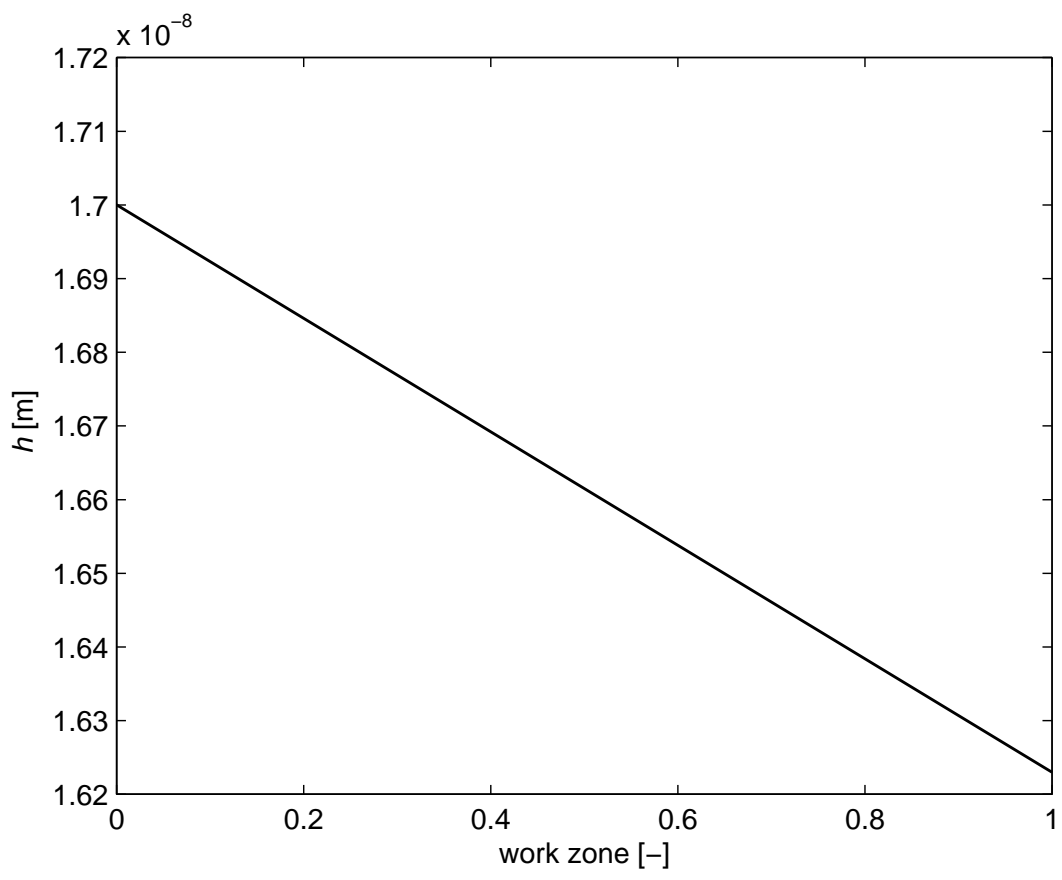

Figure 6.4 Film thickness in the work zone calculated for the experiments of Valberg [57].

Finally, the ratio of area in contact is calculated with the developed contact model of Chapter 5. The fraction of area in contact calculated without bulk strain decreases in the work zone due to the decreasing nominal pressure. If the bulk strain is incorporated in the calculation, the fraction of real contact area increases from approximately 0.3 to 0.5 . 
These values are lower than in the hydrostatic extrusion calculation, even in comparison with the calculation performed for a low extrusion ratio at a low pressure, see Figure 5.15.

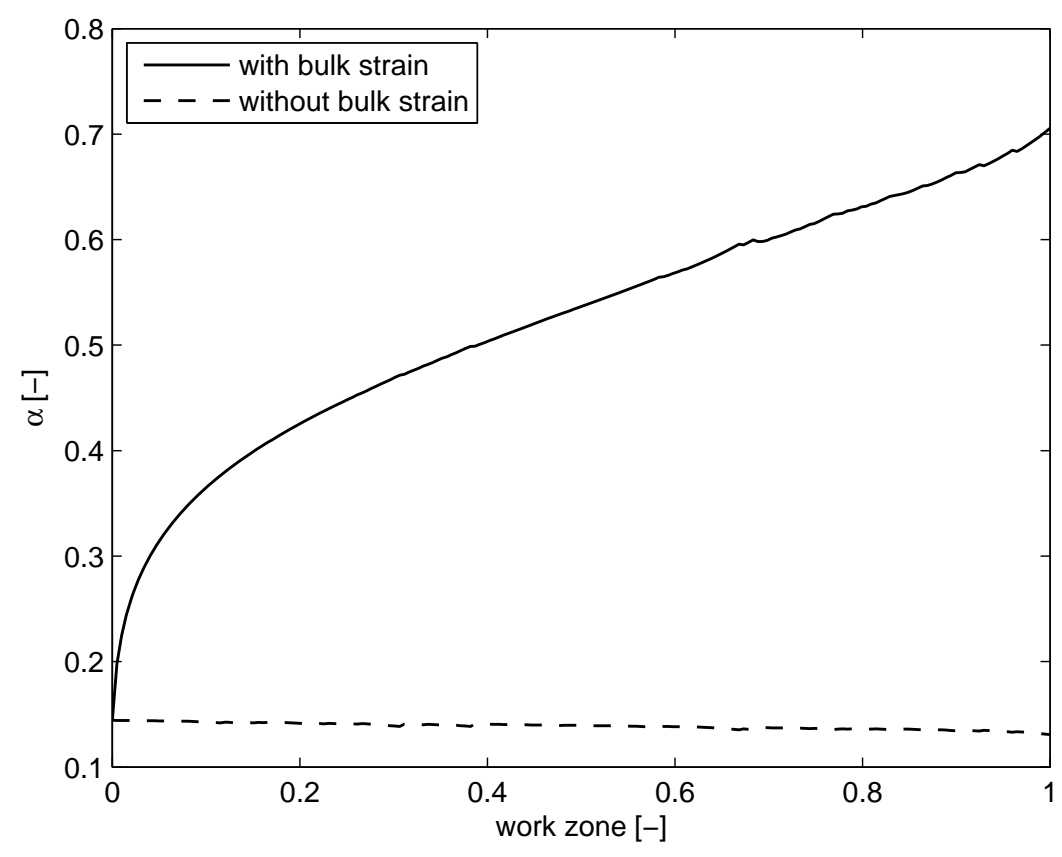

Figure 6.5 Fraction of real contact area for the experiments of Valberg [57].

The experiments of Valberg are performed at an outlet velocity of $1 \mathrm{~mm} / \mathrm{s}$. If for wire drawing a more standard velocity of $1 \mathrm{~m} / \mathrm{s}$ is used, the central film thickness becomes $h_{0}=1.7 \cdot 10^{-6} \mathrm{~m}$. For the inlet zone this will result in $h_{0} / R_{q}=1.7$; this value indicates that mixed lubrication is the prevailing lubrication regime.

The conclusion is that the experiments performed by Valberg [57] were very probably performed under boundary lubrication conditions. Depending on the roughness of the wire this could also be just above the transition from the boundary to the mixed lubrication regime. If the experiments were to be performed at a higher velocity of $1 \mathrm{~m} / \mathrm{s}$, the prevailing lubrication regime would be mixed lubrication.

\subsection{Literature case 2}

The second case studied from literature are experiments performed by Felder [59]. Felder used a stainless steel wire (AISI 304-Cu) and a sodium stearate soap lubricant (XNaLF) to perform wire drawing experiments. The process parameters used in the experiments of Felder are given in Table 6.2.

The yield stress of the stainless steel is investigated using a conventional tensile tester. The results are fitted to the relation:

$$
\sigma_{y}=\sigma_{1}(0.019+\varepsilon)^{0.4} \exp (-0.001 \Delta T)
$$


where $\Delta \mathrm{T}$ is the heating of the wire or die. The strain hardening of this stainless steel is significant. The yield stress is shown in Figure 6.6 for the relevant strain range related to Table 6.2; the yield stress varies between 235 and $765 \mathrm{MPa}$, mostly due to strain hardening.

\begin{tabular}{|l|l|l|}
\hline Symbol & Value & Description \\
\hline$\theta$ & 80 & semi die angle \\
\hline$D_{\text {in }}$ & $2.2 \mathrm{~mm}$ & wire diameter inlet \\
\hline$D_{\text {out }}$ & $1.85 \mathrm{~mm}$ & wire diameter outlet \\
\hline $\mathrm{U}$ & $0.5-3.3 \mathrm{~m} / \mathrm{s}$ & wire velocity outlet \\
\hline$\sigma_{\mathrm{b}}$ & $0 \mathrm{MPa}$ & back tension \\
\hline $\mathrm{K}_{0}$ & $0.008 \mathrm{MPa} \cdot \mathrm{s}^{\mathrm{m}}$ & shear stress constant of the soap \\
\hline $\mathrm{m}$ & 0.3 & viscoplasticity index of the soap \\
\hline $\mathrm{F}_{\mathrm{d}}$ & $700-780 \mathrm{~N}$ & drawing force \\
\hline$\Delta T$ & $25-76 \stackrel{\circ}{\mathrm{C}}$ & temperature increase depending on $\mathrm{U}$ \\
\hline
\end{tabular}

Table 6.2 Process parameters from the experiments of Felder [59].

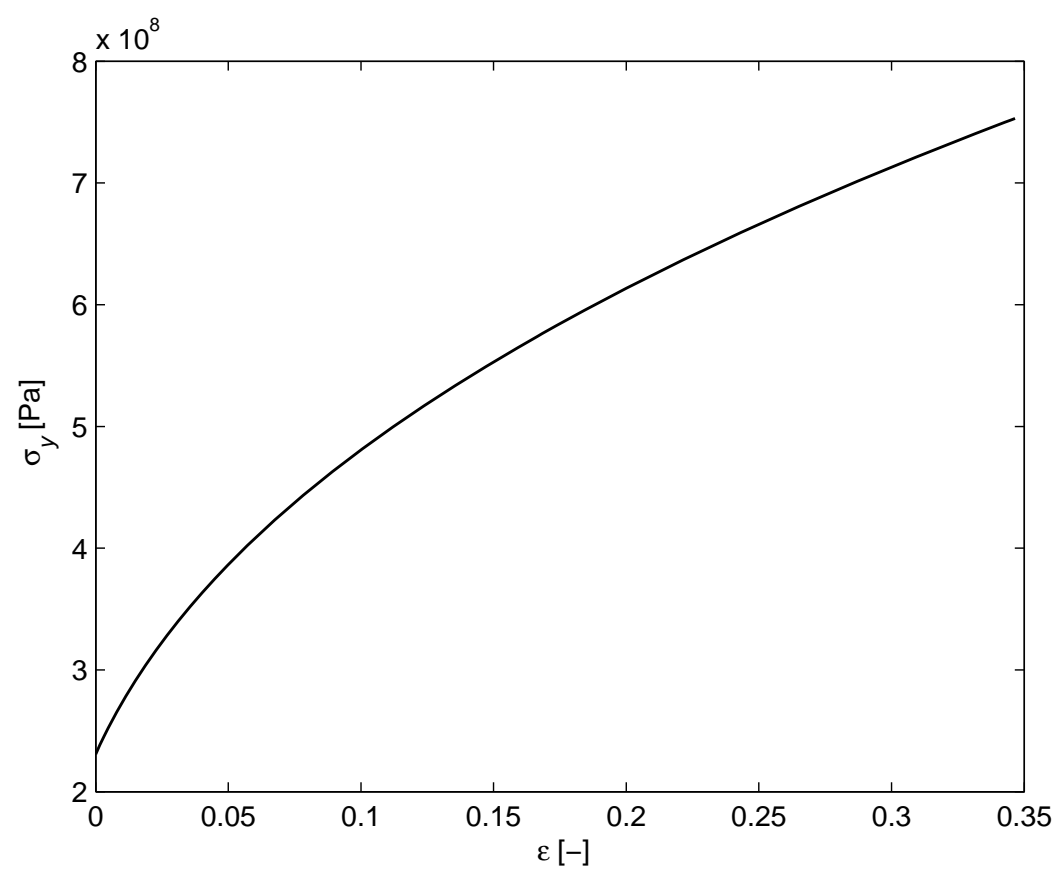

Figure 6.6 Yield stress of the stainless steel wire, AISI 304-Cu, as a function of the strain as in the experiments of Felder [59].

Before wire drawing the wire is pickled and is given a salt coating by immersing the wire in the salt solution and drying it, [59]. Felder states that this lubricant can be modelled with a non-linear viscosity law.

$$
\tau=K_{0} \dot{\gamma}^{m}
$$


where the parameters $K_{0}$ and $m$ are given in Table 6.2.

Felder performed measurements with an increasing drawing velocity from 0.5 to $3.3 \mathrm{~m} / \mathrm{s}$. The drawing force is continually measured, as is the temperature in the die close to the contact. The friction coefficient is not specified by Felder. The drawing stress is calculated using Eq. (6.2). In the calculations performed using Eq. (6.2) the friction coefficient $\mu$ is varied to determine for which $\mu$ the draw stress at the outlet is close to the value that can be calculated from $F_{d}$ and $D_{\text {out }}$ given in Table 6.2. The draw stress is in agreement with the measured value when $\mu=0.01$. Using this value, the calculated axial stress is depicted in Figure 6.7.

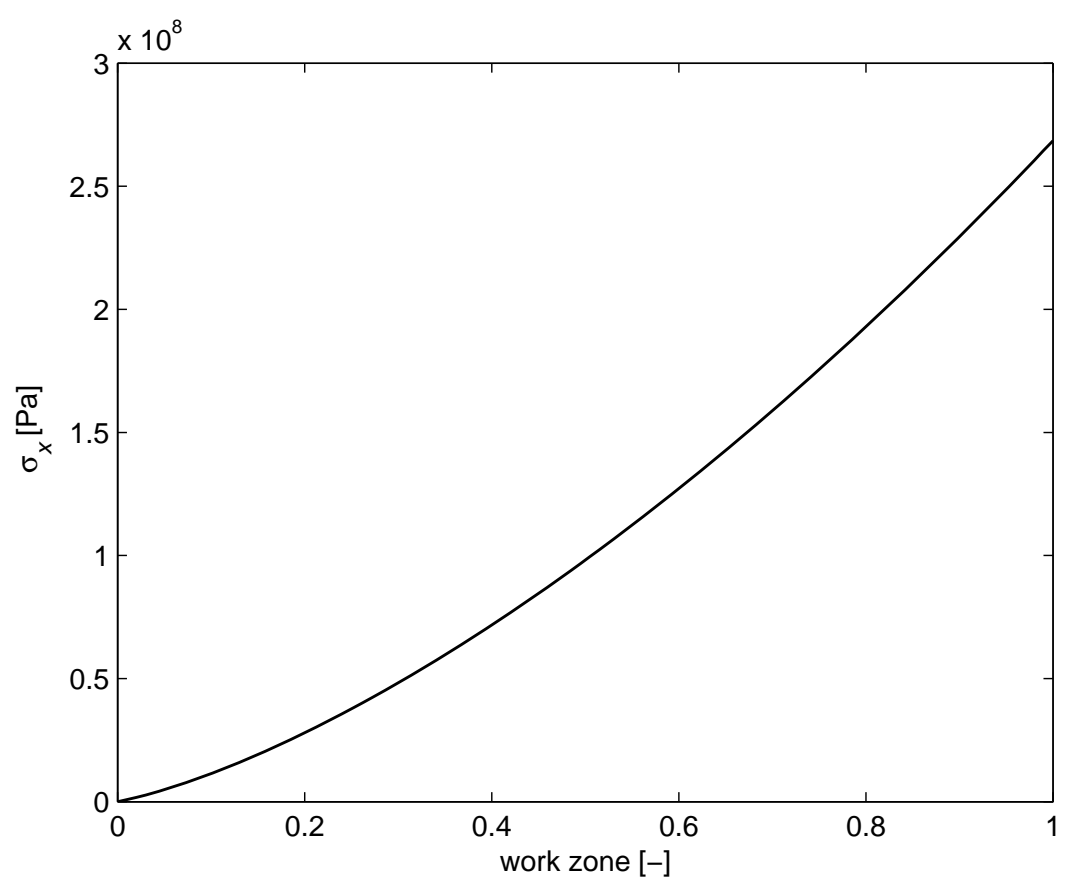

Figure 6.7 The axial stress in the work zone for the wire drawing experiments with stainless steel.

The corresponding nominal contact pressure is presented in Figure 6.8. The nominal contact pressure decreases near the exit of the work zone due to the fact that the yield stress of the stainless steel wire is increasing faster than the axial stress in the wire.

The film thickness in the inlet zone is calculated using the process parameters given in Table 6.2. For the lowest velocity at the outlet $(0.5 \mathrm{~m} / \mathrm{s})$ the central film thickness is calculated to be $h_{0}=0.84 \mu \mathrm{m}$; for the highest velocity $(3.3 \mathrm{~m} / \mathrm{s})$ the central film thickness is calculated as $h_{0}=2.9 \mu \mathrm{m}$. Dividing these values by the estimated surface roughness in the inlet zone gives $h_{0} / R_{q}=0.34 \sim 1.2$. These values indicate that mixed lubrication is the prevailing lubrication regime. 


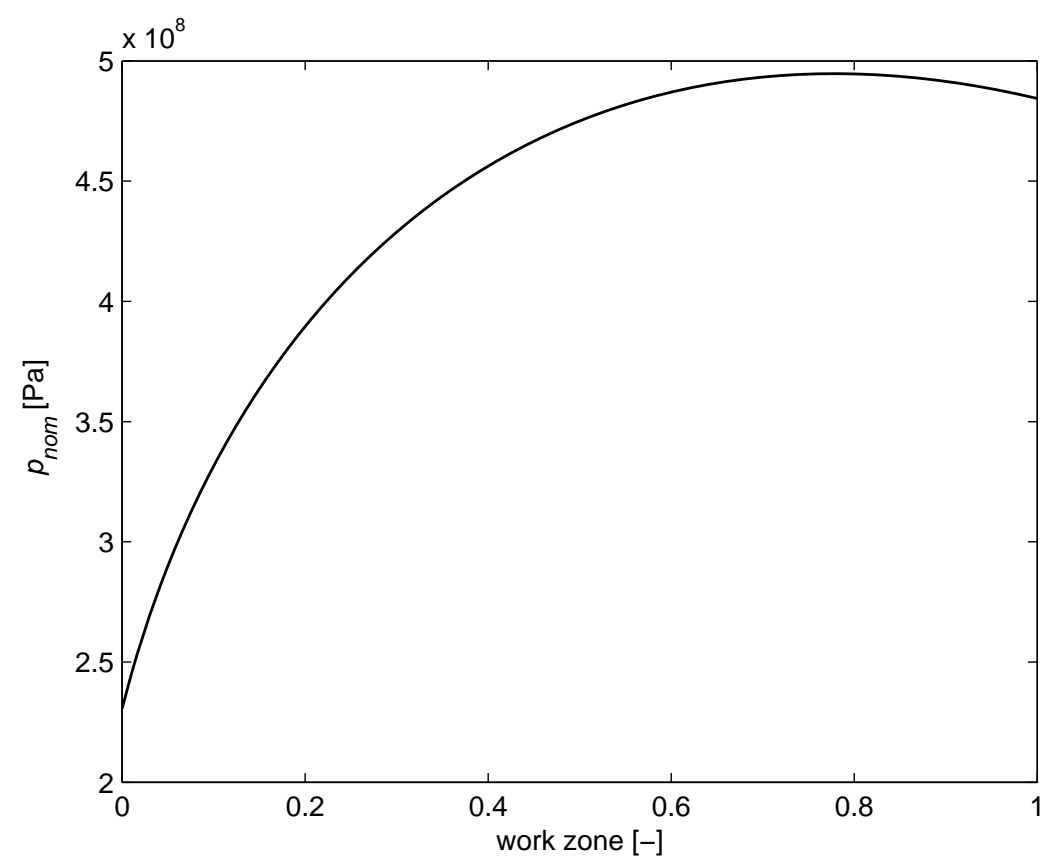

Figure 6.8 The nominal contact pressure in the work zone for the wire drawing experiments with stainless steel.

With these film thicknesses as boundary conditions, the film thickness in the work zone for the different velocities is calculated as explained previously. For the lowest velocity experiments of $U=0.5 \mathrm{~m} / \mathrm{s}$ the calculated film thickness is shown in Figure 6.9. It can be seen from Figure 6.9 that the film thickness decreases in the work zone by about $20 \%$ The surface roughness is also expected to decrease in the work zone. But even if the surface roughness were to stay constant in the work zone, at the initial value of $2.5 \mu \mathrm{m}$ the system acts in the mixed lubrication regime in the entire work zone.

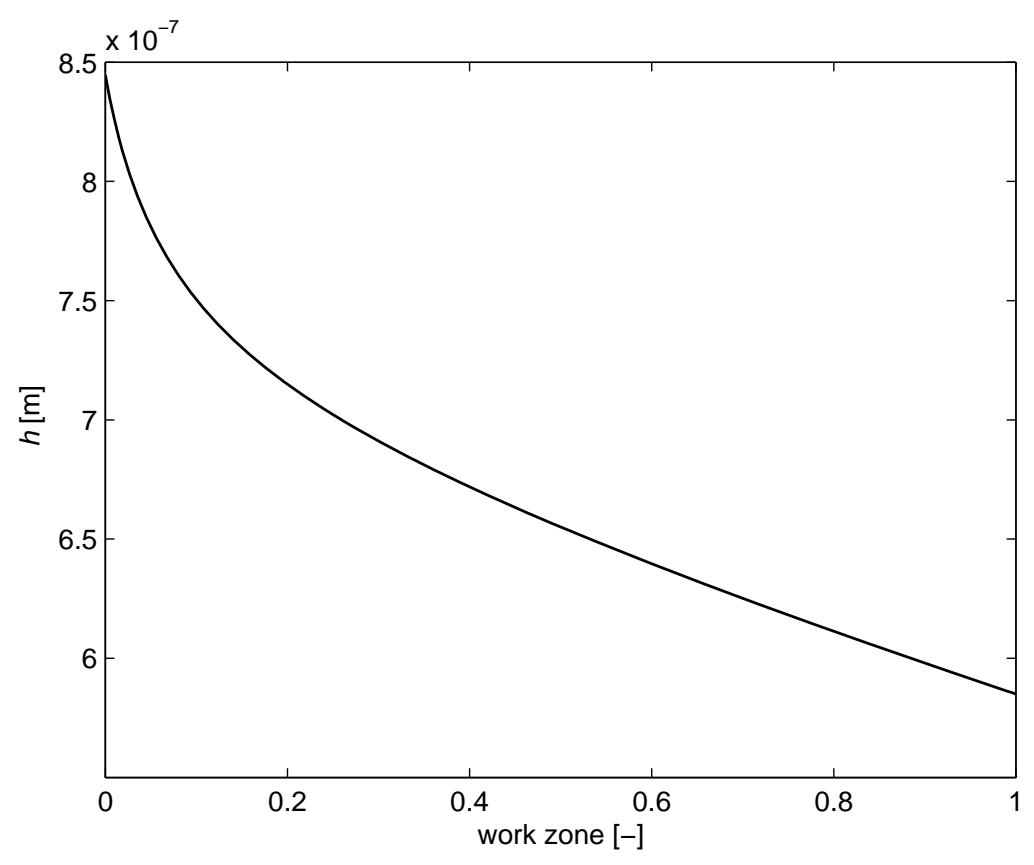

Figure 6.9 The calculated film thickness in the work zone for $U=0.5 \mathrm{~m} / \mathrm{s}$. 
In Figure 6.10 the film thickness is also calculated for the highest velocity experiment $(3.3 \mathrm{~m} / \mathrm{s})$ performed by Felder [59]. Here it can be seen that the film thickness decreases relatively more than for the lower wire velocity, approximately $50 \%$

Comparing these calculated film thicknesses to the estimated surface roughness shows that system operates in the mixed lubrication regime in the entire work zone area.

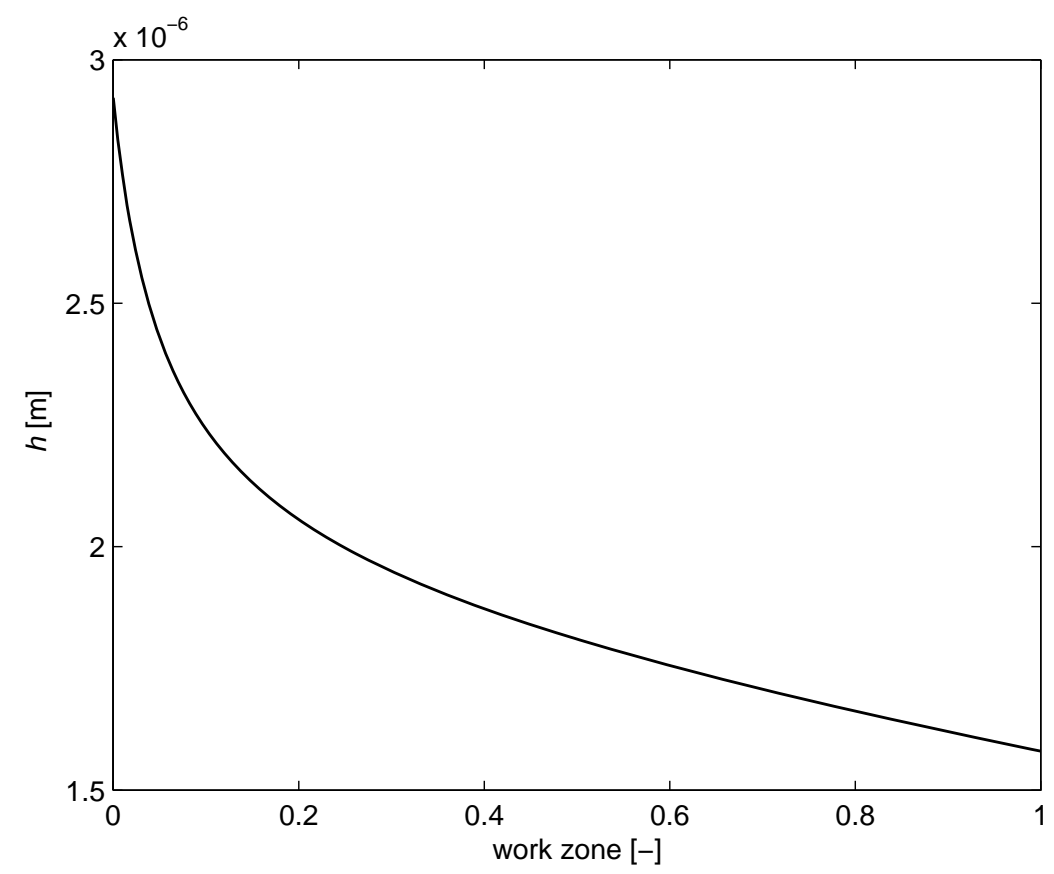

Figure 6.10 The calculated film thickness in the work zone for $U=3.3 \mathrm{~m} / \mathrm{s}$.

\subsection{Conclusions}

The models developed for the hydrostatic extrusion process are successfully applied to the wire drawing process. The lubrication models are applied to two sets of experiments taken from literature. For these wire drawing experiments the developed models give a good indication of the acting lubrication process.

In the situation with an aluminium wire and oil as lubricant at a low velocity, the experiments are most probably performed under boundary lubrication conditions. The film thickness is nearly constant throughout the entire work zone of the wire drawing process. If, however, the experiments were to be performed at a more standard velocity of $1 \mathrm{~m} / \mathrm{s}$, mixed lubrication would be the prevailing lubrication regime.

The experiments performed with a stainless steel wire and a soap as lubricant are most probably performed under mixed lubrication conditions. 


\section{Chapter 7}

\section{Conclusions and recommendations}

In this thesis contact, Iubrication and friction in the hydrostatic extrusion process are studied, in particular the extrusion of magnesium alloys. A lubrication model for the inlet zone is developed and calculations are performed using standard process conditions for the hydrostatic extrusion of magnesium. A lubrication model and a contact model are developed for the work zone area. Finally the models developed in this work are also applied to the wire drawing process, showing that the developed models are also applicable to other axisymmetrical forming processes. The main conclusions are summarized below.

\subsection{Lubrication in the inlet zone}

The lubricant film in the inlet zone of the hydrostatic extrusion process is modelled with the developed HELM ${ }^{1}$ model. The model has an analytical solution if the viscosity of the lubricant is modelled using the Barus viscosity model. When the viscosity is modelled with the more suitable Roelands model, a numerical solution is given. A parameter study is performed to investigate the film thickness in the inlet zone for different process conditions. The main conclusions are as follows.

The developed HELM model predicts a significantly higher film thickness than the original Wilson and Walowit model. However both results clearly show that the hydrodynamic build-up of lubricant pressure is negligible in the inlet zone of the hydrostatic extrusion process. Therefore the conclusion is that the billet/ die system operates in the boundary lubrication regime in the inlet zone.

The commonly used castor oil has a low pressure viscosity coefficient, i.e. $z=0.43$. Since this value for the pressure viscosity coefficient has a very significant effect on the calculated film thickness, calculations are also performed with a more common pressure viscosity coefficient for mineral oils of $z=0.7$. Results show that the predicted central film thickness increases by a factor 10 compared to the castor oil; however the system still operates in the boundary lubrication regime. The parameter study for a standard mineral oil shows that only the hydrostatic pressure and the temperature of the oil change the

\footnotetext{
${ }^{1}$ Hydrostatic Extrusion Lubrication Model
} 
predicted film thickness significantly. Using such lubricants, lowering the temperature of the oil or increasing the hydrostatic pressure can result in changing the lubrication regime from boundary lubrication to mixed lubrication.

\subsection{Lubrication in the work zone}

The film thickness in the work zone of the hydrostatic extrusion process is modelled based on the full film lubrication assumption. In this model the die of the hydrostatic extrusion process is assumed to be conical and therefore the model utilizes the Reynolds equation in a conical coordinate system. As well as modelling the film thickness, the nominal pressure in the work zone area of the hydrostatic extrusion process is modelled and studied. A suitable boundary condition for the Reynolds equation is specified, based on the results of the inlet zone calculations.

The film thickness in the work zone is calculated and compared to the roughness of the workpiece surface $\left(0.1 \cdot R_{\mathrm{q}}\right)$, to be able to distinguish between the boundary and the mixed lubrication regime. The conclusion is that in the entire work zone the system acts clearly in the boundary lubrication regime.

Changing the process parameters does not influence the predicted film thickness significantly. This is because the low film thickness causes the full film lubrication model to behave as if Couette flow alone is present.

\subsection{Contact in the work zone}

A contact model is developed for the contact between billet and die in the work zone of the hydrostatic extrusion process of magnesium. The contact model is based on Westeneng's contact model and includes bulk strain effects, a shear term and is suitable for any surface roughness geometry. This contact model is fitted to the measured results of Pullen and Williamson for contact pressures in the order of four times the hardness, as required for the hydrostatic extrusion process.

Results for typical process conditions show that the fraction of real area in contact increases rapidly to almost one and stays constant in the entire work zone.

\subsection{Process conclusions}

The calculations performed in the inlet and the work zone of the hydrostatic extrusion process of magnesium show that the prevailing lubrication regime is boundary lubrication under standard hydrostatic extrusion conditions. This is very likely the cause of the inconsistent and sometimes insufficient surface quality of the magnesium hydrostatic extrusion products. 
If a different lubricant is used with a higher pressure viscosity coefficient it is possible for the system to act in the mixed lubrication regime, resulting in better surface quality.

\subsection{Application to wire drawing}

The models developed in this work can also be used for other axisymmetrical deforming processes, like the wire drawing process. Two wire drawing case studies from literature are used to demonstrate the applicability of the developed models. This investigation analyses the friction and lubrication phenomena taking place in the wire drawing process.

\subsection{Recommendations}

The calculations have shown that the viscosity properties of the lubricant have a dominant influence on the prevailing lubrication regime. A suitable approach to improving the surface quality of the hydrostatic extrusion products could be to use a lubricant other than castor oil. The system might benefit in particular from using a pressure medium with a higher pressure viscosity coefficient such as most standard mineral oils.

On residual aluminium billets with spherical dies, it has been seen that the original transversal roughness stays intact in the entire work zone, in contrast to magnesium extruded billets with a conical die. This transversal roughness indicates that mixed lubrication is the prevailing lubrication regime in the entire work zone. The analysis of the percolation threshold shows that for a transversal roughness a much lower fraction of area in contact forms the boundary above which no blow-out is likely than in the case of a longitudinal roughness. Thus in this case it is possible to have a larger film thickness as required for the mixed lubrication regime without the risk of a blow-out. Based on the observed differences between spherical aluminium and conical magnesium extrusions, it is recommended to investigate the influence of the different die shapes.

It is recommended to validate the presented models with experimental data. A friction sensor could be installed in the die of the hydrostatic extrusion process to measure the friction in the work zone. With these measurements the friction coefficient can be determined, which plays an important role in the lubrication models. All experimental data should ideally be acquired from an actual hydrostatic press, to realise the high strains and the stress state of the hydrostatic extrusion process.

The temperature of the lubricant is a significant parameter due to its influence on the viscosity properties. It is recommended that the rise in temperature due to plastic deformation should be calculated and incorporated in the lubrication model of the work zone area of the hydrostatic extrusion process. 
Further it is recommended to extend the model for the extrusion of hollow profiles. Hollow end products are very common in hydrostatic extrusion and are produced using a mandrel. Also in the wire drawing process several types of mandrels are used. The use of a mandrel results in an extra contact area on the inside of the billet, which forms another tribological system that needs to be investigated. Since there is an extra area of contact on the inside of the workpiece it is expected that the friction phenomena play an even more dominant role in this type of process. 


\section{Appendix A}

\section{Magnesium, tool steel and castor oil properties}

\section{Constitutive constants of the Magnesium alloy AZ31}

The constitutive equation for AZ31 as derived by Li, [15].

$$
\dot{\varepsilon}=A(\sinh (\alpha \sigma))^{n} \exp \left(\frac{-Q}{R T}\right)
$$

Values for the parameters in Eq. (A.1) are given in Table A. 1

\begin{tabular}{|l|l|l|l|l|}
\hline$\varepsilon$ & $\mathrm{n}$ & $a\left(\mathrm{MPa}^{-1}\right)$ & $\mathrm{Q}(\mathrm{kJ} \mathrm{mol}$ & -1 \\
\hline 0.050 & 4.55 & 0.0275 & 160.0 & 24.6 \\
\hline 0.075 & 4.77 & 0.0230 & 161.5 & 25.7 \\
\hline 0.10 & 4.61 & 0.0205 & 156.6 & 25.5 \\
\hline 0.15 & 5.24 & 0.0114 & 147.7 & 27.6 \\
\hline 0.20 & 5.47 & 0.0060 & 138.5 & 29.9 \\
\hline 0.25 & 5.23 & 0.0050 & 132.7 & 29.7 \\
\hline 0.30 & 5.11 & 0.0047 & 127.2 & 29.0 \\
\hline 0.40 & 5.04 & 0.0048 & 124.2 & 28.4 \\
\hline 0.60 & 5.36 & 0.0033 & 120.8 & 30.5 \\
\hline 0.80 & 5.63 & 0.0036 & 119.8 & 30.4 \\
\hline 1.0 & 5.63 & 0.0073 & 121.8 & 26.8 \\
\hline
\end{tabular}

Table A. 1 Constitutive constants as derived by Li [15].

\section{Tool material}

The chemical composition of 1.2343 and 1.2367 tool steels are given in Table A.2 [60].

\begin{tabular}{|l|l|l|}
\hline Chemical composition wt\% & 1.2343 & 1.2367 \\
\hline Carbon, C & $0.36-0.42$ & $0.35-0.4$ \\
\hline Chromium, Cr & $4.8-5.5$ & $4.7-5.2$ \\
\hline Manganese, Mn & $0.3-0.5$ & $0.3-0.6$ \\
\hline
\end{tabular}




\begin{tabular}{|l|l|l|}
\hline Molybdenum, Mo & $1.1-1.4$ & $2.7-3.3$ \\
\hline Phosphorus, P & $\max 0.03$ & $\max 0.035$ \\
\hline Silicon, Si & $0.9-1.2$ & $0.3-0.5$ \\
\hline Sulphur, S & $\max 0.03$ & $\max 0.035$ \\
\hline Vanadium, V & $0.25-0.5$ & 0.7 \\
\hline
\end{tabular}

Table A.2 Chemical composition in wt. \% of 1.2343 and 1.2367.

\section{CPM Rex 76}

Rex 76 is a super high speed steel made by the Crucible Particle Metallurgy (CPM) process. In CPM the steel is melted and then poured through a nozzle where a high pressure gas creates a spray of tiny droplets. In this way a steel powder is created with very homogenous properties. This powder is sealed in containers which are then hot isostatically pressed. The result is steel with a homogenous and fine-grained microstructure. This process is very suitable for hard alloys like the ones used for extrusion dies. The chemical composition of Rex 76 can be found in Table A. 3.

\begin{tabular}{|l|l|}
\hline Chemical composition wt\% & Rex 76 \\
\hline Carbon, C & 1.50 \\
\hline Chromium, Cr & 3.75 \\
\hline Cobalt, Co & 8.50 \\
\hline Iron, Fe & 67.9 \\
\hline Molybdenum, Mo & 5.25 \\
\hline Sulphur, S & $0.07-0.22$ \\
\hline Tungsten, W & 9.75 \\
\hline Vanadium, V & 3.10 \\
\hline
\end{tabular}

Table A. 3 Chemical composition of Rex 76 [18].

\section{Castor oil properties}

The different values of the kinematic and dynamic viscosity of castor oil at different temperatures can be found in Table A.4. The kinematic viscosity of castor oil at 40 and $100^{\circ} \mathrm{C}$ is found in [20]. The other viscosities are calculated as described in Section 2.5.1. The density of castor oil is required so as to calculate the dynamic viscosity from the kinematic viscosity. The density is also temperature dependent and can be calculated according to [20] with

$$
\rho_{T}=\frac{\rho_{15.6}}{1+\varepsilon(T-15.6)}
$$

Here $\mathrm{T}\left[{ }^{\circ} \mathrm{C}\right]$ is the temperature and $\varepsilon\left[\mathrm{K}^{-1}\right]$ the coefficient of cubical expansion. For castor oil the base density is $0.965 \mathrm{~kg} / \mathrm{m}^{3}$ and $\varepsilon=6.8 \cdot 10^{-4} \mathrm{~K}^{-1}$. 


\begin{tabular}{|l|l|l|}
\hline Temperature & $\begin{array}{l}\text { Kinematic viscosity } v \\
\left(\mathrm{~mm}^{2} / \mathrm{s}\right)\end{array}$ & $\begin{array}{l}\text { Dynamic viscosity } \eta \\
(\mathrm{mPa} \cdot \mathrm{s})\end{array}$ \\
\hline $40^{\circ} \mathrm{C}$ & 255.6 & 244.4 \\
\hline 100 & 19.5 & 18.3 \\
\hline 150 & 6.24 & 5.97 \\
\hline 200 & 3.01 & 2.88 \\
\hline 250 & 1.82 & 1.74 \\
\hline
\end{tabular}

Table A.4 The kinematic and dynamic viscosities of castor oil at different temperatures.

\section{Reference data set}

The reference data set for hydrostatic extrusion of magnesium as described in Chapter 2 can be found in Table A. 5 .

\begin{tabular}{|l|l|l|}
\hline Symbol & Value & Description \\
\hline $\mathrm{q}$ & $0.6 \mathrm{GPa}$ & extrusion pressure \\
\hline$r_{1}$ & $73 \mathrm{~mm}$ & billet diameter \\
\hline$r_{2}$ & $8 \mathrm{~mm}$ & end diameter \\
\hline & 83 & extrusion ratio \\
\hline $\mathrm{U}_{1}$ & $8.8 \mathrm{~mm} / \mathrm{s}$ & entry velocity of the billet \\
\hline$\theta$ & $45^{\circ}$ & semi die angle \\
\hline $\mathrm{R}$ & $0.1 \mathrm{~m}$ & round-off radius of the billet \\
\hline$\sigma_{\mathrm{y}}$ & $100 \mathrm{MPa}$ & yield stress magnesium under compression $(\mathrm{AZ31})$ \\
\hline $\mathrm{T}$ & $200^{\circ} \mathrm{C}$ & oil temperature \\
\hline$\eta_{0}$ & $2.88 \mathrm{mPa} \cdot \mathrm{S}$ & viscosity of the lubricant at 1 bar at $200^{\circ} \mathrm{C}$ \\
\hline$\gamma$ & $7 \cdot 10^{-9} \mathrm{~Pa}{ }^{-1}$ & viscosity pressure coefficient \\
\hline $\mathrm{z}$ & 0.43 & Roelands pressure viscosity coefficient \\
\hline $\mathrm{R}_{\mathrm{q}}$ & $6 \mu \mathrm{m}$ & $\mathrm{R}_{\mathrm{q}}$ of the magnesium billet \\
\hline
\end{tabular}

Table A. 5 Data set for magnesium extrusion using castor oil. 


\section{Appendix B}

\section{TNO measurements lacquer layer}

TNO performed measurements on an residual billet from alloy AZ31 [17]. The results of the SEM analysis of a cross section of the original billet can be found in Figure B.1. It clearly shows an AZ31 alloy composition, as is to be expected. Figure B. 2 and Figure B. 3 show the results of the analysis done at both sides of the edge of the lacquer layer. The analysis of the lacquer layer shows a very high carbon percentage and a slightly higher oxygen weight percentage. The high carbon level indicates an organic substance, the most likely explanation is that some of the pressing oil decomposes and adheres to the die. The billet material flows under this layer until the shear forces are too high for (part of) the layer and it detaches. This is the moment surface quality issues start to develop; in the case of the analysed residual billet the layer probably detached from the die after the extrusion process was stopped, and the adhered to the billet.

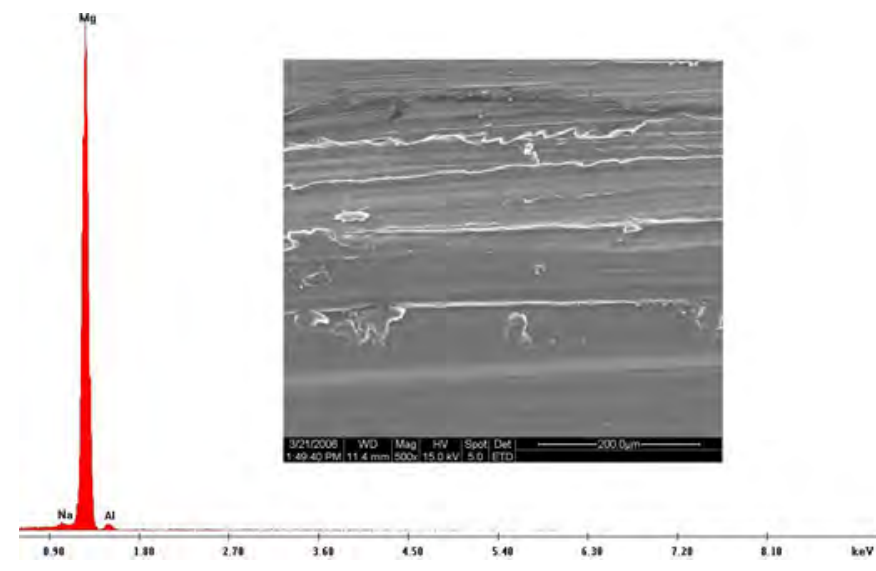

\begin{tabular}{|l|l|l|}
\hline Element & Wt \% & At \% \\
\hline C & 3.85 & 7.49 \\
\hline O & 0.66 & 0.96 \\
\hline $\mathbf{Z n}$ & $\mathbf{1 . 1 2}$ & $\mathbf{1 . 1 4}$ \\
\hline $\mathbf{M g}$ & $\mathbf{9 1 . 6 2}$ & $\mathbf{8 8 . 0 3}$ \\
\hline $\mathbf{A l}$ & $\mathbf{2 . 7 5}$ & $\mathbf{2 . 3 8}$ \\
\hline Total & 100.0 & 100.0 \\
\hline
\end{tabular}

Figure B. 1 SEM analysis cross section original alloy, picture courtesy of [17]. 


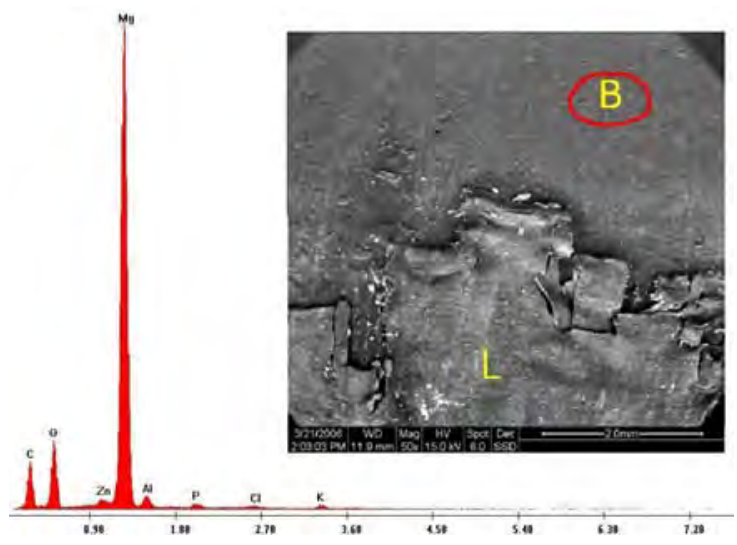

\begin{tabular}{|l|l|l|}
\hline Element & Wt \% & At \% \\
\hline $\mathbf{C}$ & $\mathbf{3 4 . 1 0}$ & $\mathbf{4 8 . 4 8}$ \\
\hline $\mathbf{O}$ & $\mathbf{1 5 . 6 1}$ & $\mathbf{1 6 . 6 6}$ \\
\hline $\mathrm{Zn}$ & 0.69 & 0.51 \\
\hline $\mathbf{M g}$ & $\mathbf{4 6 . 2 9}$ & $\mathbf{3 2 . 5 1}$ \\
\hline $\mathrm{Al}$ & 1.61 & 1.02 \\
\hline $\mathrm{P}$ & 0.58 & 0.32 \\
\hline
\end{tabular}

Figure B.2 SEM analysis bare zone, picture courtesy of [17].

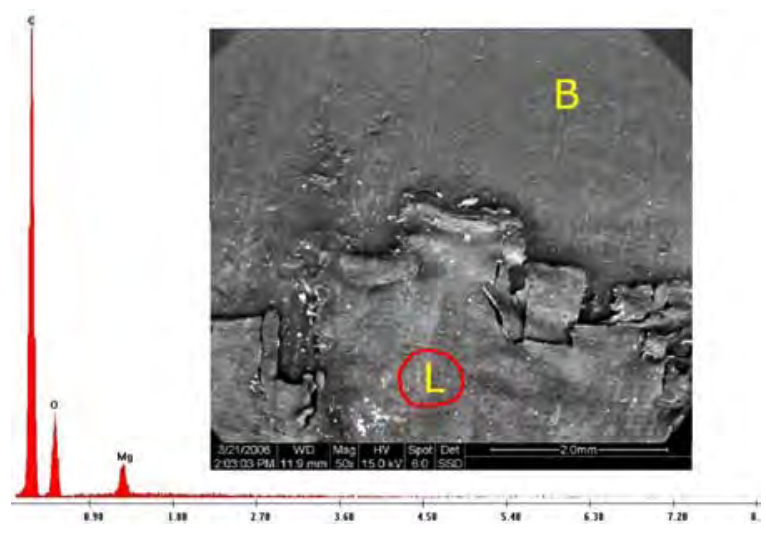

\begin{tabular}{|l|l|l|}
\hline Element & Wt \% & At \% \\
\hline $\mathbf{C}$ & $\mathbf{7 7 . 3 9}$ & $\mathbf{8 2 . 6 0}$ \\
\hline $\mathrm{O}$ & 19.97 & 16.00 \\
\hline $\mathrm{Mg}$ & 2.64 & 1.39 \\
\hline Total & 100.0 & 100.0 \\
\hline
\end{tabular}

Figure B.3 SEM analysis lacquer layer zone, picture courtesy of [17]. 


\section{Appendix C}

\section{Measurements}

\section{Pin on Disk}

Friction measurements were performed on a Pin on Disk Tribotester, manufactured by CSEM in Switzerland. Discs can be placed in the holder, which rotates at a specified speed. The counter surface is the pin, which can be a ball or another desired surface mounted in a sample holder. The force on the contact is applied by placing a dead weight on the arm on top of the pin as can be seen in Figure C.1. Oil can be placed in the holder if a lubricated contact needs to be examined.

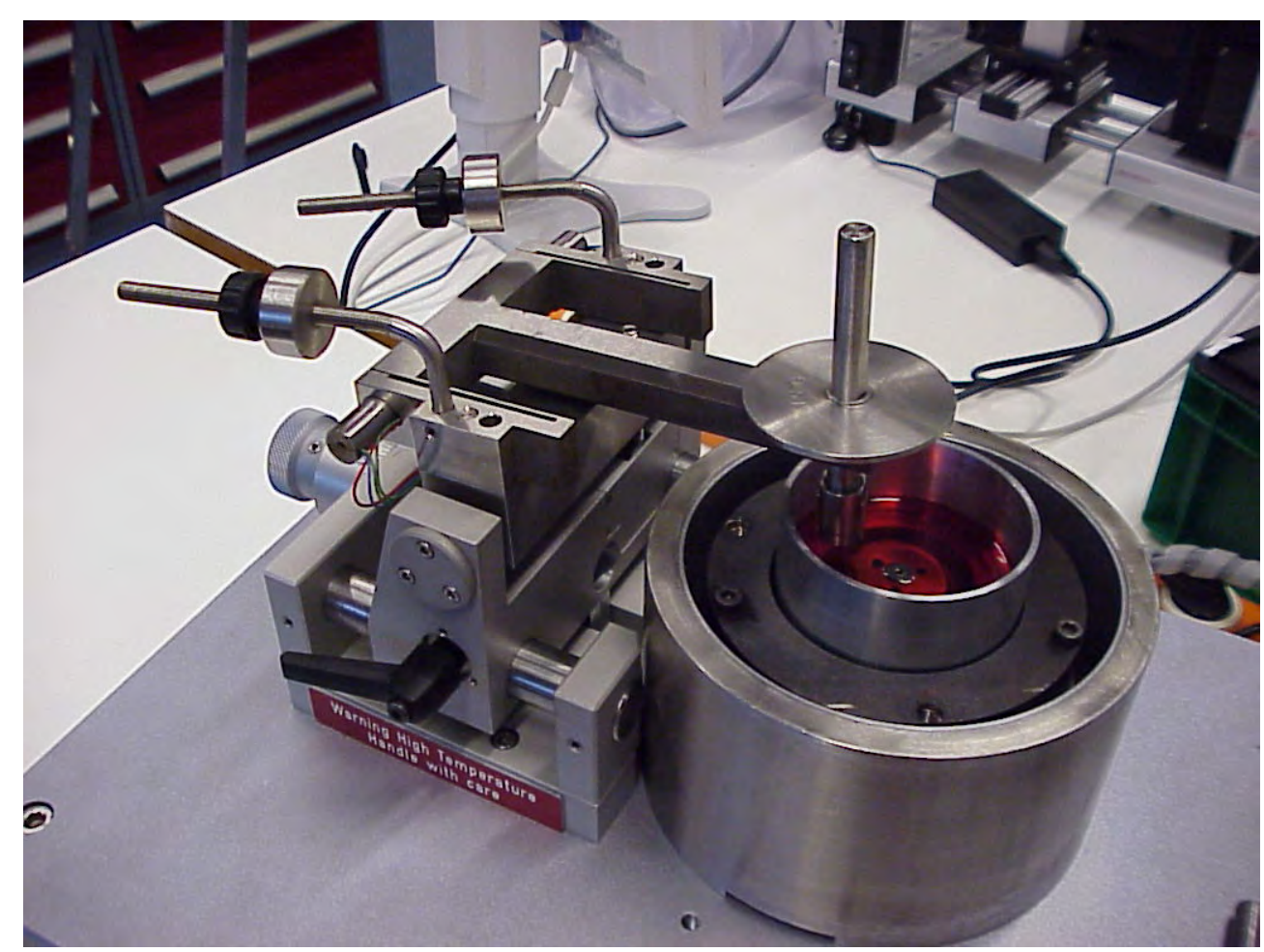

Figure C.1 Pin on disk Tribotester.

For this work magnesium discs were prepared which were placed in the holder, as can be seen in Figure C.1. As counter surface, standard bearing balls were used to represent the die material. Friction tests were performed with and without castor oil present in the contact. An example output can be seen in Figure C.2. The average measured friction coefficients for these situations are given in Table C.1. 


\begin{tabular}{|l|l|}
\hline & $\mu$ \\
\hline Dry & 0.3 \\
\hline Castor oil & 0.1 \\
\hline
\end{tabular}

\section{Table C. 1 Measured friction coefficients}

The values of the friction coefficient performed under lubricated conditions represent the hydrostatic extrusion process, therefore this value is used as the standard friction coefficient in this work.

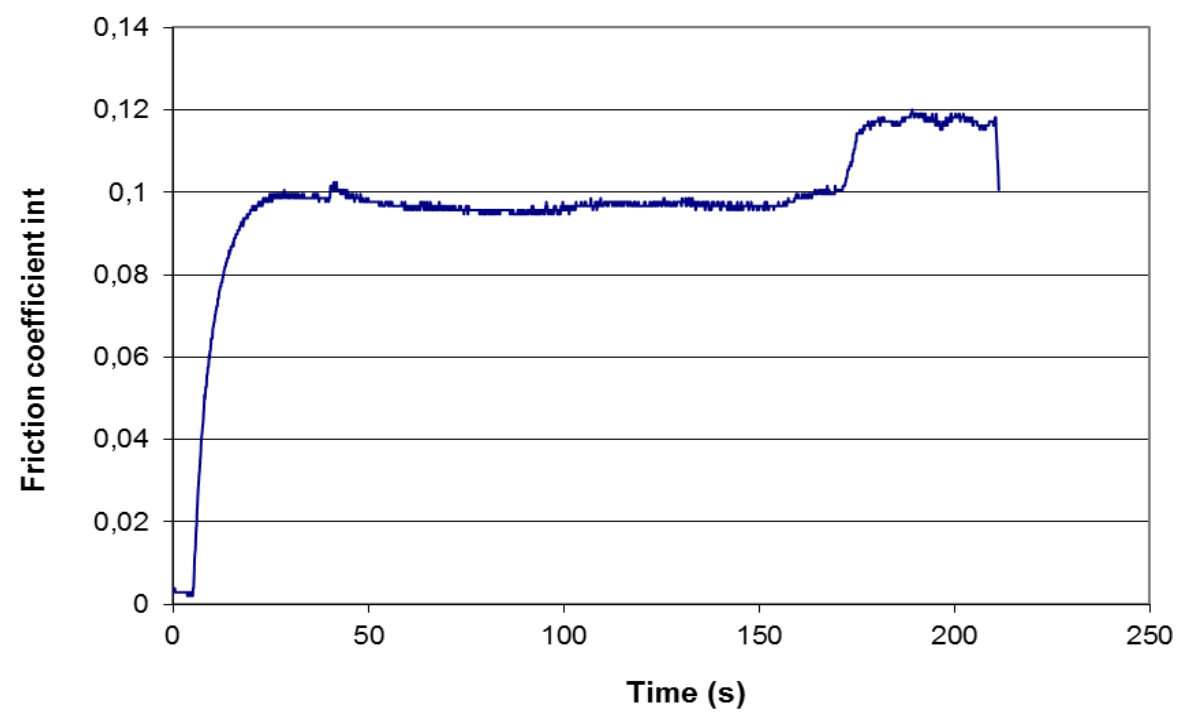

Figure C.2 Measured friction coefficient during pin on disk measurement with castor oil, $U=0.1 \mathrm{~m} / \mathrm{s}, \mathrm{p}=470 \mathrm{MPa}$.

\section{Surface roughness in the work zone}

Surface roughness measurements were performed on several end products and on the work zone of a residual billet. The measurements were performed using an interference microscope as explained in Section 2.3.2. With these roughness values an interpolating function was made to estimate the roughness in each point of the work zone area.

The roughness measurements performed on the end products give $R_{q}$ values ranging between 0.8 and $1.4 \mu \mathrm{m}$. An average surface roughness value for the end product of $1.0 \mu \mathrm{m}$ is used in the interpolation.

The surface roughness of a residual billet was measured at $15 \%$ of the distance between entry and exit of the work zone area. Here the surface roughness could be measured and was found to be $4.5 \mu \mathrm{m}$. The roughness of the turned billet was already given in Section 2.3.2 to be $6.0 \mu \mathrm{m}$. This gives three surface roughness values in the work zone to obtain the interpolation function. A large part of the work zone of this residual billet is covered with a lacquer layer, as discussed in Appendix B, so it is not possible to measure the surface roughness at other points in the work zone. The resulting surface roughness in 
the entire work zone can be found in Figure C. 3. On the horizontal axis the work zone is depicted with a normalised coordinate, meaning that 0 is the entry of the work zone and 1 the exit.

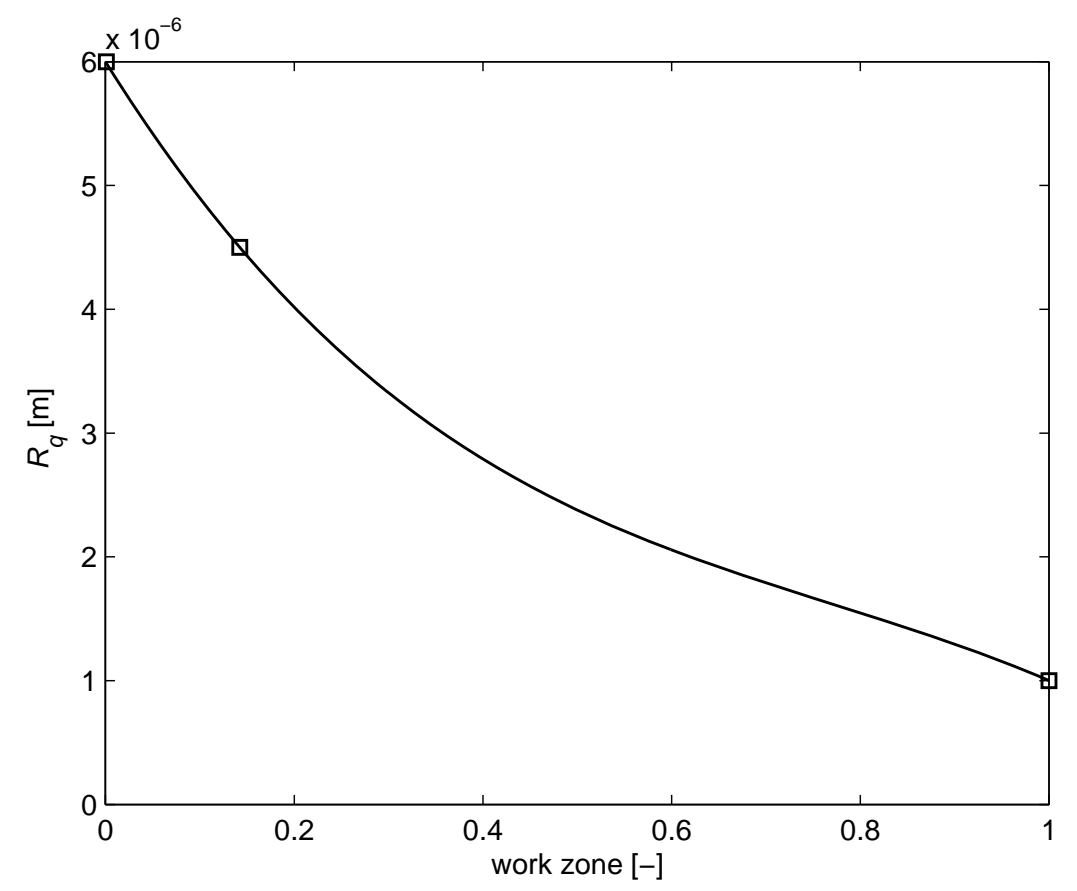

Figure C.3 Estimated surface roughness of the workpiece in the work zone area. 


\section{Bibliography}

1. Avedesian, M.M. and H. Baker, eds. Magnesium and Magnesium Alloys. ASM Specialty Handbook. 1999, ASM International. 314.

2. Davy, H., Electro-chemical researches on the decomposition of the earths; with observations on the metals obtained from the alkaline earths, and on the amalgam procured from ammonia. Philosophical Transactions of the Royal Society of London, 1808. 98: pp. 330-370.

3. http:// www.intlmag.org/ statistics.html. [cited J anuary 2011].

4. Meskers, C.E.M., Coated Magnesium - Designed for Sustainability? PhD thesis, Delft University of Technolgy, 2008.

5. Laue, K. and H. Stenger, Extrusion: Processes, Machinery, Tooling. 1981, Metals Park, Ohio: American Society for Metals.

6. Kalpakjian, S., Manufacturing Engineering and Technology. Second Edition ed. 1992: Addison-Wesley Publishing Company.

7. Inoue, N. and M. Nishihara, eds. Hydrostatic Extrusion - Theory and Applications. 1985, Elsevier Applied Science Publishers: London and New York.

8. Lee, W., Surface Roughening in Metal Forming Processes. PhD thesis, Northwestern University, 1996.

9. Osakada, K. and M. Oyane, On the Rougening of Free Surface in Deformation Processes. Bulletin of the J SME, 1971. 14(68): pp. 171-177.

10. Czichos, H., Tribology: A systems Approach to the Science and Technology of Friction, Lubrication and Wear. Tribology Series. Vol. 1. 1978, Amsterdam, Oxford, New York: Elsevier Scientific Publishing Company. 
11. Mourik, P. van and J. van Dam, Materiaalkunde voor Ontwerpers en Constructeurs. 2001, Delft, The Netherlands: DUP Blue Print.

12. Doege, E. and K. Dröder, Sheet metal forming of magnesium wrought alloys formability and process technology. Journal of Materials Processing Technology, 2001. 115: pp. 14-19.

13. Doege, E., B. Haller and St. Janssen, Precision forging of magnesium wrought alloys. Wire, 2002. 52(5): pp. 46-52.

14. McQueen, H. J. and N. D. Ryan, Constitutive analysis in hot working. Materials Science and Engineering A, 2002. 322(1-2): pp. 43-63.

15. Li, L., J. Zhou and J. Duszczyk, Determination of a constitutive relationship for AZ31B magnesium alloy and validation through comparison between simulated and real extrusion. J ournal of Materials Processing Technology, 2006. 172: pp. 372-380.

16. Tasan, Y.C., Measurement of deformation in rolling and sliding contacts. PhD thesis, University of Twente, 2005.

17. Ortega de Luis, A., SEM analysis of an AZ31 billet. 2006, TNO: Eindhoven. report number. MT-RAP-06-18236/ gge.

18. http://www.matweb.com/. [cited September 2010].

19. Gelinck, E.R.M., Olieresten op magnesium extrusie profielen. 2004, TNO. report number. 42/04.012779/ sec.

20. Booser, E. R., Tribology data handbook, in STLE. 1997, CRC Press: New York, USA.

21. Barus, C., Isothermals, isopiestics and isometrics relative to viscosity. American J ournal of Science, 1893. 45: pp. 87-96.

22. Roelands, C.J.A., Correlational Aspects of the Viscosity-Temperature-Pressure Relationship of Lubrication Oils. PhD thesis, Technische Hogeschool Delft, 1966.

23. Nakamura, Y., H. Matsubo, K. Yoshizaki and H. Komiya, High-Pressure Viscosity Measurements of Vegetable Based Biodegradable Lubricant Oils up to $2.5 \mathrm{GPa}$ and Tribological Characteristics. in Austrib. 2006. 
24. Nishihara, M., K. Matsui, T. Makita and H. Kashiwagi, Effects of Pressure, Temperature and Shear Rate on Viscosity of Lubricant Oils. J ournal of the Society of Materials Science, J apan (Zairyou), 1984. 33(365): pp. 114-119.

25. Personal communication with Nakamura, Y., 2007.

26. Reynolds, O., On the theory of Iubrication and its application to Mr. Beauchamp Tower's experiments, including an experimental determination of the viscosity of olive oil. Phil. Trans. R. Soc., 1886. 177: pp. 157-234.

27. Wilson, W.R.D. and J.A. Walowit, An Isothermal Hydrodynamic Lubrication Theory for Hydrostatic Extrusion and Drawing Processes With Conical Dies. Journal of Lubrication Technology, 1971. 92: pp. 69-74.

28. Schey, J.A., Tribology in Metalworking: Friction lubrication and wear. 1983, Metals Park, Ohio: American Society for Metals.

29. Stribeck, R., Die wesentlichen Eigenschaften der Gleit- und Rollenlager. VDIZeitschrift, 1902. 46: pp. 1341-1348, 1432-1438 and 1463-1470.

30. Schipper, D.J., Transitions in the lubrication of concentrated contacts. PhD thesis, University of Twente, 1988.

31. Hersey, M.D., The laws of lubrication of journal bearings. Transactions of the ASME, 1914. 4: pp. 542-552.

32. Spikes, H.A. and A.V. Olver, Basics of Mixed Lubrication. Lubrication Science, 2003. 16(1): pp. 3-28.

33. Moodij, E., M.B. de Rooij and D.J. Schipper, Hydrodynamic modelling of hydrostatic magnesium extrusion. in Austrib. 2006. Brisbane, Australia.

34. Evans, C.R., Measurements and Mapping of the Rheological Properties of Elastohydrodynamic Lubricants. PhD thesis, University of Cambridge, 1983.

35. Schipper, D.J . and W.E. ten Napel, The Effect of the Viscosity-Pressure Behaviour of Lubricants on the Film Thickness in Elastohydrodynamically Lubricated Line Contacts. in 24th Leeds-Lyon Symposium on Tribology. 1997. London, UK.

36. Wilson, W.R.D. and Der-form Chang, Low speed mixed lubrication of bulk metal forming processes. J ournal of tribology, 1996. 118: pp. 83-89. 
37. Kim, H., G. J ang and H. Ha, A generalized Reynolds equation and its perturbation equations for fluid dynamic bearings with curved surfaces. Tribology International, 2012. 50: pp. 6-15.

38. Hoffman, O. and G. Sachs, Introduction to the theory of plasticity for engineers. 1953, New York: McGraw-Hill.

39. Personal communication with Barton, G.

40. Zhao, F., Y. Li, T. Suo, W. Huang and J. Liu, Compressive deformation behavior of AZ31 magnesium alloy under quasi-static and dynamic loading. Trans. of Nonferrous Metals Society of China, 2010. 20(7): pp. 1316-1320.

41. Lo, S.W., A study on flow phenomena in mixed lubrication regime by porous medium model. J ournal of Tribology, 1994. 116: pp. 640-647.

42. Patir, N. and H.S. Cheng, An average flow model for determining effects of threedimensional roughness on partial hydrodynamic Iubrication. J. Lubr. Technol., Trans ASME, 1978. 100(1): pp. 12-17.

43. Liu, G., Q. Wang and C. Lin, A Survey of Current Models for Simulating the Contact between Rough Surfaces. Tribology Transactions, 1999. 42(3): pp. 581-591.

44. Greenwood, J.A., A Unified Theory of Surface Roughness. Proc. of the R. Soc. of London. Series A, Math. and Phys., 1984. 393(1804): pp. 133-157.

45. Rooij, M.B. de, Tribological aspects of unlubricated deepdrawing processes. PhD thesis, University of Twente, 1998.

46. Greenwood, J.A. and J.B.P. Williamson, Contact of Nominally Flat Surfaces. Proc. of the R. Soc. of London. Series A, Math. and Phys., 1966. 295(1442): pp. 300-319.

47. Westeneng, J.D., Modelling of contact and friction in deep drawing processes. PhD thesis, University of Twente, 2001.

48. Wilson, W.R.D. and S. Sheu, Real area of contact and boundary friction in metal forming. Int. J. Mech. Sci., 1988. 30(7): pp. 475-489.

49. Sutcliffe, M.P.F., Surface Asperity Deformation in Metal Forming Processes. Int. J. Mech. Sci., 1988. 30(11): pp. 847-868. 
50. Kimura, Y. and T.H.C. Childs, Surface asperity deformation under bulk plastic straining conditions. Int. J. Mech. Sci., 1999. 41(3): pp. 283-307.

51. Pullen, J. and J.B.P. Williamson, On the plastic contact of rough surfaces. Proc. of the R. Soc. of London. Series A, Math. and Phys., 1972. 327(1569): pp. 159-173.

52. Childs, T.H.C., The Persistence of Roughness between Surfaces in Static Contact. Proc. of the R. Soc. of London. Series A, Math. and Phys., 1977. 353(1672): pp. 3553.

53. Tabor, D., The hardness of metals. 1951, Oxford, UK: Oxford University Press.

54. Avitzur, B., Handbook of metal forming processes. 1983, New York: Wiley.

55. Bowden, F.P. and D. Tabor, The Friction and Lubrication of Solids Pt. 2. The International Series of Monographs on Physics, ed. N.F. Mott. 1964, Oxford, UK: Clarendon Press.

56. Korzekwa, D.A., P.R. Dawson and W.R.D. Wilson, Surface asperity deformation during sheet forming. Int. J. Mech. Sci., 1992. 34(7): pp. 521-539.

57. Kalpakjian, S. and S.R. Schmid, Manufactering Processes for Engineering Materials. 2003, Upper Saddle River, USA: Prentice Hall.

58. Valberg, H., E Doege, A. Kroeff and A. Rzepka, Analysis of the influence of backpull during drawing of aluminium wires. Int. J. of Materials \& Product Technology, 2000. 15(6): pp. 518-534.

59. Felder, E., C. Levrau, M. Mantel and N.G. Truong Dinh, Identification fo the work of plastic deformation and the friction shear stress in wire drawing. Wear, 2012. 286-287: pp. 27-34.

60. Wegst, C.W., Stahlschlüssel. 1995, Marbach, Germany: Verlag Stahlschlüssel Wegst. 


\section{Dankwoord}

Daar zit ik dan op mijn vertrouwde werkplek het laatste hoofdstuk van mijn proefschrift te schrijven. Het heeft even geduurd, maar het is toch maar mooi gelukt. Na ruim 10 jaar is het dan eindelijk echt klaar. In deze periode heb ik veel steun gehad van allerlei mensen en die wil ik in dit laatste hoofdstuk dan ook graag bedanken.

Als eerste wil ik het Innovatiegerichte Onderzoeksprogramma (IOP) Magnesium bedanken. Zij hebben dit onderzoeksproject mogelijk gemaakt door het te financieren. De georganiseerde magnesiumdagen gaven een mooie gelegenheid om kennis te delen en informatie uit te wisselen.

Ten tweede wil ik graag Hydrex Materials B.V. bedanken en met name Pieter Hoogendam. $\mathrm{Bij}$ het opstarten van mijn project heb ik veel moeten leren over hydrostatische extruderen. Hiervoor ben ik regelmatig op bezoek geweest en ik kon altijd terecht met mijn vragen. Deze directe link met het bedrijfsleven maakte dit onderzoek voor mij interessanter en leerzamer. Naast de nodige kennis en ervaring leverden ze ook de benodigde materialen voor mijn experimenten.

Mijn promotor tijdens dit onderzoek was Dik Schipper. Dik, ik heb met jou vaak hele intense discussie gevoerd. Tijdens het schrijven kwamen de laatste correcties altijd van jou. En hoewel het stoom vaak uit mijn oren kwam, heeft jouw commentaar zeker bijgedragen aan de kwaliteit van dit proefschrift. Dank voor al je hulp om dit project tot een goed einde te brengen. Lezen doe je dit hoofdstuk toch niet, zeg je altijd, dus hier laat ik het verder bij.

Het eerste aanspreekpunt in dit project was mijn assistent promotor Matthijn de Rooij. Matthijn, bedankt voor je eindeloze geduld. Je deur stond altijd open voor vragen en dat heb ik zeer gewaardeerd. We hebben veel en soms ook lange discussies gehad en dat vond ik erg plezierig en daar heb ik veel van geleerd. Ook als het ik het niet meer zag zitten, wist jij altijd een concreet plan te bedenken en me weer te motiveren. Mede dankzij jouw inspiratie ben ik, hoewel ik nog steeds geen fietsenmaker ben, wel een triboloog geworden. 
Daarnaast wil ik graag alle mensen van de vakgroep Tribologie bedanken. My fellow PhD students provided a relaxed atmosphere during the breaks or elsewhere. Also, I found the mix of nationalities and cultures very enjoyable and interesting. Erik, Walter en Willie wil ik graag bedanken voor hun hulp bij alle technische zaken. Jullie waren altijd bereid om mee te denken en waar mogelijk snel en oplossing te creëren. Daarnaast zijn jullie ook gewoon hele gezellige collega's geweest de afgelopen jaren. En uiteraard wil ik Belinda bedanken voor alle administratieve hulp. Een bijzonder bedankje voor de mensen waar ik langere tijd mee op een kamer heb gezeten. Loredana, Xiao en Gerrit, het was me een waar genomen om met jullie een kamer te delen. Ik denk daar met heel veel plezier aan terug.

Naast alle werk gerelateerde mensen zijn er uiteraard ook privé veel mensen die mij gesteund hebben. Meestal niet direct maar vooral indirect, door mij te steunen en vooral door te accepteren die ik niet altijd de tij d en energie voor hun had. Bedankt daarvoor. Ik wil hier nog met name mijn ouders en schoonouders bedanken voor hun steun en vertrouwen en voor de vele oppassessies die er voor zorgden dat ik de tijd kreeg om dit boekje af te maken.

Tenslotte zijn, zoals het hoort, de laatste woorden voor mijn gezin. Mijn man Arnout, jij hebt in al die 10 jaar geen moment getwijfeld over de goede afloop van dit project. Jij stond en staat altijd voor mij klaar en moest eindeloos verhalen aanhoren over smeringsregimes en film diktes. Bedankt voor al je goede zorgen en je vertrouwen. En tenslotte een bedankje voor mij lieve dochter Anne. J ij hebt mij perspectief gegeven over wat echt belangrijk is in het leven. Jij kunt me altijd laten lachen, ook als ik het even helemaal niet meer zag zitten. Het spijt me dat je vooral de laatste maanden heel vaak te horen kreeg: "Nu niet meis, ik ben aan het werk, vraag maar aan papa." Ik hou van je lieve, grote, kleine dochter van mij. 

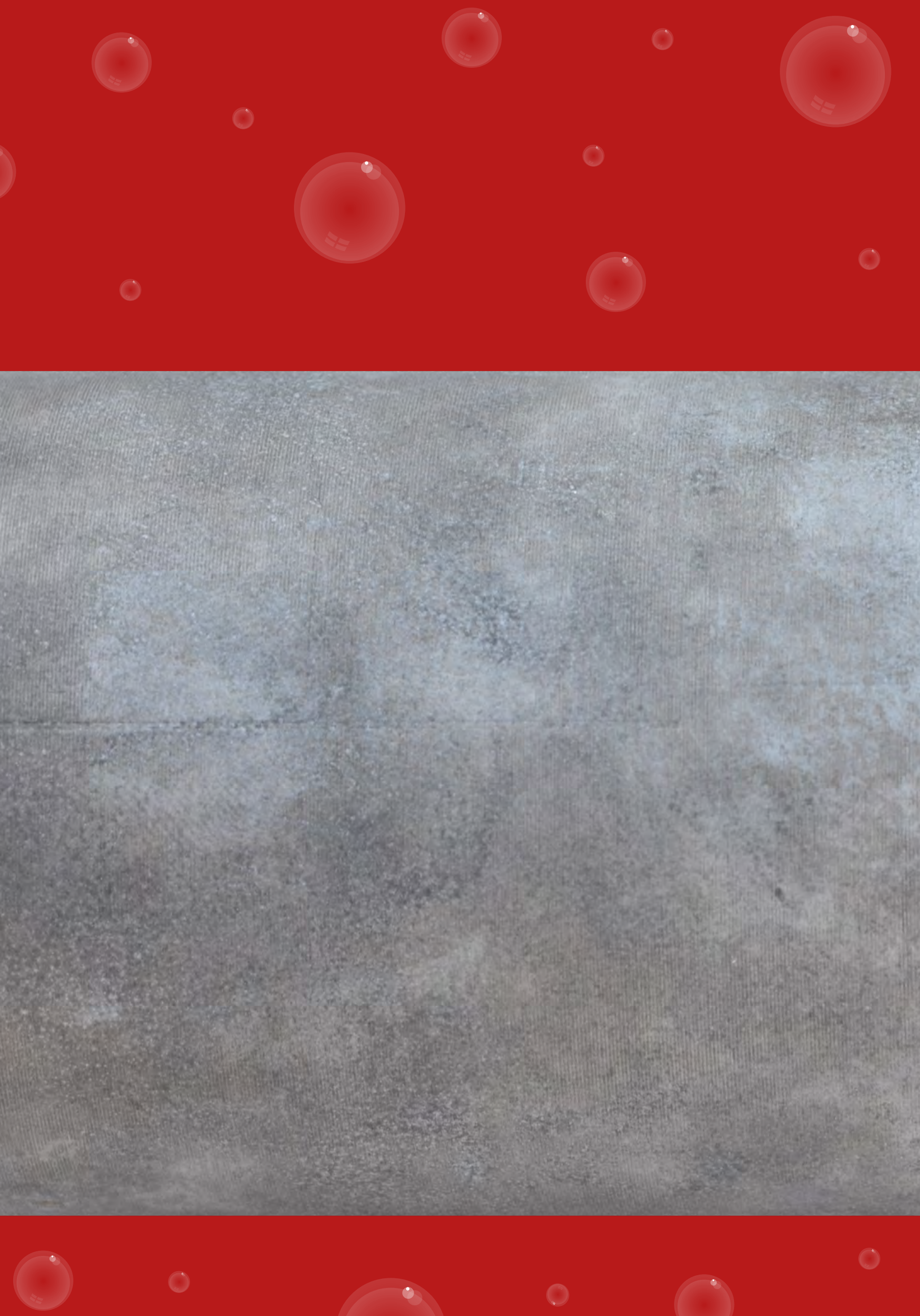

○

ISBN 978-90-365-3805-3 